\title{
Agglomeration effects and housing market dynamics
}

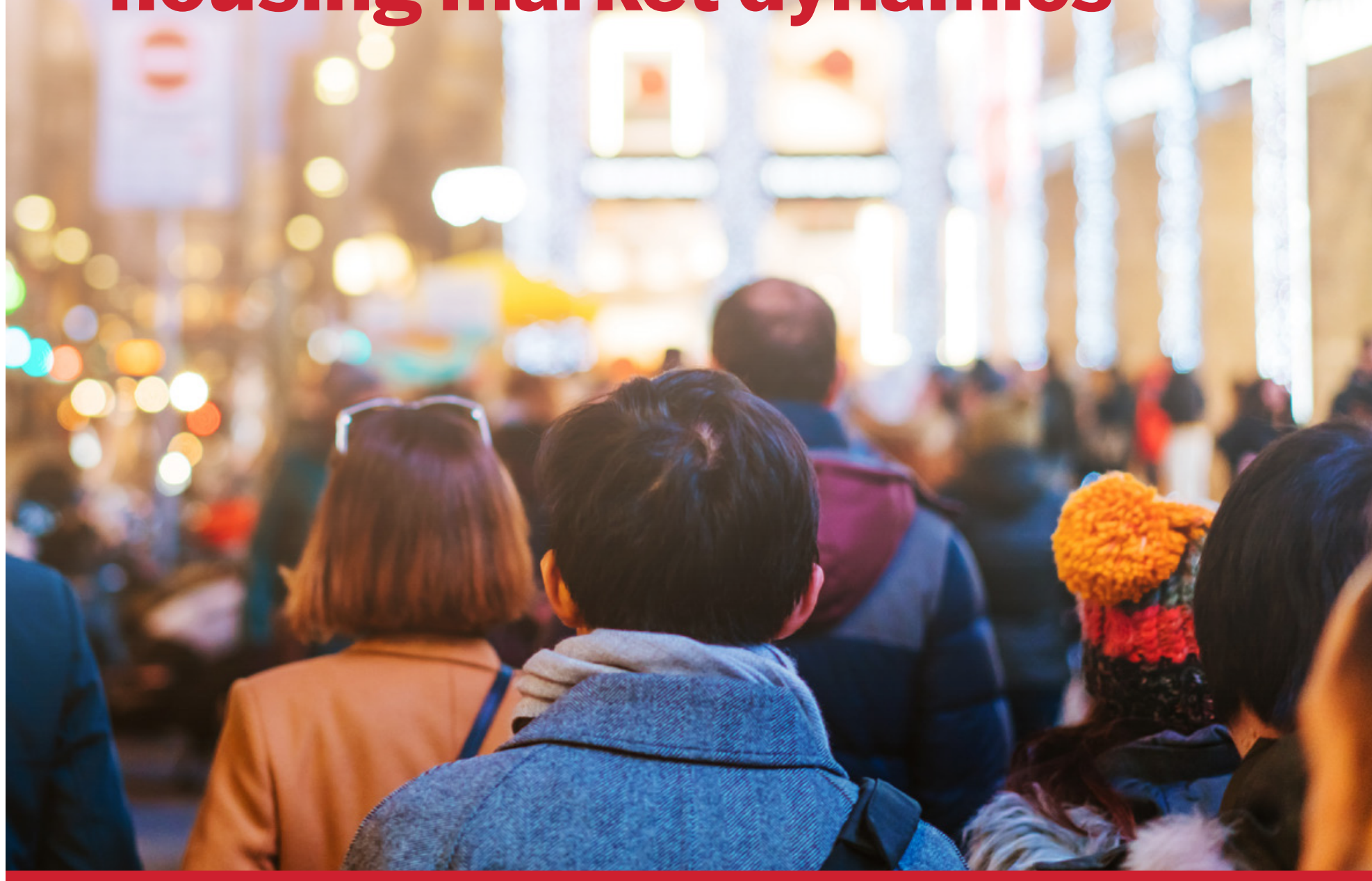

From the AHURI Inquiry: Inquiry into population growth, migration and agglomeration

Authored by

Christian A. Nygaard, Swinburne University of Technology

Sharon Parkinson, Swinburne University of Technology

Margaret Reynolds, Swinburne University of Technology
Publication Date October 2021

DOI 10.18408/ahuri5122401

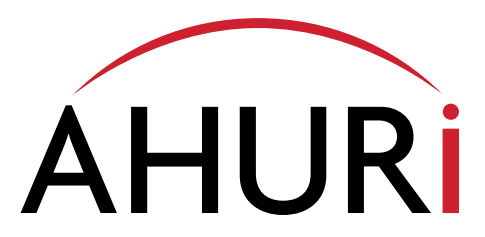


Title

Agglomeration effects and housing market dynamics

\section{Authors}

Christian A. Nygaard, Swinburne University of Technology Sharon Parkinson, Swinburne University of Technology Margaret Reynolds, Swinburne University of Technology

\section{ISBN}

978-1-922498-33-5

\section{Key words}

Productivity, agglomeration effects, housing affordability, population growth.

\section{Series}

AHURI Final Report

\section{Number}

\section{ISSN}

1834-7223

\section{Publisher}

Australian Housing and Urban Research Institute Limited Melbourne, Australia

\section{DOI}

10.18408/ahuri5122401

\section{Format}

PDF, online only

URL

https://www.ahuri.edu.au/research/final-reports/366

\section{Recommended citation}

Nygaard, C., Parkinson, S. and Reynolds, M. (2021) Agglomeration effects and housing market dynamics, AHURI Final Report No. 366, Australian Housing and Urban Research Institute Limited, Melbourne, https://www.ahuri.edu.au/research/final-reports/366, doi: 10.18408/ahuri5122401.

\section{Related reports and documents}

Inquiry into population growth, migration and agglomeration

https://www.ahuri.edu.au/housing/research-in-progress/ population-growth,-migration-and-agglomeration

\section{AHURI}

AHURI is a national independent research network with an expert not-for-profit research management company, AHURI Limited, at its centre.

AHURI's mission is to deliver high quality research that influences policy development and practice change to improve the housing and urban environments of all Australians.

Using high quality, independent evidence and through active, managed engagement, AHURI works to inform the policies and practices of governments and the housing and urban development industries, and stimulate debate in the broader Australian community.

AHURI undertakes evidence-based policy development on a range of priority policy topics that are of interest to our audience groups, including housing and labour markets, urban growth and renewal, planning and infrastructure development, housing supply and affordability, homelessness, economic productivity, and social cohesion and wellbeing.

\section{Acknowledgements}

This material was produced with funding from the Australian Government and state and territory governments. AHURI Limited gratefully acknowledges the financial and other support it has received from these governments, without which this work would not have been possible.

AHURI Limited also gratefully acknowledges the contributions, both financial and in-kind, of its university research partners who have helped make the completion of this material possible.

\section{Disclaimer}

The opinions in this report reflect the views of the authors and do not necessarily reflect those of AHURI Limited, its Board, its funding organisations or Inquiry Panel members. No responsibility is accepted by AHURI Limited, its Board or funders for the accuracy or omission of any statement, opinion, advice or information in this publication.

\section{HILDA disclaimer}

This paper uses unit record data from the Household, Income and Labour Dynamics in Australia (HILDA) Survey. The HILDA project was initiated and is funded by the Australian Government Department of Social Services (DSS) and is managed by the Melbourne Institute of Applied Economic and Social Research (Melbourne Institute). The findings and views reported in this report, however, are those of the authors and should not be attributed either to the DSS or the Melbourne Institute.

\section{AHURI journal}

AHURI Final Report journal series is a refereed series presenting the results of original research to a diverse readership of policy-makers, researchers and practitioners.

\section{Peer review statement}

An objective assessment of reports published in the AHURI journal series by carefully selected experts in the field ensures that material published is of the highest quality. The AHURI journal series employs a double-blind peer review of the full report, where anonymity is strictly observed between authors and referees.

\section{Copyright}

(C) Australian Housing and Urban Research Institute Limited 2021

This work is licensed under a Creative Commons Attribution-NonCommercial 4.0 International License, see http://creativecommons.org/licenses/by-nc/4.0/. 


\section{Contents}

List of tables

Acronyms and abbreviations used in this report

Executive summary

1. Introduction

1.1 Why this research was conducted

1.2 Policy context

1.3 Previous research

1.4 Research methods

2. On the relationship between agglomeration economies and housing market dynamics

2.1 Introduction

2.1.1 Agglomeration and wages

2.1.2 Agglomeration and amenities

2.1.3 Agglomeration and the future of work

2.1.4 Policy implications

3. Labour (wage) productivity and agglomeration in Australia

3.1 Introduction

3.2 Determinants of wages

3.3 Agglomeration effects and productivity

3.3.1 Agglomeration and wage effects, all workers

3.3.2 Agglomeration and labour productivity, by industry and occupation

3.3.3 Alternative estimation strategies $\quad 35$

$\begin{array}{ll}3.4 \text { Policy implications } & 37\end{array}$

4. Agglomeration and housing costs $\quad 38$

$\begin{array}{ll}4.1 \text { Introduction } & 39\end{array}$

4.1.1 Employment density and basic housing cost-adjusted wages 39

4.1.2 Policy implications 47

5. Policy development options $\quad 48$

5.1 Introduction $\quad 49$

5.1.1 Should jobs be located centrally, or distributed across metropolitan and regional areas? 49

5.1.2 Should our cities expand at low density or consolidate inwards?

5.1.3 How may digital connectivity and automation affect the agglomeration-housing market dynamic? 53

5.1.4 Policy development options to harness the productivity potential of agglomerations 54

$\begin{array}{ll}\text { References } & 56\end{array}$

Appendix A: Variable construction and estimation strategy $\quad 61$

Appendix B: Additional results $\quad 71$ 


\section{List of tables}

Table 1: Determinants of wages

Table 2: Agglomeration effects and hourly wages 26

Table 3: Industry specialisation and diversity based on SA4 level inputs 30

Table 4: Non-linear agglomeration effects and hourly wages

Table 5: Quantile regression, agglomeration effects and hourly wages

Table 6: Agglomeration effects by industrial sectors, SA2 and SA4 level inputs

Table 7: Agglomeration effects by occupations, SA2 and SA4 level inputs

Table 8: Alternative estimation strategies

Table 9: Agglomeration effects and hourly wages net of basic housing costs $\quad 40$

Table 10: Quantile regression, agglomeration effects and hourly wages net of basic housing cost

Table 11: Agglomeration effects and wages net of basic housing costs, at place of residence

Table 12: Quantile regression, agglomeration effects and wages net of basic housing costs, at place of residence 46

Table A1: Descriptive statistics hourly wage

Table A2: Descriptive statistics hourly wage adjusted for housing costs

Table A3: HILDA Survey Waves 17 and 18 descriptive statistics, SA4 level inputs 68

Table A4: Variable definitions $\quad 70$

Table A5: Agglomeration effects, SA4 level input, no market potential

Table A6: Quantile regression, SA4 level inputs, wages, no market potential

Table A7: Quantile regression, SA4 level inputs, net wages no market potential 72

Table A8: Quantile regression, SA4 level inputs, net wages no market potential, place of residence 73 


\section{Acronyms and abbreviations used in this report}

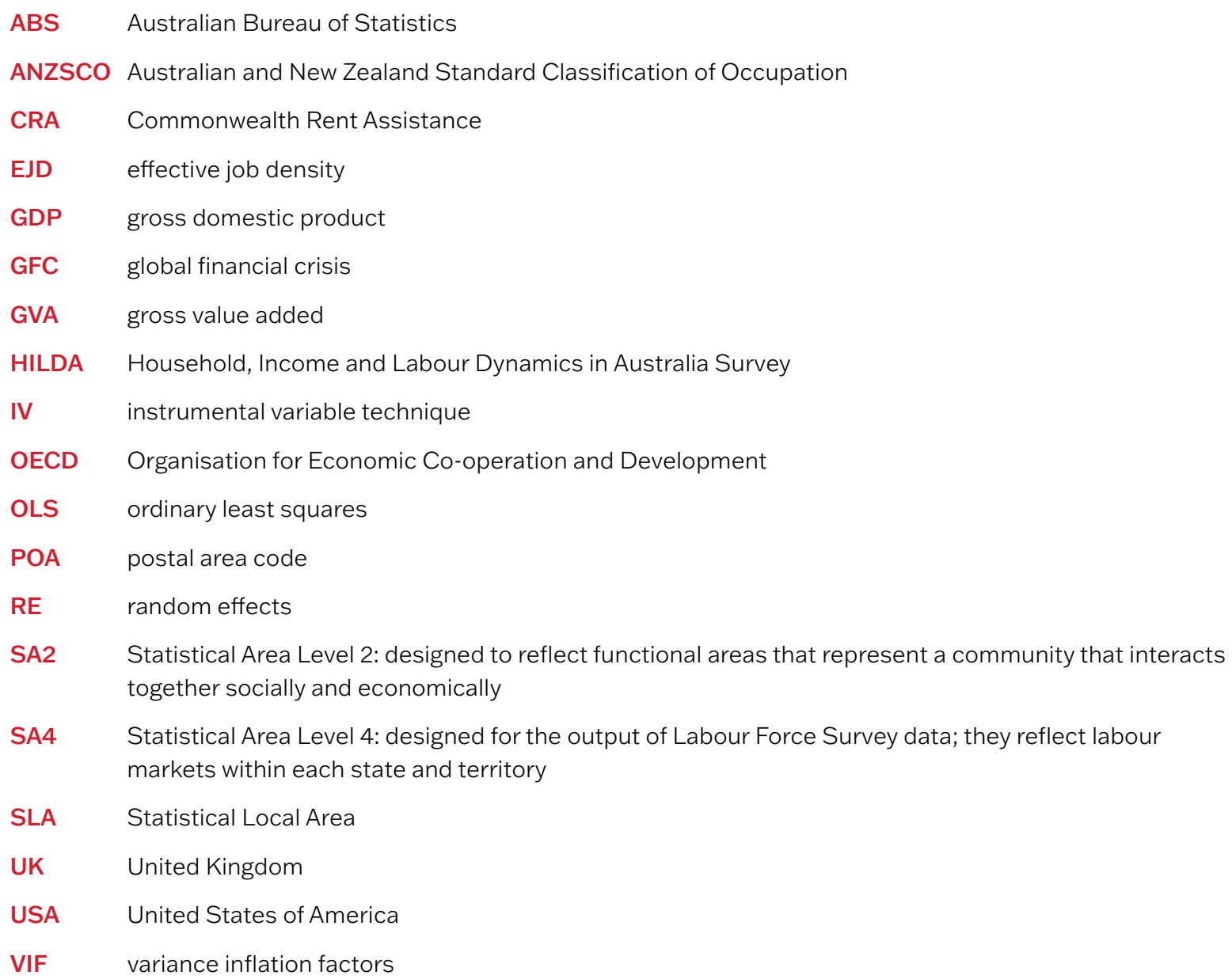




\section{Executive summary}

\section{Key points}

This project aims to quantify productivity-related agglomeration benefits arising from the concentration of employment in Australia. Agglomeration of firms and employment reduces the impact of distance on the exchange of goods and services, skills and people, and ideas and information. Concentration of firms and employment can thus lead to spatial variation in productivity.

Our measure of productivity is individual wages. We control for individual and firm-specific characteristics. Agglomeration benefits are examined across the wage distribution, as well as before and after adjusting for basic housing costs (mortgages and rents). Our key agglomeration measure is concentration of employment (or employment density). We also include employment in nearby locations, urbanisation economies and localisation economies.

- Our estimates suggest that a doubling of employment density raises hourly wages by 1 to 4 per cent. While agglomeration has a positive effect, individual and firm characteristics are the key determinants of spatial variation in wages.

- Localisation (industry specialisation) and urbanisation (diversity of industry) economies also generate agglomeration effects and will be critical to the evaluation of population and employment dispersal strategies and aims. Broadly a doubling of economic specialisation, relative to the state as a whole, is associated with a further 4-10 per cent higher hourly wage level.

- Analysis of agglomeration benefits across the wage distribution reveals considerable variation. Lower-wage earners benefit less from agglomeration than higher-wage earners. 
- The wage premium typically remains also after adjusting for basic housing costs (mortgages and rents). However, agglomeration benefits are substantively capitalised in housing costs for the lowest 20 per cent of earners. The net benefit for middle-income earners also appears less than for higher-income earners.

- Housing markets potentially exacerbate inequality by distributing gains from agglomeration from lower-wage earners to property ownersalthough the total effect is likely mitigated by transfer payments and rent assistance.

- Housing market policies that reduce this distributive role may have additional productivity-enhancing effects by incentivising investment in productive capital, new technology and infrastructure.

- The results in this report highlight the role that housing markets and affordability play in distributing gains from agglomeration. The implication for urban transitions is that housing policy and affordability are key to harnessing agglomeration benefits at the societal level.

\footnotetext{
Most Australians live in cities. Barring a continuation of the COVID-19 pandemic, our urban populations will grow considerably over the next few decades. Cities enable agglomeration benefits through the proximity of workers and firms. They also typically have:

- higher house prices - which reduce entry and ongoing affordability

- greater pollution and other wellbeing detriments-such as crime, noise etc.
}

Like many other nations, Australia has experienced declining productivity over the last few decades, has an ageing population, and is facing significant climate, technological and urban transition challenges.

Recent policy directions, such as the Australian Government's 2019 Planning for Australia's future population and Infrastructure Australia's 2018 Future cities: planning for our growing population highlight the role of urban economies in enabling future prosperity. In a post-COVID-19 environment-where teleworking has, at least temporarily, become endemic for some types of employment and occupations - the relationship between agglomeration, productivity and housing markets remains particularly important for enabling future prosperity. This study quantifies wage-related agglomeration benefits and assesses these relative to basic housing costs (mortgages and rents) and distributional differences across the income distribution to inform strategic decisionmaking around urban form and density.

This report is part of the AHURI Inquiry into Population Growth, Migration and Agglomeration. The aim of the Inquiry is to interrogate Australian and international evidence on the range of costs and benefits associated with agglomeration economies, when these effects may arise, how they might change with city scale, and how they might depend on spatial context. 
The overall research question for this report is:

How do jobs and skills concentration affect labour productivity and housing costs in Australia?

Within this, the report is structured along three research questions:

- RQ1: What is the relationship between agglomeration effects and housing market dynamics? (Section 2)

- RQ2: To what extent is labour productivity in Australia a function of agglomeration effects? And do agglomeration effects differ across skills and/or income groups? (Section 3)

- RQ3: To what extent do spatial wage differences reflect spatial variation in housing costs? And do housing market effects vary between high- and low-wage earners? (Section 4)

\section{Key findings}

\section{Relationship between agglomeration effects and housing market dynamics}

This study is informed by the urban economics literature around agglomeration economies and housing. Employment density is frequently accompanied by higher housing costs. Thus, housing costs, in addition to wages, also serve as an indicator of agglomeration economies. Residential location decisions and property price formation are multifaceted. Property prices are typically a function of:

- local supply conditions-such as planning or political economy

- households' preferences for living and working in different locations-access to employment, access to urban amenities, local networks and attachment to place.

Agglomeration effects potentially affect each of these.

- First, an urban surplus is generated where agglomeration results in greater productivity. In turn, businesses benefit more from each worker. They may therefore use some of the urban surplus to offer higher wages to attract labour. Higher wages compensate households for urban inconveniences-such as higher housing costs, crowding and pollution - which results in additional population growth. Alternatively, more productive workers may self-select into cities, in which case the urban premium is partly a function of self-selection, rather than wage-related agglomeration effects. Workers, incentivised by higher wages, bid up the price of housing to secure access to more productive localities (higher wages). If benefits from agglomeration are conditional on specific worker characteristics - for example, skills in limited supply - then housing market outcomes for lower-skilled and higher-skilled workers may differ.

- Second, cities can also provide consumption amenities that-either independently, or in addition to wages -increase households' preferences for living in cities, and in specific parts of cities. For instance, larger cities often provide a diverse mix and choice of schools, hospitals, restaurants, bars, shops, sports facilities, music, theatres and museums, which can influence liveability and self-selection into particular cities, or into areas within those cities. If urban consumption amenities compensate households for urban inconveniences, then housing affordability may continue to worsen independently of changes to wage distributions or wage increases. Also, urban amenities may be a function of agglomeration, with concentrations of households generating market scale to sustain a greater variety and diversity of consumer offerings (local goods). 
- Third, agglomeration benefits arise out of proximity - that is, reduction of costs associated with distance. Digital connectivity and automation may provide a means of substituting physical proximity for digital connectivity. For instance, economies of scale relating to marketplaces can thus be captured through digital geographies, rather than physical geographies, which enables more decentralised or regional economic development. At the same time, changing the need for physically anchored employment locations will likely alter the geography of housing demand. This may lead to some regionalisation of residential demand. However, where urban amenities and lifestyles are an integral part of the location decision, this will increase demand for housing in high-amenity cities or parts of cities. Domestic and international research on the spatial impact of automation suggests that outer parts of capital cities and smaller cities may be more affected than inner parts of capital cities.

\section{Labour (wage) productivity and agglomeration in Australia}

Hourly wages (hereafter hourly wages or wages), as a proxy for the productivity of labour, are determined by the interaction of a range of factors:

- individual 'human capital' (such as education, skills, attributes), gender, demographic factors

- firm and industry-specific factors-products/services, public/private

- institutional factors-collective bargaining, contract status, regulation.

These factors are expected to determine variation in wages separately from any agglomeration effect.

Agglomeration effects, such as employment density, market potential, urbanisation economies and localisation economies, have the potential to raise the productivity of labour (and thus wages) in addition to the individual, firm and institutional factors.

An assumption in the literature is that wage differentials reflect differences in workers' marginal product. Wages are thus a proxy for capturing labour-related agglomeration effects - this is despite their being an imperfect tool, as agglomeration effects may be reflected in housing costs and amenities (Rosenthal and Strange 2008). Agglomeration economies have the potential to enhance overall productivity through scale and network effects that:

- reduce the costs of intermediate inputs and labour

- allow for better matching of skills (labour) to jobs

- enable knowledge and information flows within and between different economic sectors (spillovers).

The labour productivity-related wage-agglomeration effect can be isolated in wage differentials-when controlling for individual, firm and industry - and institutional determinants. In this report we identify agglomeration effects using four measures common in the literature. The key measure is employment density where the individual works. In addition, we control for employment in nearby locations (market potential), urbanisation economies (economic diversity) and localisation economies (economic specialisation). We estimate agglomeration effects with SA2 and SA4 level agglomeration inputs at postcode level (hereafter SA2/SA4 level inputs). The key findings are outlined below.

- Employment density (or agglomeration) is significantly associated with higher hourly wages and thus productivity. However, these wages are in addition to individual, firm and institutional factors that explain the largest part of wage variation in Australia. Specifically, our modelling suggests that after controlling for individual and firm, institutional factors, a doubling of employment density will increase the productivity of labour by 1 to 4 per cent. This is in line with international evidence, but somewhat lower than earlier Australian estimates. Point estimates with small area levels (SA2 level input) are marginally lower than point estimates at larger (SA4 level input) levels.

- There is some evidence that proximity to nearby employment concentration has a positive impact on the wages of higher-income earners with SA2 level inputs, but this effect appears to disappear with SA4 level inputs. Spillovers in this respect capture interdependencies between areas. The average spillover effect is insignificant. The marginally higher productivity-point estimates with SA4 level inputs, and the absence of spillovers, suggests that agglomeration benefits are spatially contained.

- Overall, agglomeration benefits appear to be greater for higher-wage earners than lower-wage earners. There are thus clear distributional effects arising from productivity-enhancing agglomeration effects. 
- There is some evidence of urbanisation economies - that is, wage benefits arising from a diversified economic structure with SA4 level inputs. However, the effect is again stronger for higher-skilled earners, and only marginally significant for all earners.

- The evidence of localisation (specialisation) economies is stronger, both with SA2 and SA4 level inputs. Areas with more spatially concentrated industries tend to experience additional wage benefits. Outside of mining industries, spatial concentration appears particularly relevant for 'Information Media and Telecommunication', 'Financial and Insurance Services' and 'Arts and Recreation Services'. Broadly a doubling of economic specialisation, relative to the state as a whole, is associated with a further 4-10 per cent increase in wages. However, the degree of economic specialisation differs substantially for different sectors of the economy, and further research is required to more robustly identify which sectors specifically benefit from concentration.

\section{Agglomeration and housing cost}

In Section 4, the modelling adjusts wages for basic housing costs to control for the cost-of-living adjusted wage element. That is, compensating workers for higher housing costs. However, housing costs are not the only congestion costs that might arise with agglomeration, as commuting costs directly affect an individual's locational choices and benefits from agglomerations.

Basic housing costs include mortgage and rent payments, but exclude transfer payments (benefits) or income support payments (such as Commonwealth Rent Assistance [CRA]). Transfer payments and income support potentially mitigate some of the distributional and housing market impacts of agglomerations. From an analysis perspective, however, they also potentially disguise the relationship between agglomeration effects and housing market dynamics. The area-based measures used in this research to isolate the effect of basic housing costs, are tested where individuals work and where individuals live. The key findings in this section are as follows.

- The positive and significant agglomeration effect remains after adjusting for basic housing costs. However, there is also some evidence that part of the urban premium is absorbed by higher housing costs. Overall, this is the case when considering employment agglomeration at both the place of work and the place of residence, although the results are more pronounced when examining housing cost-adjusted wages at the place of residence. On average, therefore, workers benefit from working in denser employment concentrations also after considering the higher housing costs in denser agglomerations. This does not include other congestion costs, which may also be higher in denser agglomerations.

- Quantile regressions reveal that higher-wage workers benefit more from employment agglomeration than lower-wage workers, also after adjusting for basic housing costs. For the lowest 20 per cent of the wage distribution, productivity gains are substantively capitalised in housing costs, and middle-income earners also benefit less than higher-income earners. This effect becomes particularly pronounced when analysing housing cost-adjusted wages at the place of residence. In this case, the lowest half of employees receive little net wage benefit from agglomeration effects. Differences across the wage distribution suggest that housing markets play a significant role in redistributing the gains from agglomeration to higher-wage earners and property owners. Importantly, the residential location-higher-housing-cost outcome may also reflect non-wage benefits, such as access to urban amenities that increase the willingness to pay for housing in locations closer to employment agglomerations.

- Quantile regressions also show that the residential location of lower-wage earners is substantially more responsive to commuting costs than higher-wage earners.' Higher commuting costs are thus likely to affect the residential locations of lower-wage earners more than higher-wage earners, and lead to additional residential concentration of lower-wage earners close to employment concentrations. 


\section{Policy development options}

Recent policy directions highlight the role of urban economies in enabling future prosperity. Future cities (Infrastructure Australia 2018) and Planning for Australia's future population (Australian Government 2019) set out a number of urban and regional development considerations about urban form, population distribution and impacts of technological innovations on economic geography. The widespread uptake of technologies enabling teleworking during the COVID-19 pandemic-for some types of employment and occupations-has accelerated some of these considerations, particularly relating to urban form and population distribution.

The results in this report also relate to productivity, including the importance of a place-based policy agenda to support economic and social development, beyond major cities (Beer, McKenzie et al. 2020). The findings in this report also highlight significant housing affordability, productivity and equitability gains to be made by understanding the link between agglomeration and housing markets over time.

- Clustering of employment and economic activity generates agglomeration benefits. Concentration of economic activity, rather than dispersal, thus generates a greater productivity dividend. However, there is little evidence of non-linearity in agglomeration effects. In other words, agglomeration can potentially be replicated elsewhere. There will, however, be transition challenges in building up new agglomerations and there is a need to carefully consider scale, composition of productivity sources and variation in agglomeration benefits across the wage distribution.

- Digital connectivity and automation potentially reshape the effect of physical distance. This means that some agglomeration effects can still be harnessed without physical proximity. The development of digital marketplaces and spaces potentially provides market scale, without physical proximity to customers. Digital connectivity and automation reshapes economic geography and, for some individuals and households, enables residential location decisions free from proximity to fixed places of employment. This will invariably generate some decentralisation, as well as some increase in demand for amenity-rich urban locations.

- Housing policy and affordability are instrumental in distributing and harnessing productivity benefits in the short-term and long-term. Thus, housing policy is critical to economic policymaking. The agglomeration benefit that is paid out in higher wages is, for some lower-wage earners, substantially capitalised in higher housing costs. This has significant distributional impacts. It also carries public costs in the form of higher CRA payments. In the long-term, this potentially has productivity-inhibiting effects through incentivising rent-seeking rather than productive investment.

- Regional development (or population growth decentralisation) needs to be complemented with physical and digital infrastructure investment, economic diversity, economic specialisation, skills development and housing supply to enable productivity gains. It may also need to be complemented with 'lifestyle' and social-infrastructure investment to be self-sustaining, although some of these will likely arise with income growth.

- Increasing housing supply close to centres of employment needs to be complemented with planning and regulatory incentives that provide appropriate, affordable and sustainable housing options, and that protect public and private green spaces. However, density of employment and population may also generate additional non-wage-related agglomeration benefits - such as amenities and lifestyle-that, in turn, generate demand for housing options close to agglomerations.

To harness societal benefits from agglomeration effects, an overarching policy goal should be to ensure earners benefit across the wage distribution, while also ensuring that both lower-skilled and higher-skilled workers can live affordably and sustainably. Housing policy is key, and can include:

- Support for the direct provision and supply of affordable dwellings, including within precinct developments and private rental support packages close to major employment hubs and within direct access to transport. This may counter effects that exacerbate inequality and, in the longer-term, counter rent-seeking behaviour related to land use and development. 
- An active strategy that provides incentives for businesses and employers to facilitate a more 'permanent' transition to teleworking-in other words, working from home-can have 'social dividends', particularly in the form of housing costs. However, teleworking is not equally feasible across all employment types and occupations. Therefore, there is a need to further investigate:

- future scenarios associated with new ways of working and living

- implications for residential locations, along with costs and options for different types of workers

- implications for urban form and commuting patterns, for example, compact cities, and;

- implications for service-related employment and entrepreneurial opportunities arising from income concentration-such as economies of scale, product diversity, specialisation, and division of labour.

- Individual wage determinants remain a critical supply-side factor in determining productivity. Greater and continual access to education and training - and pathways for current and new generations of workers - is critical to long-term prosperity, and as part of a post-COVID-19 economic recovery process. This may include providing incentives for regional students to access housing and training packages.

- Productivity is critical to long-term prosperity. However, inadequate employment protection and barriers to employment participation can erode productivity gains. In a context of digital transformations, automation and economic recovery, employment protection and participation are critical to reducing income and housing inequalities.

\section{The study}

This research is one of three projects in the AHURI Population Growth, Migration and Agglomeration Inquiry, which explore the relationship between agglomeration effects, productivity and housing dynamics.

A review of international and domestic literature on agglomeration theory, effects and urban impacts was conducted to explore how agglomeration effects are-or might be-related to the cost of housing in cities.

An econometric analysis based on HILDA Surveys (Waves 17 and 18) and ABS Census data (Place of Workbased) was then conducted to identify whether agglomeration effects (density, market potential, diversity and specialisation) are associated with higher wages (as an indicator of productivity), using SA2 and SA4 level Census data inputs linked to HILDA Survey postcode-area information on place of employment. Measuring postcode-area agglomeration effects with SA2 and SA4 level inputs provide a means incorporating spatial attenuation, but further research is required to more accurately identify spatial reach. The analysis was repeated to then test whether greater agglomeration of employment is associated with higher wages net of (after deducting) basic housing costs. 


\section{Introduction}

- Over the next 40 years, the rate of increase in Australia's working-age population is projected to fall short of overall population growth. Consequently, there will be fewer taxpayers per resident to generate the income required to pay for education, health and welfare services.

- Australia's labour productivity is below the rate required to maintain historic per capita income-growth levels. Agglomeration economies are a potential source of productivity growth.

- Agglomeration effects are the benefits that arise when businesses, workers and people locate in close proximity to each other. These are posited as increasing the productivity of workers.

- In this report, we operationalise productivity as earnings per hour worked in main job. Clustering of jobs can improve labour productivity by reducing the costs of exchanging goods and services, labour and ideas. Labourmarket depth may allow for better matching of skills to jobs.

- Clustering of firms and people also generates congestion costs, which can include housing costs, pollution and increased concentration of traffic, as well as social costs such as crime.

- This project aims to provide quantifiable evidence revealing the magnitude of agglomeration effects in Australia to inform decision-making relating to potential trade-offs between productivity and agglomeration strategies, versus congestion and dispersal approaches. 


\subsection{Why this research was conducted}

By 2061, Australia's population is projected to grow by between 12 million and 23.5 million people-a near doubling of the 2017 population at the high end of this range. A key driver of projected population growth is international migration. Over the same period, however, the proportion of working-age individuals (15-64 years) is expected to decline from 67 per cent to 59-61 per cent (ABS 2013). Like many advanced economies, Australia is confronted with slowing relative labour supply growth and hence a demographic 'cash call'-where there will be fewer taxpayers per resident to generate the income that pays for education, social security, old-age provision and health care.

In Australia, population and immigration growth and ageing raises complex policy and economic issues in relation to:

- spatially balanced population growth and deconcentration of growth to regions (Australian Government 2019)

- adequate infrastructure provision to support economic activity and wellbeing

- decisions around denser and more dispersed urban forms and climate change (Infrastructure Australia 2018).

The COVID-19 pandemic also raises questions in relation to demand for living and working in agglomerations in the short-term and long-term. In making decisions about urban and regional development strategies that can deliver socially and environmentally sustainable urban transitions, the key is having a better understanding of the role of agglomeration economies and productivity.

Australia's labour productivity — while marginally improved since the 2007-2008 global financial crisis (GFC) (Campbell and Withers 2017) -is nevertheless below the rate required to maintain Australia's historic per capita income-growth rate of 2.5 per cent and is driven by capital deepening-that is, more capital per worker-rather than multifactor productivity (MFP) (Campbell and Withers 2017). In a longer perspective, the average GDP per capita growth has declined each decade since the 1980s (ABS 2020). The demographic shift that Australia is experiencing requires that the productivity of the remaining labour force improves year-on-year simply to maintain the same level of GDP per capita growth.

A potential source of productivity growth is agglomeration economies. Clustering of employment generates proximity that, potentially, increases productivity by reducing the costs of exchanging:

- goods and services

- people-labour market pooling and matching

- ideas-diffusion of knowledge, innovation and entrepreneurship (Glaeser 2010).

Agglomeration economies-or external economies of scale-can also arise from the structure of economic organisation:

- localisation-when firms and people locate near similar firms -

- urbanisation - when a variety of firms locate in cities or industrial clusters (Duranton and Puga 2000; Glaeser 2010).

By locating closer together, each worker potentially becomes more productive than if they were located further apart. In turn, higher productivity is reflected in higher wages as firms compete for skilled labour. Thus, agglomeration benefits provide a policy rationale for densifying cities and concentrating employment. Agglomeration benefits also generate a rationale for technological innovations and infrastructure that reduces effective distance, such as digital connectivity and transport infrastructure. These may enable some agglomeration effects, without the same physical distance.

However, clustering of firms and people also generates congestion costs that potentially reduce or negate any benefit from agglomeration. Congestion costs can include higher housing costs (living costs). Higher housing costs arise because people compete to be closer to places of work or study, as well as consumption lifestyles that flow from clustering high-income workers in a given area. Therefore, high housing costs are also an indicator of productivity. Congestion costs can also include traffic congestion-commuting costs-and levels of pollution that 
exceed the capacity of the environment to absorb emissions. Although the research evidence-base is still under development, congestion costs can also relate to higher rates of transmission of communicable diseases-such as COVID-19-or pollution as a comorbidity factor and transmission vector (Wu, Nethery et al. 2020). Congestion costs provide a policy rationale for dispersing population growth to regional centres.

Therefore, the purpose of this project is to provide quantifiable evidence on the magnitude of agglomeration effects in Australia to inform decision-making relating to potential trade-offs between productivity and agglomeration versus congestion and dispersal strategies. With this in mind, the overarching research question is this:

- RQ: How do jobs and skills concentration affect labour productivity and housing costs in Australia?

Labour productivity is proxied by hourly labour wages (hereafter hourly wages or wages). Agglomeration may also result in additional congestion costs and non-wage benefits. A wage effect is therefore only one proxy for labour productivity and agglomeration benefits.

This question is guided by three research sub-questions:

- RQ1: What is the relationship between agglomeration effects and housing market dynamics?

- RQ2: To what extent is labour productivity in Australia a function of agglomeration effects? And do agglomeration benefits differ across skills and/or income groups?

- RQ3: To what extent do spatial wage differences reflect spatial variation in housing costs? And do housing market effects vary between high- and low-wage workers?

\subsection{Policy context}

Australia's population is expected to increase by the equivalent of at least Sydney and Melbourne combined over the next few decades. Immigration (assuming a resumption in the medium term following COVID-19) is a key source of both total population growth-and, importantly - labour supply growth, with the growth in labour supply fuelling overall economic expansion (GDP) in Australia. International migrants tend to be young, of working age, or students, and Australia's selective immigration policy - which includes large numbers of international students-ensures a high rate of temporary and permanent skilled immigration. Younger and more educated or skilled immigrants make a net fiscal contribution (Australian Government 2019; Dustman and Frattini 2014) and may have further productivity-enhancing effects (Peri 2016), although the short-term and long-term adjustments to skilled migration are complex (Borjas 1994).

Further population growth and continued importing of skilled workers from abroad may also be a source of additional agglomeration benefits and productivity gains. However, population growth also requires infrastructure investment and responsive housing development to avoid infrastructure bottlenecks, inequality and reduced community wellbeing. This has raised debate about the economic and social benefits and costs of alternative urban transition and population distribution strategies.

In 2018, Infrastructure Australia's Future cities: planning for our growing population (2018: 2) raised a series of questions about population growth and urban transitions:

- Are our cities going to grow out or up?

- How do we align the location of jobs with the needs of our changing economy?

- How do our infrastructure networks need to change to accommodate more demand?

There are no straightforward answers to these questions, as responses depend on how location of jobs, urban form and infrastructure affect the economy's ability to meet other challenges, including:

- an ageing population

- impacts of climate change 
- technological innovations

- continued transition to knowledge-intensive activities

- changes to the nature and location of work (Infrastructure Australia 2018: 4).

The impact of 'megatrends' (Balliester and Elsheikhi 2018) will significantly shape the policy challenge, as will the disruption generated by COVID-19. Megatrends also co-shape the future of work, as well as the infrastructure and institutional investment and innovation required to deliver sustainable industries. That is, industries able to provide an adequate number of decent jobs with wages growth that can redress inequalities and be overseen by an industrial relations system that offers appropriate social protections (Balliester and Elsheikhi 2018).

Agglomeration economies are about the effects of proximity on productivity. Going forward, a key policy issue is, therefore, the 'future of work' and technological change, including digital connectivity and automation (Infrastructure Australia 2018; Australian Government 2019). A critical direction in urban and housing governance and the governance of cities will be how to shape the spatial-temporal fix between home and work-or 'workresidence' commutes - in the context of the increasing significance of the digital economy, especially in the wake of COVID-19 (Belzunegui-Eraso and Erro-Garcés 2020).

The Australian Government's 2019 Planning for Australia's future population recognised the productivityenhancing benefits of employment concentration (Australian Government 2019). As such, it makes provision for federal-level investment to support infrastructure and housing bottlenecks in cities so that cities can continue to harness agglomeration benefits. In this perspective, infrastructure investment becomes a means of reconfiguring the spatial relationships between housing and employment (Pill, Gurran et al. 2020). However, Planning for Australia's future population also sets out a 'decentralisation agenda' as a means of relieving pressure on capital cities (Australian Government 2019: 6).

Provision of infrastructure to support population growth is a multi-level exercise that relies on a high degree of coordination across government levels and infrastructure agencies (Pill, Gurran et al. 2020). In Australia, City Deals have emerged as a vehicle for supporting connectivity in cities, but also multi-level coordination and collaboration around land-use planning and governance (Pill, Gurran et al. 2020). City Deals sit within a suite of place-based metropolitan economic strategies that aim to enhance the productive capacity of cities by reducing persistent inefficiencies. This could be done, for instance, by operating across governance levels to enable transport infrastructure that better coordinates the flow of workers between home and work. Here too, an important question will be how such a strategy can_or will-affect the economy's ability to absorb a larger population and meet challenges associated with an ageing population and climate change.

\subsection{Previous research}

Agglomeration economies are frequently discussed by economists and policy makers, but they can be difficult to measure or robustly evidence. To date, there has been little microeconometric analysis of labour productivity in Australia. Previous Australian research has drawn on area-level productivity measurements. In these studies, gross value added (GVA) at Statistical Local Area (SLA) level and total hours worked per industry provide a measure of the per hour output at SLA level. Variations in per hour output is modelled as a function of the effective jobs density (EJD) of each SLA.

EJD recognises that the spatial extent of labour markets and agglomeration will in many cases exceed that of its spatial unit of measurement. Employment in other locations is thus weighted by distance or travel time to produce a summary measure of the EJD. Investment in transport infrastructure thus becomes a means of increasing the EJD of localities. Based on this methodology, Rawnsley and Szafraneic (2010) estimated that the overall productivity gain from doubling EJD in Melbourne is 7 per cent. When estimated by industry, the effect of EJD on wages ranges from 0 in 'Manufacturing and Wholesale Trade', to 18 per cent and 29 per cent respectively in 'Property and Business Services' and 'Cultural Recreation Services'. This methodology is also used by SGSEP (2012). 
Further Australian research by Trubka (2011) measured SLA-level labour productivity as the sum of the industryspecific average wages weighted by the share of employment in each industry in each Australian capital city. Variation in SLA-level labour productivity here is also a function of SLA level employment and/or employment density. The effect of doubling jobs density ranges from 3.5 per cent in Perth, to 36.7 per cent in Canberra. Trubka (2011) also provides estimates for localisation and urbanisation economies.

In connecting productivity and housing, there is an emerging literature that has focussed on the potential productivity-enhancing benefits for housing and affordable housing supply (Dodson, de Silva et al. 2017; Gurran, Phibbs et al. 2015; Maclennan, Ong et al. 2015; van den Nouwelant, Crommelin et al. 2016). Maclennan, Ong et al. (2015: 1) argued that housing investment can provide an important economic stimuli through expanding aggregate demand, but also concluded that there is little evidence on the long-run growth and productivity impact of housing. Several productivity-enhancing channels are identified as possible-including human capital accumulation and business innovation - as well as the role of housing in configuring spatial relationships independently or in conjunction with transport investment.

Housing affordability is sometimes seen as instrumental to productivity by enabling employment participation and better matching an individual's skills to the jobs available (Coulson and Fisher, 2009; Ferreira, Gyourko et al. 2010; Oswald 1996; van den Nouwelant, Crommelin et al. 2016; Whelan and Parkinson 2017). Therefore a mismatch between the geography of affordable housing and employment concentrations is sometimes seen as detrimental to economic development (SCITC 2018). Previous research suggests that the impact of a potential mismatch may be moderate (Dodson 2005; Productivity Commission 2015; Terrill, Batrouney et al. 2018; van den Nouwelant, Crommelin et al. 2016). This is likely due to jobs that lower-income households would typically access being distributed throughout metropolitan areas (Hulse, Reynolds et al. 2019).

This study approaches the issue of labour productivity - as measured by wages - and the relationship between productivity and housing market dynamics from new perspectives. First, our study can control for a wide set of worker-specific characteristics that, in addition to employment density, may determine labour productivity. Second, based on an urban economics approach, we explore the impact of productivity on housing costs and the distributional impacts arising from employment agglomerations.

\subsection{Research methods}

This study is informed by the urban economics literature on agglomeration and microeconometric analysis of wages and employment density in Australia. Specifically, it draws on the spatial equilibrium concept in urban economics, which holds that mobility across cities enables most individuals to balance things they like with things they do not like. More formally, it means that higher wages (benefits) in some areas must be offset by higher costs or less attractive urban environments (costs). This also means that more attractive urban environments can offset the need for higher wages. A key insight from this perspective is that both wages and house prices are, in principle, indicators of urban productivity. Given the separate role that attractive urban environments-urban amenities - can play in attracting workers, wages (and housing cost) are only a proxy for productivity.

We use the Household Income and Labour Dynamics in Australia (HILDA) Survey to quantify the extent of agglomeration effects. A detailed microeconometric analysis explores whether a higher density of employment is associated with a wage premium before and after subtracting housing costs. Variable construction reflects the primary focus of the research: agglomeration and housing market dynamics and costs. Housing costs are not the only congestion costs that might arise with agglomeration. Indeed, housing costs are also related to commuting costs, with lower commuting cost also capitalised in property prices. Given the primary focus on housing costs, the approach taken in this report is to control for commuting costs separately, rather than also subtracting from wages. 
HILDA is a nationally representative panel survey that has followed individual respondents over the age of 15 years each year since commencing in 2000. We use a small, pooled panel of the most recent waves (2017 and 2018) for our analysis as these are the first waves to contain detailed locational information on respondents' place of work.

The basic modelling framework employed on the HILDA data follows a Mincer single equation earnings function, with additional area-based variables that capture density of employment, market potential, relative economic diversity, and relative economic specialisation (as per Melo and Graham 2009). The Mincer equation explains wages as a function of schooling and experience (Mincer 1958) and has been used widely in microeconometric studies of wages. In HILDA, information about respondents' postal area code (POA) of employment is available. This enables construction of agglomeration measures based on weighted SA2 and SA4 level inputs (Census data), but also measures of nearby employment (market potential). The area measures are derived from the 2016 Census information 'Place of Work'. We also capture:

- diverse economic structure-urbanisation economies that might arise from economic interaction across multiple sectors

- specialised economic structure-localisation economies that might arise from interaction within sectors.

Key variables in HILDA include demographic information, education, occupation, industry of employment and characteristics of employers.

More detailed outlines on agglomeration measures, the computation and estimation strategies are provided in Appendix A. As our data has repeated measures across two waves for the same individuals, we estimated regression models with random effects with robust standard errors to control for potential serial correlation. Instrumental variable technique is used to address potential endogeneity issues between wages and density of employment. Additional pooled ordinary least squares (OLS) with weights, and mixed-level pooled estimations with random and fixed intercept and coefficient slopes were also run as robustness tests. Quantile regressions are used to analyse distributional effects. 


\section{On the relationship between agglomeration economies and housing market dynamics}

- Agglomeration economies are regarded as a part-solution to addressing Australia's demographic 'cash call' and low rates of wage growth.

- Where agglomeration results in greater productivity, it generates an urban surplus. Businesses can use some of this urban surplus to offer higher wages to attract skilled labour. This creates an urban wage premium.

- The spatial equilibrium model assumes that households are (mostly) mobile within and across cities. Households' location decisions, therefore, (partly) seek to balance out benefits, such as higher wages, against congestion costs, such as higher cost of living and less attractive environments.

- Where agglomeration leads to higher wages, agglomeration should also lead to higher housing costs as these are 'bid up' by higher-paid workers willing to pay more for access to more productive and high-amenity localities. As such, high house prices are also an indicator of agglomeration effects and labour productivity.

- The provision of urban amenities is often a function of the purchasing power (or income concentration) of areas. Thus, locations with concentrations of employment may also have higher concentrations of urban amenities (shops, restaurants and cafes) and parks, museums and public spaces. Demand for such amenities may also attract mobile households to employment agglomerations-even when this is not associated with higher wages. 


\subsection{Introduction}

Agglomeration effects are the benefits that arise when businesses, workers and people locate in close proximity to each other. Productivity-enhancing agglomeration effects arise from scale and network effects that:

- reduce the costs of intermediate inputs and labour

- allow for better matching of skills (labour) to jobs

- enable spillovers - knowledge and information flows between different economic sectors.

Agglomeration effects can further be categorised as urbanisation economies and localisation economies. Urbanisation economies arise when the interactions between multiple sectors enhance productivity; localisation economies arise when interactions within particular economic sectors enhance productivity (Duranton and Puga 2000).

Agglomeration economies may also have temporal dynamics. For example, Brülhart and Mathys (2008) found that agglomeration effects have increased over time and are driven by cross-sectoral agglomeration effects. In their analysis - and exempting financial services - within-sectoral agglomeration effects appear to be dominated by congestion costs. That is, economic interaction across a diversity of sectors generates (urbanisation economies) positive effects that offset congestion costs specific to sectors (localisation diseconomies). However, the balance of positive and negative effect may change over time, with diseconomies dominating primarily in the short-run (Brülhart and Mathys 2008).

Of particular policy interest in Australia-and elsewhere-is the effect of agglomerations on the productivity of workers. Economists typically define productivity as the amount of output produced by each worker, relative to the inputs available to them. When workers produce more output with the same amount of inputs-or the same output with fewer inputs - productivity increases. Thus the definition used by economists differs from that used in policy or popular discourse, where output expansion is often equated to productivity gain. An additional hour (or worker) increases output, but not necessarily productivity. Productivity only increases when the additional hour (or worker) results in higher output than the preceding hours (or workers).

In turn, agglomeration may also affect housing markets. Property prices are typically a function of local supply conditions - such as planning or political economy - and households' preferences for living and working in different locations. Subject to local supply restrictions, households then choose locations based on the income obtainable in different labour markets or access to amenities_for example, liveability, availability of services (both public and private). Agglomeration potentially affects both obtainable earnings and the provision of amenities. The following subsections briefly discuss each of these processes separately, but it is important to note that in many instances they are jointly determined outcomes.

\subsubsection{Agglomeration and wages}

Where agglomeration results in greater productivity, businesses will benefit more from each worker and therefore use some of the urban surplus to offer higher wages to attract labour. Higher wages thus compensate households for greater congestion costs (or reservation wages) in cities. The prospect of higher wages (or urban premium) also increases households' willingness to cover the cost of accessing productive areas, which results in additional population growth.

This economic logic is the basis for the spatial equilibrium model used by many economists (Duranton and Puga 2015; Glaeser and Gottlieb 2009). The key assumption of the spatial equilibrium model is that households are mobile across space. This mobility means that the balance of wellbeing (or utility) derived from income and amenities -including subjective perceptions and attachment to areas-varies and, at least to some extent, equalises across space. In other words, subject to their income, households move to improve their housing, working and leisure-time outcomes. 
However, in reality there are many reasons why households may not be fully mobile across space, including both:

- longer-term structural changes in the supply of affordable private rental dwellings (Hulse, Reynolds et al. 2019)

- enduring patterns of social segregation that reproduce spatial inequalities and impede 'upward socio-spatial mobility' (Bailey and Minton 2018; Whelan and Parkinson 2017).

There is a large international literature, predominantly from the USA, that estimates the relationship between labour productivity and various measures of agglomeration (reviewed in Combes and Gobillon 2015; Rosenthal and Strange 2004). Average agglomeration effects are typically found to lie in the range of 1-8 per cent (Ahlfeldt and Pietrostefani 2019; Melo, Graham et al. 2009). Melo, Graham et al. (2009) also show that agglomeration effects differ across economic sectors and may be higher in service industries. Previous Australian studies, based on area-level productivity estimates (see Section 1.3), found evidence that Australian agglomeration benefits are at the higher end of this range or even exceed 8 per cent.

The implications of this for the link between agglomeration and housing dynamics are twofold. (Amenity-related implications are discussed in Section 2.1.2).

First, where agglomeration leads to higher wages, agglomeration should also lead to higher housing costs. Workers, incentivised by higher wages, bid up the price of housing in order to secure access to more productive localities (wages). The location of housing, being fixed in space, plus additional transport costs, determines the overall cost of accessing areas that are more productive. It follows then that high house prices are also an indicator of agglomeration effects. Under spatial equilibrium, gains from higher wages are, at least partially, absorbed by higher costs (Glaeser and Gottlieb 2009). Evidence from Australia and the UK shows that an increase in income typically leads to an even greater increase in property prices (Abelson, Joyeux et al. 2005; Meen 2008). In both Australia and the UK, the aggregate responsiveness of new housing supply to changes in prices is shown to be low (Ball, Meen et al. 2010; Gitelman and Otto 2012), resulting in income increases disproportionally manifested in price hikes rather than supply expansion.

Second, the effect of agglomeration is assumed similar for all workers. Subsequently, and subject to supply conditions, higher wages become capitalised in higher land values for all. However, if some workers-for example, those with higher human capital (skills that are in limited supply) - benefit more from agglomeration than other workers, then agglomeration effects are only partially capitalised in land values and house prices. The price of housing is determined by the willingness of households to live and work from particular localities and is, therefore, the intersection of total demand - those benefiting a little and those benefiting a lot-and supply of housing. Those benefiting a lot from agglomeration therefore also retain a larger part of the urban surplus, whereas those benefiting less from agglomeration, also end up spending more of their benefit on housing costs. Collier and Venables (2017) showed that differential preferences for housing - that is, small and large properties - result in households with a preference for smaller properties retaining part of the urban surplus.

Both of the above points raise important considerations about agglomeration benefits, housing policy and urban and regional development strategies. Both the international and Australian evidence suggest that there are positive productivity effects from jobs agglomeration. However, the net benefits from agglomeration are mediated by the responsiveness of housing markets to demand for spatially better-placed locations. This means that the increasing housing costs associated with density may reduce or negate the benefits otherwise created by agglomeration effects. Recent meta-analysis of the relationship between urban density, wages and rents (Ahlfeldt and Pietrostefani 2019) appear to bear out Henderson's (1974) bell-shaped net-agglomeration benefit curve. Thus the effect of density on wages and housing costs may have significant redistributional effects that, over time, may bias investment decisions towards none or less productive forms of asset investment (Stiglitz 2016). 


\subsubsection{Agglomeration and amenities}

The presence of an urban wage premium is an important explanation for why mobile households may want to live in cities. The size and diversity of the labour market also provides assurances against future or long-term spells of unemployment and increases the likelihood that a job search will be successful (Whelan and Parkinson 2017). However, this effect is balanced out by the higher housing costs that urban residents pay, and longer and more costly commutes-often in more polluted environments because of greater concentration of traffic or economic activity. Benefits may also be balanced out by the presence of social issues, such as crime, which is typically higher in more densely populated areas. For instance, in 2019-2020, the City of Melbourne had the highest incidence of crime in Metropolitan Melbourne, followed by the local government areas of Yarra, Greater Dandenong, Stonnington and Port Phillip. ${ }^{1}$ Finally, congestion costs may also relate to greater rates of community transmission of some communicable diseases. For instance, emerging and preliminary research suggests that population density might be associated with higher rates of COVID-19 transmission, and exposure to air pollution may be acting as a comorbidity factor (Wu, Nethery et al. 2020).

Congestion costs provide a counterbalance to households' desire to live and work in particular localities, and so have a price-reducing effect on rents and property prices-or a wage-inflating effect if the productivity gain from agglomeration exceeds the additional compensation required to live in more congested cities.

However, cities also provide a series of consumption amenities that may be attractive characteristics and that independently_or in addition to wages-increase households' preferences for living in cities, and in specific parts of cities. For instance, Australian cities regularly feature high on The Economist's Global Liveability Index and the value (or benefit) derived from 'liveability' may be additional compensation to offset higher housing and congestion costs. The connectivity and global integration of global (or alpha) cities such as Sydney and Melbourne generate cultural and economic amenities in areas of these cities. Population growth in Australia has been particularly high in capital cities, especially Sydney and Melbourne-which are typically the cities ranked higher by liveability indices. Both at the city-wide and intra-city level, a critical mass of demand (or income concentration) and scale economies enable a greater diversity in private and public services and urban amenities across a range of quality categories - such as schools, hospitals, restaurants, bars, shopping, sports facilities, theatres and museums.

Glaeser, Kolko et al. (2001) showed that high-amenity cities in the US grew faster in the period 1977-1995 than lowamenity cities. Moreover, rents in high-amenity cities typically increased faster than wages in the corresponding cities, suggesting that households' desire to live in these cities increased for reasons beyond the urban wage premium. Adamson, Clark et al. (2004) showed that although urban US workers have a wage advantage, the net returns to education decline with urban scale. This, Adamson, Clark et al. (2004) argued, suggests that higher-skilled workers are attracted to urban amenities, separately from any wage benefit.

This has implications for the relationship between agglomeration and housing market dynamics.

First, if urban consumption amenities compensate households for urban disamenities, then housing affordability may continue to worsen independently of changes to wage distribution or increase. For instance, as cities de-carbonise and public policy_including planning and infrastructure investment_facilitates more 'liveable' cities, the counter-balancing effects of traditional congestion costs and consumption disamenities will abate.

1 www.crimestatistics.vic.gov.au 
If the abatement of congestion costs - in terms of demand for urban living-exceeds the additional productivity gain from household agglomeration, either on average or socially differentiated, then expenditure on housing costs as a proportion of incomes may very well continue to increase for some or all households. Kahn and Walsh (2014) reviewed the relationship between quality of life in urban areas, abatement of congestion costs and demand for urban living, and concluded that improvement in urban quality of life is reducing the need for employers and cities to provide additional wage inducements. Similarly, the significant implications of emerging spatial inequalities that can result from agglomeration economies may lead us to consider whether this is a tradeoff we should be prepared to accept-particularly in relation to those locked out of the wage premium benefits, such as young people, who face significant future housing costs.

Second, amenities may also be a function of agglomeration (Adamson, Clark et al. 2004; Glaeser, Kolko et al. 2001). Concentrations of households generate market potential that can enable economies of scale to sustain a greater variety and diversity of consumer offerings (local goods), which some (or all) households may perceive as attractive attributes of urban living. However, market size is intimately linked with the purchasing power of individuals. The spatial distribution of purchasing power also effects available consumption amenities and, in turn, affects the geography of housing demand both across and within cities.

Finally, the presence of city and local amenities (and disamenities) may affect the regulatory and political economy of the very supply conditions that affect the extent to which increases in demand for urban living translate into price appreciation or housing stock expansion. Brueckner, Thisse et al. (1999) argued that the location of many consumption amenities within cities is a function of spatial concentrations of different income groups. In the absence of large shocks (Nygaard and Meen 2013), concentrations of different income groups can become a self-reinforcing spatial process both within cities and at the city level. Saiz (2010) showed that regulatory constraints at the metropolitan level in the USA are a function of initial price levels and price growth. That is, historically attractive residential areas are likely to have more restrictive regulatory systems in place then less attractive residential areas. Thus, demand for regulation and planning can be an endogenous process that serves to preserve the positive amenity effects generated by agglomeration from potential dilution through negative disamenities.

\subsubsection{Agglomeration and the future of work}

Agglomeration effects are associated with proximity and reduced transport costs. Technology, digital connectivity and automation may reshape some aspects of distance and proximity, and alter the economic geography of cities and regions. The digital economy and automation are likely to affect workers and sectoral productivity by:

- creating 'superstar firms' and 'superstar workers'-where technology complements some form of human capital (which means it has a skills bias)

- creating substitution and task replacement-where technology substitutes for other forms of human capital.

These changes follow on from evidence that technological change has had a skills bias throughout the 20th century (Acemoglu 2002). Technological change and automation are already shaping the nature of many jobs, and lead to the substitution of automated labour for human labour. Automation of tasks over the past three decades has contributed to a decline in the demand for routine and manual tasks (SGSPE 2019).

The loss of routine jobs to processes of automation and blockchain technology also alters the geography of employment location. For instance, SGSPE (2019) analysis suggested that outer areas of Melbourne are more vulnerable to job losses stemming from automation than inner areas. The growth in 'workplace mobility' or mobile ways of teleworking - that is, working from home-across a myriad of places and modalities, including cafes, in transit, from home or within hot-desking office spaces shared across multiple companies, alters value creation and urban space, including office space management and real estate investment (Putri and Shearmur 2020). Teleworking has increased sporadically among knowledge workers attached to physical organisations, but is pervasive in the growing gig economy, where there is no 'office' (Belzunegui-Eraso and Erro-Garcés 2020; Nakrošienè, Bučiūnienè et al. 2019). 
These digital-enabled transitions are also likely to alter the economic geography and spatial form of cities. Recent research by Delventhal, Kwon et al. (2020) examined the changes that happen within cities with a more permanent and sizeable shift to teleworking. One outcome from this transformation is that jobs are more likely to move and be concentrated within the core, while people move further to more affordable areas, which in turn leads to a decline in house prices within inner urban areas. This move to more affordable areas can potentially lead to quality of life gains from reduced travel times and reduced housing affordability stress. It may also lead to changes in the socioeconomic geography of cities, as some employment and occupation types are better placed to benefit from teleworking than others. A key feature of urban developments over the past few decades has been the reconcentration of higher-income residents in more central parts of cities as many knowledge-based industries clustered in city CBDs (Terrill, Batrouney et al 2018). The impact of digital transitions on these trends ultimately depends on both:

- the employment-wage amenity generated by proximity to employment concentrations

- the urban amenities that arise from the concentration of income, employment and people.

There are also productivity gains via less congestion and commute times. Frank, Sun et al. (2018) examined the impact of automation across different city sizes. They found that smaller cities can expect greater worker displacement and task substitution because of automation than larger cities, because of the higher concentration of managerial and professional occupations in larger cities. At the same time, technological change may enable managerial and professional occupations to be more mobile or flexible in their choice of residential location regarding the physical location of their employer.

COVID-19 has accentuated and accelerated both the employment-security and employment-location considerations arising from technological change and may continue to do so. Specifically, COVID-19 has re-emphasised significant disparities in the social protection and impact of work-related changes across different groups of workers. These disparities translate to:

- inequity in workforce stability and connectivity

- inequity in access to adequate and secure wages over time in a manner that enables individuals and families to manage risks

- unequal rates of human capital depreciation.

Moreover, the widespread shift to, and acceptance of, teleworking during COVID-19 has enabled some workers to reconsider their residential locations in relation to the physical location of their employer. In the short and long run, the potential for teleworking is expected to be particularly high in employment such as clerical, administrative, professional and managerial occupations, but much less in sales, technicians, trades, community services, labourers and machine operators (Pennington and Standford 2020). Out-migration from key agglomerations has been particularly marked in Melbourne. However, elsewhere in Australia property prices in regional areas and towns within commutable distances to the capital cities increased relative to capital cities (CoreLogic 2021). One explanation for agglomeration benefits is that proximity, face-to-face interactions and knowledge networks increase opportunities for learning that enhances individuals' productivity (Glaeser 1999). Once acquired, however, learning (human capital) is portable. Thus teleworking provides an opportunity to disperse higher wages more widely, without loss of productivity.

\subsubsection{Policy implications}

Agglomeration economies are regarded as a potential part-solution to addressing Australia's demographic 'cash call', and part-solution to low rates of wage growth - which also is caused by casualisation and underemployment-by raising the productivity of labour. However, as discussed earlier in this section, links between agglomeration and housing market dynamics and the distribution of any agglomeration benefits are complex. The international literature suggests that a doubling of jobs/skills concentrations is associated with a 1-8 per cent increase in productivity and urban wage premiums. Therefore, higher house prices are also an indicator of productivity (agglomeration) effects. 
However, in practice, skills concentrations are also accompanied by household and income concentrations that can generate additional inducements to living in cities, thereby reducing the need for an urban wage premium, but also increasing other non-housing congestion costs. This amenity link between agglomeration and housing dynamics is an often-neglected aspect of housing policy and planning discussions. As a result, housing cost and affordability issues may also increase in the absence of wage and productivity growth. Finally, digital connectivity and automation has the potential to reshape the returns to physical proximity. In terms of planning for population growth and urban development in a post-COVID-19 environment, the impact of teleworking, digital transitions and automation is expected to shape the geography of employment and demand for housing for different types of employment and occupations differently.

This brief discussion of the relationship between agglomeration effects, housing market dynamics and the 'future of work' raises several issues for harnessing 'agglomeration economies' and policy solutions that can boost productivity, and mitigate adverse housing market outcomes, such as alternative population and urban development strategies. These effects are discussed further in Section 5. 


\section{Labour (wage) productivity and agglomeration in Australia}

- Agglomeration effects raise wages by 1 to 4 per cent. With SA2 level inputs, there is some evidence of additional productivity benefits for higher-wage workers from closeness to other labour markets. This proximity effect appears to disappear with SA4 level inputs.

- However, most of the differences in wages are not determined by agglomeration effects, but by individual, institutional and industry characteristics-such as education, experience and firm size.

- Our results suggest that additional agglomeration benefits arise from firms in the same industries locating together-called localisation economies. Broadly a doubling of economic specialisation, relative to the state as a whole, is associated with a further 4-10 per cent higher wages. Outside raw material and transport sectors, specialised economic structures are particularly evident for 'Information Media and Telecommunication', 'Financial and Insurance Services' and 'Arts and Recreation Services'.

- With SA4 level inputs, productivity is also enhanced by economic diversity (or urbanisation economies).

- Agglomeration benefits are not equally distributed. Higher-wage workers benefit approximately 50 per cent more than lower-wage earners from density of employment. If other things are equal-transfer payments, taxation, etc. - then agglomeration-related productivity gains also generate inequality. 
- There is little variation in agglomeration benefits when looking at skillsbased versus all employment agglomeration. With both SA2 (finer) and SA4 (broader) level inputs, density of Skills level A is broadly the same as density of Skills level B or C.

\section{- Strategies to disperse population growth-for instance, by incentivising expansion and urban growth to regional urban centres-need to carefully consider the multiple sources of productivity, and trade-offs between positive (productivity) and negative (congestion) agglomeration effects.}

\subsection{Introduction}

Labour productivity from agglomeration effects in Australian cities is a potential source of enhancing the output from Australia's technology, human and physical capital. With an ageing population, increased productivity is a means of offsetting the changing balance of those who work to those who are retired, under education or children. However, measuring agglomeration economies is not straightforward. The presence of higher wages in denser employment locations is not evidence that co-location generates agglomeration effects. Variation in wages across space could, in practice, simply reflect sorting of employees across firms reliant on particular types of employees-for instance, high-skilled employees and low-skilled employees sorted into denser and less dense areas. Office jobs, for instance, can more easily be stacked on top of each other than car manufacturing jobs. Earlier research in Australia finds that effective jobs density (EJD) does have a positive impact on sectoral gross value added (GVA). However, these studies draw on area-level data that are less suited to control for the wide range of individual and firm characteristics that determine the productivity of the individual.

In this study, we make use of additional information on respondents' place of work by the HILDA Survey. RQ2 asks:

- To what extent is labour productivity in Australia a function of agglomeration effects?

- And do agglomeration benefits differ across skills and/or income groups?

Section 3 presents and discusses the results from estimating the impact of individual characteristics, firm characteristics and labour market context on the earnings (in main job) per hour. Specifically, we are interested in whether-after controlling for different characteristics related to the individual — there is an additional association between their wage and density of employment at their place of employment. Information on respondents' place of work (detailed location) is only available in Waves 17 and 18 of HILDA. The short timeseries $(T=2)$ reduces the robustness of estimating our wage model based on fixed effects panel estimators that also control for unobserved individual characteristics.

In presenting the results, the report divides these into:

- individual, institutional and industry components of the wage model-Section 3.2

- agglomeration components of the wage model-Section 3.3.

Methodologically, the different components are estimated together (as a single regression) and are only divided into separate parts for presentational purposes.

Our main estimation results are based on random effects panel estimators. Instrumental variable (IV) technique is used to address potential endogeneity between wages and density of employment. In practice, differences in the interpretation of results between the OLS and IV are small. Nevertheless, the IV regression makes it possible to go beyond interpretation of effects as just correlations, and instead focus on causal relationships. 
Additional pooled OLS with weights, and mixed-level pooled estimations with random and fixed intercept and coefficient slopes were run as robustness tests. Rather than reporting on each of the estimation methods, a summary table is provided in Table 8 in Section 3.3.3. Overall, there is little variation in the estimated results.

Quantile regressions are used to analyse distributional effects. Appendix A gives further detail on variable construction, selection and estimation strategy.

Results are presented by SA2 and SA4 level inputs (agglomeration effects). Although further research is required for more precise identification of spatial reach, the separate estimates make it possible to say something about spatial dimensions of agglomeration effects and to draw additional insights for policymaking and planning.

The wage model was also estimated by industry and by occupation. Sample numbers for these estimations are much smaller, and thus need to be treated with caution. Further waves of the HILDA Survey will enable more robust workplace disaggregated estimation.

\subsection{Determinants of wages}

Before detailing agglomeration specific effects, Section 3.2 provides a summary of the individual and firm level determinants of hourly wages: individuals' demographic characteristics such as gender, age and education; collective institutional factors such as union membership; occupations, industry of employment and size of firms. This element of the model shows that the most significant determinants of wages are demographic variables, education and occupation (human capital). There is also significant variation across industries and firm sizes. In other words, the main determinants of spatial variation in wages are standard individual and industry variables. These variables reflect the empirical literature on heterogeneity in wages across individuals, industries, occupations and business/employer structure (see Section 7.5 in Appendix A for more information).

Reporting on these parts of the wage regression is not repeated throughout. Instead, the remainder of this report focusses specifically on the agglomeration measures and indicators. Results are discussed for the wage model based on SA2 level inputs, random effects (RE) panel estimations and IV panel estimations. In practice, variations in these wage determinants are negligible across SA2 and SA4 level input estimations. Similarly, differences between the RE panel results and IV results are negligible with the exemption of the fixed effects for 'Financial intermediaries' and 'Real estate and renting'. Results are reported in Table 1.

Table 1: Determinants of wages

\begin{tabular}{|c|c|c|c|c|}
\hline \multirow[b]{2}{*}{ Variable } & \multicolumn{2}{|c|}{ RE panel } & \multicolumn{2}{|c|}{ IV panel } \\
\hline & Coef. & $p$-val. & Coef. & $p$-val. \\
\hline Male (1=yes) & 0.096 & 0.000 & 0.095 & 0.000 \\
\hline Age (natural log of years) & 0.279 & 0.000 & 0.268 & 0.000 \\
\hline Legally married (1=yes) & 0.098 & 0.000 & 0.102 & 0.000 \\
\hline De facto (1=yes) & 0.076 & 0.000 & 0.074 & 0.000 \\
\hline Managers (1=yes) & 0.254 & 0.000 & 0.245 & 0.000 \\
\hline Professionals (1=yes) & 0.228 & 0.000 & 0.214 & 0.000 \\
\hline Technicians (1=yes) & 0.095 & 0.000 & 0.093 & 0.000 \\
\hline Health and welfare (1=yes) & 0.066 & 0.000 & 0.060 & 0.001 \\
\hline Clerical/admin (1=yes) & 0.078 & 0.000 & 0.062 & 0.000 \\
\hline Sales workers (1=yes) & 0.030 & 0.103 & 0.022 & 0.251 \\
\hline Machine operators (1=yes) & 0.026 & 0.198 & 0.032 & 0.110 \\
\hline Main English speaking (excl AUS) (1=yes) & -0.012 & 0.369 & -0.005 & 0.710 \\
\hline Germany, Netherlands, Italy (1=yes) & -0.011 & 0.560 & -0.007 & 0.732 \\
\hline
\end{tabular}




\begin{tabular}{|c|c|c|c|c|}
\hline \multirow[b]{2}{*}{ Variable } & \multicolumn{2}{|c|}{ RE panel } & \multicolumn{2}{|c|}{ IV panel } \\
\hline & Coef. & $p$-val. & Coef. & $p$-val. \\
\hline China (1=yes) & -0.051 & 0.197 & -0.040 & 0.322 \\
\hline India (1=yes) & -0.100 & 0.062 & -0.098 & 0.059 \\
\hline Philippines (1=yes) & -0.039 & 0.147 & -0.032 & 0.239 \\
\hline Vietnam (1=yes) & -0.145 & 0.000 & -0.155 & 0.000 \\
\hline Other (1=yes) & -0.055 & 0.097 & -0.045 & 0.172 \\
\hline ATSI (1=yes) & -0.063 & 0.000 & -0.065 & 0.000 \\
\hline Bachelor degree or higher (1=yes) & 0.175 & 0.000 & 0.165 & 0.000 \\
\hline Advanced diploma (1=yes) & 0.072 & 0.000 & 0.072 & 0.000 \\
\hline Tenure with current employer (years) & 0.002 & 0.000 & 0.002 & 0.000 \\
\hline Employed full-time (1=yes) & -0.048 & 0.000 & -0.048 & 0.000 \\
\hline Primary industries (1=yes) & -0.162 & 0.000 & -0.121 & 0.001 \\
\hline Mining quarrying (1=yes) & 0.299 & 0.000 & 0.328 & 0.000 \\
\hline Manufacturing (1=yes) & 0.005 & 0.778 & 0.006 & 0.692 \\
\hline Utilities (1=yes) & 0.269 & 0.000 & 0.243 & 0.000 \\
\hline Construction (1=yes) & 0.095 & 0.000 & 0.078 & 0.000 \\
\hline Wholesale trade (1=yes) & -0.066 & 0.000 & -0.075 & 0.000 \\
\hline Hotels and restaurants (1=yes) & -0.151 & 0.000 & -0.159 & 0.000 \\
\hline Transport and storage (1=yes) & 0.017 & 0.386 & -0.003 & 0.833 \\
\hline Financial intermediary (1=yes) & 0.051 & 0.009 & -0.001 & 0.950 \\
\hline Real estate and renting (1=yes) & 0.034 & 0.024 & -0.002 & 0.880 \\
\hline Public administration (1=yes) & 0.105 & 0.000 & 0.077 & 0.000 \\
\hline Education (1=yes) & -0.051 & 0.000 & -0.037 & 0.009 \\
\hline Health and social care (1=yes) & -0.082 & 0.000 & -0.101 & 0.000 \\
\hline Union member (1=yes) & 0.045 & 0.000 & 0.050 & 0.000 \\
\hline Micro employer ( $1-4$ employees) (1=yes) & -0.149 & 0.000 & -0.120 & 0.000 \\
\hline Small employer (5-19 employees) (1=yes) & -0.100 & 0.000 & -0.077 & 0.000 \\
\hline Medium employer (20-199 employees) (1=yes) & -0.063 & 0.000 & -0.049 & 0.000 \\
\hline Employer has only one location in Australia (1=yes) & -0.032 & 0.000 & -0.027 & 0.001 \\
\hline Has health condition ( $1=y e s)$ & -0.054 & 0.000 & -0.055 & 0.000 \\
\hline Casual employee, ABS definition (1=yes) & -0.004 & 0.708 & -0.002 & 0.837 \\
\hline Remote or very remote (1=yes) & 0.024 & 0.534 & 0.027 & 0.485 \\
\hline State or territory fixed effect & Included & & Included & \\
\hline Commuting distance & Included & & Included & \\
\hline Agglomeration variables & Included & & Included & \\
\hline Year dummy & Included & & Included & \\
\hline Constant & 1.968 & 0.000 & 2.652 & 0.000 \\
\hline Observations & 14,814 & & 14,814 & \\
\hline Overall $R^{2}$ & 0.454 & & 0.406 & \\
\hline
\end{tabular}

Note: CPI-adjusted estimates ( $\$=2017$ ). Base categories are all other marital statuses, 'Labourers', 'Australians', all other education levels, 'Other community' and 'Private household' sectors, 'Large employers (200+ employees), and 'Major cities'. Fixed effects for 'States/ territories' and 2018 are not reported. Robust errors due to heteroscedasticity in OLS estimations of wage model. Bold type indicates significant at the conventional 5 per cent level. Italics indicate significant at 10 per cent level.

Source: Authors' estimations, HILDA Survey Waves 17 and 18; ABS Census TableBuilder, 2016. 
The key insights from individual, institutional and industry components of the wage model (Equation 3) are outlined below.

- The hourly wage rate of women is 10 per cent less than that of men, after controlling for age, employment experience (tenure with employer), occupation, industry and education. Quantile regressions (not reported) show that the gender gap increases across the wage distribution.

- Individuals in partnered relationships-formally married or de facto-typically experience a wage premium of 8-10 per cent. Reasons for this are not explored but may reflect both institutional and cultural determinants including a tendency for males to defer partnering until they have higher earnings. Unpartnered women with children may experience wage scarring.

- Wages are strongly hierarchical by occupations. Higher occupations (managers, professionals) earn higher wages than lower occupations (machine operators, labourers).

- There is little variation in wages across those who are Australian-born and migrants from other English-speaking countries and western European migrants. The two largest migration groups in recent years are workers from China and India. On average there is no difference in the wages earned by Chinese migrants (after controlling for age, employment experience, occupation, industry and education), but there is a marked wage discount for Indian migrants - approximately 10 per cent. Similarly, there is a marked wage discount for Aboriginal and Torres Strait Islanders, approximately 6 per cent.

- The returns to education remain significant for those with bachelor's degree or higher (18 per cent) or advanced diplomas (7 per cent).

- Wages in the mining, construction and public administration sectors are significantly above those in other sectors; wages in wholesale, hotels and restaurants, and health and social care are substantially below.

- Employees working for smaller employers typically earn lower wages than those working for larger employers. Wages working for employers that operate out of only one location in Australia on average earn some 3 per cent less than multi-location employers.

- Employees with a self-reported health condition typically experience a 5 per cent wage discount.

Overall, the results of the individual, institutional and industry component of the wage model conform to prior expectations, but they are also an important reminder that agg/omeration effects do not determine most of the differences in wages. Unsurprisingly, significant wage differentials mean that some workers are better able to compete for housing than other workers.

From a household perspective, the higher wages of partnered individuals suggest increased purchasing or renting potential for the individual, but also for dual earnings. An implication of this is the housing market marginalisation of single people with lower earnings and a lack of ability to pool incomes at the household level.

The differentials also imply that in a dynamic perspective (over time) a proportional increase in wages, such as might arise from collective bargaining agreements or agglomeration effects, would result in an accentuation of these differentials and, other things being equal, improve the ability of better-paid workers to compete for housing, relative to less-well-paid workers. In the following subsections, we turn to the impact of employment density (agglomeration) on wages.

\subsection{Agglomeration effects and productivity}

This section details the results relating to the agglomeration components of the wage model. The variables discussed in this section are in relation to agglomeration effects at place of work. The discussion focuses on employment density, employment in nearby areas and two economic structure related agglomeration measures economic diversity (urban economies) and economic specialisation (locational economies). Finally, a measure of commuting distance is included. 


\subsubsection{Agglomeration and wage effects, all workers}

Table 2 provides the RE and IV panel estimation of the wage model. Results are presented with SA2 and SA4 level inputs. Columns 2 and 7 estimate the wage regression without any individual, firm or institutional characteristics. All other estimates contain all controls. Estimates are provided separately for density of all employees and density of employees based on skills levels A-C (see Section 7.3 in Appendix A for more about Skills levels).

Table 2: Agglomeration effects and hourly wages

\begin{tabular}{|c|c|c|c|c|c|c|c|c|c|c|c|c|}
\hline & \multicolumn{6}{|c|}{ SA2 inputs } & \multicolumn{6}{|c|}{ SA4 inputs } \\
\hline & \multicolumn{3}{|c|}{ All employment } & \multirow{2}{*}{$\frac{\text { Skills level A }}{\text { RE panel }}$} & \multirow{2}{*}{$\begin{array}{r}\text { Skills level B } \\
\text { RE panel }\end{array}$} & \multirow{2}{*}{$\frac{\text { Skills level C }}{\text { RE panel }}$} & \multicolumn{3}{|c|}{ All employment } & \multirow{2}{*}{$\begin{array}{r}\text { Skills level A } \\
\text { RE panel }\end{array}$} & \multirow{2}{*}{$\begin{array}{r}\text { Skills level B } \\
\text { RE panel }\end{array}$} & \multirow{2}{*}{$\begin{array}{r}\text { Skills level C } \\
\text { RE panel }\end{array}$} \\
\hline & RE panel & RE panel & IV panel & & & & RE panel & RE panel & IV panel & & & \\
\hline Density & 0.026 & 0.011 & 0.066 & 0.010 & 0.010 & 0.011 & 0.037 & 0.017 & 0.027 & 0.016 & 0.016 & 0.016 \\
\hline$p$-value & $(0.000)$ & $(0.000)$ & $(0.000)$ & $(0.000)$ & $(0.000)$ & $(0.000)$ & $(0.000)$ & $(0.000)$ & $(0.003)$ & $(0.000)$ & $(0.000)$ & $(0.000)$ \\
\hline Market potential & 0.002 & 0.010 & -0.092 & 0.009 & 0.012 & 0.013 & -0.075 & -0.018 & -0.059 & -0.020 & -0.016 & -0.011 \\
\hline$p$-value & (0.799) & $(0.141)$ & $(0.000)$ & $(0.204)$ & $(0.081)$ & $(0.049)$ & $(0.000)$ & $(0.205)$ & $(0.085)$ & $(0.162)$ & $(0.282)$ & $(0.445)$ \\
\hline Relative diversity & -0.046 & -0.004 & 0.097 & -0.003 & -0.008 & -0.008 & -0.011 & 0.023 & 0.028 & 0.026 & 0.022 & 0.016 \\
\hline$p$-value & $(0.043)$ & $(0.806)$ & $(0.000)$ & $(0.875)$ & $(0.670)$ & $(0.654)$ & $(0.532)$ & (0.074) & $(0.044)$ & $(0.045)$ & (0.093) & $(0.244)$ \\
\hline Relative specialisation & 0.064 & 0.038 & 0.106 & 0.037 & 0.037 & 0.036 & 0.065 & 0.047 & 0.053 & 0.046 & 0.048 & 0.044 \\
\hline$p$-value & $(0.000)$ & $(0.000)$ & $(0.000)$ & $(0.000)$ & $(0.000)$ & $(0.000)$ & $(0.000)$ & $(0.000)$ & $(0.000)$ & $(0.000)$ & $(0.000)$ & $(0.000)$ \\
\hline Commute & 0.057 & 0.017 & 0.014 & 0.017 & 0.017 & 0.017 & 0.060 & 0.019 & 0.018 & 0.019 & 0.019 & 0.019 \\
\hline$p$-value & $(0.000)$ & $(0.000)$ & $(0.005)$ & $(0.000)$ & $(0.000)$ & $(0.000)$ & $(0.000)$ & $(0.000)$ & $(0.000)$ & $(0.000)$ & $(0.000)$ & $(0.000)$ \\
\hline \multicolumn{13}{|l|}{ Fixed effects for: } \\
\hline Demographics & No & Yes & Yes & Yes & Yes & Yes & No & Yes & Yes & Yes & Yes & Yes \\
\hline Skills/education & No & Yes & Yes & Yes & Yes & Yes & No & Yes & Yes & Yes & Yes & Yes \\
\hline COB/ethnicity & No & Yes & Yes & Yes & Yes & Yes & No & Yes & Yes & Yes & Yes & Yes \\
\hline
\end{tabular}




\begin{tabular}{|c|c|c|c|c|c|c|c|c|c|c|c|c|}
\hline & \multicolumn{6}{|c|}{ SA2 inputs } & \multicolumn{6}{|c|}{ SA4 inputs } \\
\hline & \multicolumn{3}{|c|}{ All employment } & \multirow{2}{*}{$\frac{\text { Skills level A }}{\text { RE panel }}$} & \multirow{2}{*}{$\frac{\text { Skills level B }}{\text { RE panel }}$} & \multirow{2}{*}{$\frac{\text { Skills level C }}{\text { RE panel }}$} & \multicolumn{3}{|c|}{ All employment } & \multirow{2}{*}{$\frac{\text { Skills level A }}{\text { RE panel }}$} & \multirow{2}{*}{$\frac{\text { Skills level B }}{\text { RE panel }}$} & \multirow{2}{*}{$\frac{\text { Skills level C }}{\text { RE panel }}$} \\
\hline & RE panel & RE panel & IV panel & & & & RE panel & RE panel & IV panel & & & \\
\hline Industry/occupation & No & Yes & Yes & Yes & Yes & Yes & No & Yes & Yes & Yes & Yes & Yes \\
\hline Union & No & Yes & Yes & Yes & Yes & Yes & No & Yes & Yes & Yes & Yes & Yes \\
\hline Employer characteristics & No & Yes & Yes & Yes & Yes & Yes & No & Yes & Yes & Yes & Yes & Yes \\
\hline State or territory fixed effect & Yes & Yes & Yes & Yes & Yes & Yes & Yes & Yes & Yes & Yes & Yes & Yes \\
\hline Year dummy & Yes & Yes & Yes & Yes & Yes & Yes & Yes & Yes & Yes & Yes & Yes & Yes \\
\hline Constant & 3.101 & 1.968 & 2.652 & 1.994 & 1.963 & 1.960 & 4.016 & 2.269 & 2.731 & 2.304 & 2.250 & 2.228 \\
\hline$p$-value & $(0.000)$ & $(0.000)$ & $(0.000)$ & $(0.000)$ & $(0.000)$ & $(0.000)$ & $(0.000)$ & $(0.000)$ & $(0.000)$ & $(0.000)$ & $(0.000)$ & $(0.000)$ \\
\hline Number & 14,814 & 14,814 & 14,814 & 14,814 & 14,814 & 14,814 & 14,817 & 14,817 & 14,817 & 14,817 & 14,817 & 14,817 \\
\hline Overall $\mathrm{R}^{2}$ & 0.086 & 0.434 & 0.406 & 0.434 & 0.434 & 0.434 & 0.072 & 0.433 & 0.433 & 0.433 & 0.433 & 0.433 \\
\hline Number of groups & 8,998 & 8,998 & 8,998 & 8,998 & 8,998 & 8,998 & 8,999 & 8,999 & 8,999 & 8,999 & 8,999 & 8,999 \\
\hline
\end{tabular}

Note 1: Figures in brackets are p-values, robust standard errors. Minor variations in sample size are due to confidentiality censoring (null cells) when disaggregating by skills level. All effects are elasticities. Estimates obtained using Stata's xtreg command. Full list of estimation variables are enclosed in Appendix A, Table A4. Estimations in columns 2 and 7 only control for state and remote area. Bold type indicates significant at the conventional 5 per cent level. Italics indicate significant at 10 per cent level.

Note 2: See Note to Table 1 for additional specification details.

Source: Authors' estimations, HILDA Survey Waves 17 and 18; ABS Census TableBuilder, 2016. 
Comparing SA2 to SA4 level input outcomes provides some additional insight on the spatial reach of any agglomeration effects; comparing outcomes by skills level provides additional insight on human capital and agglomeration. All results are elasticities, we report point estimates (Table 2) as percentage results and provide variability of the estimates as a 95 per cent confidence interval (C195). The results in Table 2 contain a number of insights for understanding agglomeration effects and labour productivity in Australia:

- Across the results in Table 2, employment density is associated with an increase in wages. After controlling for a range of individual, firm and institutional characteristics that may also generate variation in worker productivity, our agglomeration benefit measure is reduced by 55-58 per cent (column 2 and column 3; column 7 and column 8). This shows that there is considerable endogeneity between employment density and the propensity of firms / employees to locate or take-up employment in particular locations. Adding the additional controls substantially improves the models' ability to predict wages. While agglomeration benefits are significant, the majority of wage variation is determined by individual and firm level characteristics. These may also be the outcome of self-selection into more urbanised areas as a result of non-wage amenities-for example, urban amenities and social dynamics.

- Broadly speaking, after controlling for individual and firm characteristics, a doubling of employment density would raise wages by 1.1 per cent (CI95: 0.6-1.5 per cent) with SA2 level inputs and 1.7 per cent (CI95: 1.0-2.3 per cent) with SA4 level inputs. The average agglomeration effects with SA4 level inputs are somewhat greater than the average effect at SA2 level. There is little evidence of multicolinearity with SA2 level inputs. All variance inflation factors (VIF) are below 4. With SA4 level inputs, the VIF for employment in other locations (market potential) is marginally above 10. Removing market potential (for the SA4 level input estimations) changes the agglomeration elasticity to 1.3 per cent $(p<0.05)$ (CI95: 0.9-1.7 per cent), bringing this more in line with the SA2 level input estimates. Economic diversity also becomes significant at 5 per cent level. (Results are included in Appendix B, Table A5.)

- The IV estimates show somewhat greater agglomeration point estimates with both SA2 and SA4 level inputs, 6.6 (Cl: 4.7-8.7 per cent) and 2.7 (Cl: 1.0-4.5 per cent) per cent, respectively. For the SA2 level input estimates, there is now a negative and significant effect of market potential so that the overall agglomeration effect is reduced, closer to the RE panel results. Dropping market potential (due to a marginally raised VIF) from the SA4 level input estimations increases the agglomeration effect to 4.1 per cent (C195: 2.9-5.3 per cent). (Results are included in Appendix B, Table A5.) The IV results attempt to control for the endogenous nature of agglomeration effects and thus make it possible to speak of causality in the relationship between employment density and wages.

Compared to existing Australian area-based measures of agglomeration effects, these effects are substantially lower. However, compared to the international literature, the results in Table 2 are broadly comparable. The RE panel results are within the lower bound found in the international literature (see Section 2.1.1), and IV panel results are close to the average of international findings (Ahlfeldt and Pietrostefani 2019). An important reason for the lower estimates, compared to previous Australian research, is that the results in Table 2 control for a rich set of individual, employment and firm characteristics that also affect wages.

- Trubka (2011) provides agglomeration elasticities based on capital cities ranging from 3.5 per cent (Perth) to 36.7 per cent (Canberra) across Australian capital cities. In comparison to those estimates, the results presented here are based on hourly wages (not average wages) and controls for individual heterogeneity in demographics, skills and employment characteristics. SGSPE (2012) estimates of agglomeration elasticities for Sydney, Melbourne and Adelaide, similarly based on area measures, are 7, 8 and 9 per cent. Existing Australian research thus typically exceeds the agglomeration elasticity found internationally. Ahlfeldt and Pietrostefani's (2019) meta-analysis of density and wages finds an average effect of 4 per cent. The results in Table 2 suggests that 4 per cent is an upper estimate of an employment density effect in Australia.

- Skills-based agglomeration-columns 4-6 and 9-11-show that the skills nature of agglomeration has a relatively little impact. With both SA2 and SA4 level inputs, density of Skills level A is broadly the same as density of Skills level B or C. 
Additional agglomeration measures

\section{Market potential}

Market potential is distance-weighted proximity to all other postcodes of employment, but it does not appear to have a significant effect with either SA2 or SA4 level inputs. However, although neither coefficient is significant, differences in sign (positive and negative) may be indicative of different spatial dynamics at smaller and larger areas of agglomeration. As noted earlier, the market potential variable has a somewhat raised VIF statistic for the SA4 level inputs analysis. Collinearity with SA4 level inputs is potentially a function of the variable construction (see Appendix A). Dropping market potential for the SA4 level input estimations, as reported earlier, does have a small effect, without materially affecting interpretation. (Results are reported in Appendix B.)

\section{Economic diversity (urbanisation economies)}

Economic diversity - also known as urbanisation economies-measures the extent to which the economic structure for each postcode based on SA2/SA4 level inputs differs from that of the overall state or territory economy. Thus, it provides a measure of urbanisation economies-interaction between multiple sectors. A more diversified economic structure is often considered conducive to productivity, as it enables appropriate matching and resilience to industry-specific shocks, allowing reemployment opportunity, but is also conducive to business start-up and entrepreneurship (Duranton and Puga 2000; Fujita, Krugman and Venables 2001; Jacobs 1969; Rosenthal and Strange 2003).

The RE panel results in Table 2 show little productivity boost from economic diversity based on SA2 level inputs. However, the IV panel results are positive and significant. With SA4 level inputs, the aggregate effect (column 9) is positive, but only weakly significant ( $p<10$ per cent). Here too, the IV panel results become significant. Moreover, there is some evidence that economic diversity may benefit higher-skilled concentrations, rather than lowerskilled concentrations. Diversity is also significant for Skills level A in the RE panel results (column 10). Overall, the results suggest that urbanisation economies are relevant to productivity in Australia's cities. However, further research is required to identify and quantify urbanisation effects more precisely.

\section{Economic specialisation (localisation economies)}

Economic specialisation-also known as localisation economies-measures the degree of within-industry specialisation -in other words, the degree to which particular industries are concentrated in particular localities. This means that labour markets may be both industrially diversified, but also contain within them sectors that are spatially concentrated. Industrial specialisation is significant with both SA2 and SA4 level inputs. The RE panel results with SA4 level inputs are somewhat higher than with SA2 level inputs. In both cases, the results imply that there are agglomeration benefits from firms in the same industry to locate together spatially. Broadly a doubling of relative specialisation is associated with a 4-5 per cent increase in wages. The IV panel results suggest that RE panel results may biased downwards (by approximately 6 percentage points) for SA2 level inputs, but largely unchanged with SA4 level inputs. ${ }^{2}$

The results in Table 2 show that in addition to density of employment, there are productivity benefits from more diversified urban economies and concentration of particular industrial sectors. For instance, diversified urban economies enable economies of scale in the production of a range of specialised services (intermediate inputs). In turn, these intermediate service inputs enable economies of scale to sectoral concentration.

2 The estimations were also conducted by successively dropping the different agglomeration measures. Apart from the effect noted in bullet point 2 and 3 on p. 28, the outcome of dropping the different measures did not affect the employment density measure. The low VIF statistics again underline the absence of any significant colinearity concerns. Neither diversity (urbanisation) nor specialisation (localisation) are instrumented in these specifications. Differences between the SA2 level input RE and IV results therefore require further research. 
Table 3 ranks industries by their specialisation and diversification, and reveals two trends based on SA4 level inputs:

1. Primary industries are spatially specialised. The positive specialisation effect potentially reflects wages that also are determined by international terms of trade (such as 'Mining'), rather than agglomeration-related productivity effects.

2. 'Information Media and Telecommunication (IMT)' and 'Financial and Insurance Services' are also spatially concentrated. These are sectors where knowledge diffusion, face-to-face interactions and proximity may be particularly relevant in interaction with other industries and headquarter functions in both primary and secondary industries.

In terms of considering options for urban development and strategies for the location of population growth and economic activity, the results in Table 2 (with respect to specialisation) and the variation in industry spatial specialisation in Table 3 suggest that productivity inducing agglomeration effects may be more significant for some industries such as IMT and financial services, than others such as 'Public administration' and 'Health care and social assistance'. Notably, further research is thus required to test for sectoral variations more specifically.

Table 3: Industry specialisation and diversity based on SA4 level inputs

\begin{tabular}{|c|c|c|}
\hline Industrial sector & $\begin{array}{r}\text { Average relative } \\
\text { specialisation }\end{array}$ & $\begin{array}{r}\text { Average relative } \\
\text { diversity }\end{array}$ \\
\hline Mining & 4.978 & 3.933 \\
\hline Agriculture, Forestry and Fishing & 4.611 & 4.213 \\
\hline Information Media and Telecommunications & 3.192 & 2.658 \\
\hline Transport, Postal and Warehousing & 2.518 & 5.641 \\
\hline Financial and Insurance Services & 2.464 & 3.530 \\
\hline Arts and Recreation Services & 2.229 & 3.673 \\
\hline Electricity, Gas, Water and Waste Services & 2.006 & 3.109 \\
\hline Education and Training & 1.860 & 3.827 \\
\hline Manufacturing & 1.794 & 3.823 \\
\hline Wholesale Trade & 1.639 & 7.871 \\
\hline Retail Trade & 1.548 & 4.937 \\
\hline Public Administration and Safety & 1.462 & 14.770 \\
\hline Accommodation and Food Services & 1.431 & 4.283 \\
\hline Health Care and Social Assistance & 1.375 & 6.978 \\
\hline Rental, Hiring and Real Estate Services & 1.345 & 6.002 \\
\hline
\end{tabular}

Note: While there is some inverse association between specialisation and diversity, the correlation is weak: $(r=-0.36)$. Source: Authors' estimations, HILDA Survey Waves 17 and 18; ABS Census TableBuilder, 2016.

Finally, Table 2 shows that, consistently across the specifications, there is a trade-off between the length of commuting and higher wages. In other words, a 10 per cent increase in commuting time requires an hourly wage compensation of approximately $0.17-0.19$ per cent.

A key question is whether agglomeration effects are non-linear. A non-linear effect would potentially imply increasing returns to agglomeration. One way of testing this is to include employment density as a squared term. These results are reported in Table 4. 
Table 4: Non-linear agglomeration effects and hourly wages

\begin{tabular}{lrr}
\hline & $\begin{array}{c}\text { All employment, } \\
\text { SA2 level inputs }\end{array}$ & $\begin{array}{r}\text { All employment, } \\
\text { SA4 level inputs }\end{array}$ \\
\hline Density & -0.0005 & -0.002 \\
\hline$p$-value & $(0.915)$ & $(0.706)$ \\
\hline Density squared & 0.001 & $\mathbf{0 . 0 0 2}$ \\
\hline$p$-value & $(0.006)$ & $(0.000)$ \\
\hline Market potential & 0.009 & -0.019 \\
\hline$p$-value & $(0.191)$ & $(0.200)$ \\
\hline Full variable specification & Yes & Yes \\
\hline Number & 14,814 & 14,817 \\
\hline Overall R & 0.434 & 0.434 \\
\hline
\end{tabular}

Note: Figures in brackets are p-values, robust standard errors. Minor variations in sample size are due to confidentiality censoring (null cells) when disaggregating by skills level. All effects are elasticities. Estimates obtained using Stata's xtreg command. Full list of estimation variables are enclosed in Appendix A, Table A4. Bold type indicates significant at the conventional 5 per cent level. Italics indicate significant at 10 per cent level. See Note to Table 1 for additional specification details.

Source: Authors' estimations, HILDA Survey Waves 17 and 18; ABS Census TableBuilder, 2016.

The results in Table 4 show little evidence of a non-linear effect with either SA2 or SA4 level inputs. The results remain largely unchanged when reducing the sample to major cities and inner regional cities, or to major cities only. Thus, while there is evidence in Table 2 of agglomeration benefits, there is little evidence to suggest that agglomeration benefits enjoy non-linear returns to scale. This is a crucial result in terms of regional development policy. The results in Table 2 imply that a doubling of the employment density in a regional (low-density) and capital city (high-density) setting would have similar wage-productivity effects. If positive, a non-linear relationship would imply that a doubling of employment in a high-density area would have a greater productivity impact than a doubling of employment density in a low-density area. However, for individual businesses and employees-where the decision is not one of doubling employment density, but potentially benefiting from marginal differences-the results in Table 2 provide an incentive to seek out denser employment locations.

To test for variation in agglomeration effects across the wage distribution, the wage model was estimated using quantile regression. Table 5 summarises key results and provides insight into whether all workers benefit similarly from agglomeration effects. In Table 5, we focus on all employment density and market potential-which is employment in nearest or proximate locations - and also provide insight on commuting costs.

Table 5 provides a number of insights:

- With SA2 level inputs, the agglomeration effect remains positive and significant across the income distribution, but there is little structure to the coefficients across the wage distribution. In other words, lower-wage earners (10\% and $20 \%$ quantiles) benefit approximately as much as higher-wage earners (70\% and $80 \%$ quantiles).

- This differs when considering benefits from proximate employment (market potential). Lower-wage earners appear to gain little from concentration of employment nearby, as the point estimate is low and not significant, whereas higher-wage earners benefit from positive and significant spillover effects. A doubling of nearby employment would, for higher-wage earners, increase productivity by some 1.9-3.0 per cent. Therefore, with SA2 level inputs, the agglomeration and distributional effect cannot be assessed purely on the basis of local employment density.

- This is reflected in the SA4 level input estimates. Table 2 suggests that agglomeration spillover effects are contained within the SA4 level input measures. The results in Table 5 further highlight this. None of the market potential (proximate employment) coefficients are significant. Comparing SA2 and SA4 level input results may suggest a degree of agglomeration attenuation. Therefore, the estimates based on SA4 level inputs, to some extent, also combine (or nest) these effects. 
- The 'combined' estimation results with SA4 level inputs suggest that higher-wage earners benefit approximately 50 per cent more than lower-wage earners from density of employment. However, within this there will be variations in the effect of employment concentration at finer scales (SA2 level inputs). Dropping the market potential variable from the SA4 level input estimations has no impact on the results. (Results reported in Appendix B, Table A6.)

Unlike the density measure itself, the relative specialisation (localisation) and relative diversity (urbanisation) variables show no substantial variation across the wage distribution. (These results are not included in Table 5.)

Agglomeration effects arise for a number of reasons but are expected to remain spatially contained (Rosenthal and Strange 2008). If proximity reduces distance (transport costs), then beyond some point transportation costs again outweigh agglomeration benefits. Thus, for planning and functional housing market analysis, the spatial reach of agglomeration effects appears contained within SA4s (although further research is desirable to understand spatial attenuation more robustly).

- Table 5 provides some insight on differences in commuting costs across the wage distribution. With both SA2 and SA4 level inputs, the commuting coefficients decline along the wage distribution. In other words, the compensation (in percentage) required for lower-wage earners for a longer commute exceeds that of higherwage earners, and is nearly twice as large when comparing the $10 \%$ quantile and $80 \%$ quantile. The commuting coefficient is not significant for the very highest income quantile. In practice, this suggest that lower-wage earners are more likely to locate closer to employment than higher-wage earners.

Table 5: Quantile regression, agglomeration effects and hourly wages

\begin{tabular}{|c|c|c|c|c|c|c|c|c|c|c|c|c|}
\hline & \multicolumn{6}{|c|}{ SA2 level inputs } & \multicolumn{6}{|c|}{ SA4 level inputs } \\
\hline & Density & $p$-value & Potential & $p$-value & Commute & $p$-value & Density & $p$-value & Potential & $p$-value & Commute & $p$-value \\
\hline q10\% & 0.010 & $(0.010)$ & 0.012 & $(0.230)$ & 0.033 & $(0.000)$ & 0.011 & $(0.050)$ & -0.003 & $(0.907)$ & 0.034 & $(0.000)$ \\
\hline$q 20 \%$ & 0.010 & $(0.002)$ & 0.006 & $(0.471)$ & 0.022 & $(0.000)$ & 0.010 & (0.009) & -0.001 & $(0.974)$ & 0.024 & $(0.000)$ \\
\hline q30\% & 0.006 & $(0.014)$ & 0.011 & $(0.138)$ & 0.023 & $(0.000)$ & 0.010 & (0.003) & -0.001 & $(0.953)$ & 0.024 & $(0.000)$ \\
\hline$q 40 \%$ & 0.006 & $(0.007)$ & 0.013 & $(0.035)$ & 0.017 & $(0.000)$ & 0.012 & $(0.000)$ & -0.014 & $(0.353)$ & 0.019 & $(0.000)$ \\
\hline$q 50 \%$ & 0.008 & $(0.001)$ & 0.011 & $(0.062)$ & 0.019 & $(0.000)$ & 0.017 & $(0.000)$ & -0.026 & (0.055) & 0.020 & $(0.000)$ \\
\hline$q 60 \%$ & 0.009 & $(0.000)$ & 0.013 & $(0.041)$ & 0.021 & $(0.000)$ & 0.016 & $(0.000)$ & -0.014 & $(0.261)$ & 0.026 & $(0.000)$ \\
\hline$q 70 \%$ & 0.009 & $(0.001)$ & 0.019 & $(0.010)$ & 0.016 & $(0.006)$ & 0.015 & $(0.000)$ & -0.008 & $(0.640)$ & 0.022 & $(0.000)$ \\
\hline q80\% & 0.008 & $(0.008)$ & 0.018 & $(0.028)$ & 0.014 & $(0.010)$ & 0.013 & $(0.000)$ & 0.004 & $(0.803)$ & 0.016 & $(0.006)$ \\
\hline q90\% & 0.005 & $(0.177)$ & 0.030 & $(0.004)$ & 0.007 & $(0.360)$ & 0.017 & $(0.000)$ & -0.008 & $(0.687)$ & 0.011 & $(0.213)$ \\
\hline $\begin{array}{l}\text { Full variable } \\
\text { specification }\end{array}$ & Yes & & & & & & Yes & & & & & \\
\hline
\end{tabular}

Note: Figures in brackets are p-values, robust standard errors. All effects are elasticities. Estimates obtained using Stata's qreg command. Full list of estimation variables are enclosed in Appendix A, Table A4. Bold type indicates significant at the conventional 5 per cent level. Italics indicate significant at 10 per cent revel. See Note to Table 1 for additional specification details.

Source: Authors' estimations, HILDA Survey Waves 17 and 18; ABS Census TableBuilder, 2016. 


\subsubsection{Agglomeration and labour productivity, by industry and occupation}

Agglomeration effects are typically associated with economic activity where proximity may confer some external benefit - for example, in the diffusion of knowledge or matching of skills to tasks. Tables 6 and 7 examine the impact of employment density across industrial sectors and occupational groups.

Since location of workplace is only available in Waves 17 and 18 of HILDA, the disaggregation by industry comes at a cost. Sample sizes are quite small for a number of cases, making it difficult to assess the statistical relevance of associations. Notably, the density measures are based on total employment, rather than industry-specific employment. Overall, the impact of the lower sample sizes is quite significant. While several sectors have positive signs, only a small handful of these are significant.

- With SA2 level inputs, 'Manufacturing' has a statistically weakly significant positive effect ( $p=0.086)$. The effect remains weakly significant with SA4 level inputs $(p=0.055)$. Manufacturing is an industry typically associated with benefits from skills matching and knowledge transfers. 'Education', 'Wholesale trade', and 'Other community services' also exhibit weakly significant positive wage effects from employment density and benefit from agglomeration effects with SA2 level inputs. Only 'Health and social service' have a statistically significant effect below the conventional 5 per cent level. However, neither of these sectors show significant evidence of additional benefits from proximate employment (market potential), urbanisation or localisation economies. The effects are similar with SA4 level inputs, with the exemption of 'Construction' and 'Real estate services' also showing positive agglomeration effects, and 'Education' no longer significant.

The disaggregation of estimation by occupational group broadly conform to expectations.

- There is a positive and significant agglomeration effect-approximately 1.5 per cent-for managerial and professional occupations across both SA2 and SA4 level input estimations. For other occupations, the results are more variable across spatial scales. Clerical/administrative occupations and sales earners appear to benefit from employment concentration with SA2 level inputs. Machine operators appear to benefit with SA4 level inputs.

Tentatively, the variation in point estimates in Table 6 and Table 7 may give some indications about variations in employment density effects, but additional research is required to more accurately (and robustly) conclude whether employment density effects are more (or less) pronounced in some sectors than others, also when using individual worker wage data. ${ }^{3}$ Moreover, differences compared to more aggregate measures, such as presented in Table 3, suggest need for further research. 
Table 6: Agglomeration effects by industrial sectors, SA2 and SA4 level inputs

\begin{tabular}{|c|c|c|c|c|c|c|c|c|c|c|c|c|c|c|}
\hline & $\begin{array}{r}\text { Agriculture, } \\
\text { forestry \& } \\
\text { fishing }\end{array}$ & $\begin{array}{r}\text { Mining \& } \\
\text { quarrying }\end{array}$ & Manufacturing & Utilities & Construction & $\begin{array}{r}\text { Wholesale } \\
\text { trade }\end{array}$ & $\begin{array}{r}\text { Hotels, } \\
\text { restaurants }\end{array}$ & $\begin{array}{r}\text { Transport, } \\
\text { storage }\end{array}$ & $\begin{array}{r}\text { Financial } \\
\text { intermediary }\end{array}$ & $\begin{array}{r}\text { Real } \\
\text { estate, } \\
\text { renting }\end{array}$ & $\begin{array}{r}\text { Public } \\
\text { administration }\end{array}$ & Education & $\begin{array}{r}\text { Health, } \\
\text { social } \\
\text { services }\end{array}$ & $\begin{array}{r}\text { Other } \\
\text { community } \\
\text { services }\end{array}$ \\
\hline \multicolumn{15}{|l|}{ SA2 } \\
\hline Density & 0.008 & 0.007 & 0.015 & 0.011 & -0.004 & 0.011 & 0.001 & 0.015 & 0.018 & 0.007 & 0.001 & 0.015 & 0.013 & 0.023 \\
\hline$p$-value & $(0.608)$ & $(0.576)$ & $(0.086)$ & $(0.630)$ & $(0.712)$ & $(0.063)$ & $(0.854)$ & $(0.207)$ & $(0.152)$ & $(0.377)$ & (0.934) & (0.069) & $(0.031)$ & $(0.056)$ \\
\hline \multicolumn{15}{|l|}{ SA4 } \\
\hline Density & 0.030 & 0.017 & 0.019 & 0.044 & 0.026 & 0.002 & -0.001 & 0.026 & 0.005 & 0.030 & 0.012 & -0.005 & 0.018 & 0.036 \\
\hline$p$-value & $(0.488)$ & $(0.420)$ & $(0.055)$ & $(0.270)$ & $(0.056)$ & $(0.807)$ & $(0.933)$ & $(0.057)$ & $(0.766)$ & $(0.009)$ & $(0.205)$ & $(0.651)$ & $(0.010)$ & $(0.011)$ \\
\hline Full variable specification & Yes & Yes & Yes & Yes & Yes & Yes & Yes & Yes & Yes & Yes & Yes & Yes & Yes & Yes \\
\hline Number & 216 & 240 & 1,232 & 114 & 701 & 2,112 & 1000 & $828(9)$ & 529 & 1,524 & $1,178(9)$ & $1,762(3)$ & 2,659 & 707 \\
\hline
\end{tabular}

Table 7: Agglomeration effects by occupations, SA2 and SA4 level inputs

Managers Professionals Technicians Health/welfare Clerical/admin Salesworkers Machine operators Labourers

\begin{tabular}{|c|c|c|c|c|c|c|c|c|}
\hline \multicolumn{9}{|l|}{$\mathrm{SA} 2$} \\
\hline Density & 0.016 & 0.016 & -0.005 & 0.009 & 0.015 & 0.017 & 0.012 & -0.007 \\
\hline$p$-value & $(0.019)$ & $(0.001)$ & $(0.411)$ & $(0.130)$ & $(0.007)$ & $(0.017)$ & $(0.122)$ & $(0.423)$ \\
\hline \multicolumn{9}{|l|}{ SA4 } \\
\hline Density & 0.016 & 0.017 & 0.023 & 0.011 & -0.002 & 0.002 & 0.036 & -0.003 \\
\hline$p$-value & $(0.060)$ & $(0.009)$ & $(0.005)$ & $(0.173)$ & $(0.782)$ & $(0.822)$ & $(0.006)$ & $(0.802)$ \\
\hline Full variable specification & Yes & Yes & Yes & Yes & Yes & Yes & Yes & Yes \\
\hline Number & 1,831 & 3,884 (5) & 1,610 (11) & 1,994 & 2,144 & 1,341 & 866 & 1,145 \\
\hline
\end{tabular}

Note to Tables 6 and 7: figures in brackets are p-values, robust standard errors. All effects are elasticities. Estimates obtained using Stata's xtreg command. Full list of estimation variables are enclosed in Appendix A, Table A4. Figures in brackets in row 6 of Table 4 and 5 refers to the sample size with SA4 level inputs. Bold type indicates significant at the conventional 5 per cent level.

Note 2: See Note to Table 1 for additional specification details.

Source: Authors' estimations, HILDA Survey Waves 17 and 18; ABS Census TableBuilder, 2016. 


\subsubsection{Alternative estimation strategies}

The estimates in tables 2, 6 and 7 are based on RE and IV panel estimations. The international literature (Melo and Graham 2009) suggests that agglomeration estimates may be biased upwards because of inadequately controlling for individual-level unobserved heterogeneity. Similarly, concentration of employment may be endogenously determined by wage levels - although the impact of this endogeneity in the international literature is not always clear. Controlling for endogeneity has resulted in both higher and lower point estimates (Ahlfeldt and Pietrostefani 2019).

Table 8 presents density and market-potential estimates from our wage model based on a range of alternative estimation approaches. This includes tighter winsorisation (wages are winsorised at 1 per cent and 99 per cent in Table 2), pooled and sample-probability weighted OLS results and multi-level estimations with random postcode and individual ID intercept effects, multi-level estimation with random intercept effect for postcodes and random slope effects for individuals (employment density). For completeness, we also provide fixed effect (FE) panel results and IV FE panel results. However, due to only two years of observations, unfortunately these estimates are unreliable.

- Across the different estimation methods, SA2 level input results are largely consistent and in line with the results from Table 2 . The only substantial variation is the FE panel results, where the agglomeration benefit is halved relative to the point estimates in Table 2. The FE-IV results are similar to the results in Table 2. Neither FE set of estimations is statistically significant, which, potentially, is a function of the limited number of panel time periods $(\mathrm{T}=2)$.

- With SA4 level inputs, estimates are also in line with estimates in Table 2. Here the FE point estimates are similar to the results in Table 2 but, as mentioned above, not statistically significant.

- Multi-level estimations suggest that there is significant FE variability across locations and individuals, as well as slope effects (employment density) across individuals. However, controlling for these additional sources of variability does not substantively alter the average relationship between employment density and wages. However, multi-level fixed effects do suggest that further research around firm and industry sorting and location may be relevant for unpacking agglomeration effects more fully.

- A note of caution is necessary in interpreting the results in Table 8 (as well as Table 2). IV regressions are sensitive to the instrument specification. Diagnostic tests were run in Stata's ivreg2, but these are not directly transferrable. The fixed-effect panel point estimates are largely in line with earlier results but are not significant. However, fixed-effect results are unreliable due to the very small (2) time dimension in Tables 2 and 8. Melo and Graham (2009) find that fixed-effect estimates in the UK approximately halve the agglomeration estimate.

The estimates in Table 2 and Table 8 show that there is a statistically significant wage benefit from employment concentration. In these individual-level wage regressions, the identified agglomeration benefit remains substantially below previous area-level-based Australian estimates, but is in line with the international evidence. The results also suggest that, at local levels (with SA2 level inputs), there may be significant productivity effects arising from proximity to surrounding employment centres (market potential), but that any spillovers are largely contained within the SA4 level input labour market approximations.

Finally, we test for non-linearity in the agglomeration elasticity. However, as before, the results are not sufficiently statistically robust to allow us to conclude that agglomeration effects appear to be non-linear. 
3. Labour (wage) productivity

and agglomeration in Australia

Table 8: Alternative estimation strategies

\begin{tabular}{|c|c|c|c|c|c|c|c|c|c|c|}
\hline & \multicolumn{5}{|c|}{ SA2 level inputs } & \multicolumn{5}{|c|}{ SA4 level inputs } \\
\hline & Density & $p$-value & Potential & $p$-value & $\begin{array}{l}\text { Full variable } \\
\text { specification }\end{array}$ & Density & $p$-value & Potential & $p$-value & $\begin{array}{l}\text { Full variable } \\
\text { specification }\end{array}$ \\
\hline Winsorised (2,98 percentiles) & 0.008 & $(0.000)$ & 0.014 & $(0.020)$ & Yes & 0.015 & $(0.000)$ & -0.014 & $(0.284)$ & Yes \\
\hline Pooled OLS, probability weighted & 0.009 & $(0.001)$ & 0.012 & $(0.073)$ & Yes & 0.018 & $(0.000)$ & -0.032 & $(0.025)$ & Yes \\
\hline Multi-level, intercept random effects POA and ID & 0.012 & $(0.000)$ & 0.006 & $(0.421)$ & Yes & 0.016 & $(0.000)$ & -0.017 & $(0.291)$ & Yes \\
\hline Multi-level, intercept random effects POA and ID; random slope effect ID & 0.011 & $(0.000)$ & 0.006 & $(0.438)$ & Yes & 0.016 & $(0.000)$ & -0.018 & $(0.279)$ & Yes \\
\hline Panel fixed effects ${ }^{\dagger}$ & 0.004 & $(0.442)$ & -0.011 & (0.598) & Yes & 0.015 & $(0.126)$ & -0.067 & $(0.134)$ & Yes \\
\hline IV regression (Density=geology), fixedt & 0.042 & $(0.167)$ & -0.096 & $(0.172)$ & Yes & 0.051 & $(0.264)$ & -0.110 & $(0.326)$ & Yes \\
\hline
\end{tabular}

Note: Figures in brackets are p-values, robust standard errors. All effects are elasticities. Estimates obtained using Stata's xtreg (winsorised 2,98), reg (Pooled OLS), xtmixed (multi-level), xtivreg (ec2s/s) (panel), and ivreg2 (IV regression). Diagnostics for instrumental variable regressions also tested in ivreg2. All instruments are significantly correlated with the endogenous variable (employment density). Instruments meet under and weak identification tests/exclusion restriction diagnostics when run in Stata's ivreg2. Some evidence of over-identification, particularly with SA2 level input estimates. Exclusion restriction test are not available for xtivreg. Full list of estimation variables are enclosed in Appendix A, Table A4. Bold text cells indicate significant at the conventional 5 per cent level. 'Panel fixed effects estimates suffer from small number of repeat observations $(T=2)$ and are included for completeness only.

Source: Authors' estimations, HILDA Survey Waves 17 and 18; ABS Census TableBuilder, 2016. 


\subsection{Policy implications}

The results in Section 3 show that there is evidence in Australia of agglomeration economies. This means that there are productivity gains from employment concentration in particular locations that are not captured in other locations. However, individual, firm and institutional characteristics are the main determinants of wages.

Our estimates suggest that a doubling of employment concentration would generate an approximate 1-4 per cent increase in wages. If the increase in GDP is considered proportional to the increase in wages, then a 1 per cent increase in productivity would raise GDP by $\$ 19.9$ billion per annum. ${ }^{4}$ In comparison, May 2020 Treasury estimates of COVID-19-related direct fiscal measures to support the economy and households amount to some \$134 billion (Treasury 2020). There is also some indication that agglomeration spillover effects are largely contained within SA4s level input estimates. That is, the potential interdependency for higher-wage earners found with SA2 level inputs (positive relationship between employment in neighbouring SA2s), appears to disappear when using SA4 level inputs. For urban development and national economic policy this has a number of implications:

- In terms of urban development strategies, there is an economic rationale for continued concentration of employment and population growth, all other things being equal-transport infrastructure, urban morphology, congestion costs, etc.

- However, this economic rationale does not address the uneven distribution of agglomeration benefits and costs. The results in Table 5 suggest that wage benefits and commuting costs are not equal across the wage distribution, with potential impacts on wellbeing, inequality and urban social justice. Housing costs are considered separately in Section 4. Continued concentration of employment and population in the largest cities will therefore carefully need to consider trade-offs between productivity gains and the distribution of gains. Moreover, distributional consequences can be particularly difficult to quantify.

- Similarly, strategies to disperse population growth - for instance, by incentivising expansion and urban growth in regional urban centres - will need to carefully consider the trade-offs between positive (productivity) and negative (congestion) agglomeration effects.

- In other words, if the aim is to replicate positive agglomeration effects in non-capital cities, then a selective strategy (choosing one, maybe two) growth nodes might be more efficient than more general dispersion (multiple regional nodes). If pursuing such a strategy, our results also suggest that replication requires economic diversification (urbanisation economies) and specialisation (localisation economies) to yield the highest productivity dividend.

- From a practical perspective, in the absence of concerted regional agglomeration development, individual firms and start-ups retain an incentive to locate in existing concentrations of economic activity.

4 Assumes that participation rates are unchanged, and unchanged capital/multifactor productivity. GDP growth is determined by changes in population, participation and productivity. An increase in productivity can therefore be offset by population and participation changes. 


\section{Agglomeration and housing costs}

- In this section, wages are adjusted for basic housing costs. Basic housing costs include mortgage and rent payment, but exclude transfer payments (benefits) or income support payments (such as CRA).

- There remains a positive agglomeration effect after adjusting for basic housing costs. This is the case when considering agglomerations at place of work and at place of residence. Residence-based results are marginally lower than place-of-work estimates, indicating agglomeration-housing market interactions.

- Quantile regressions reveal that higher-wage earners benefit more from employment agglomeration than lower-wage earners do, also after adjusting for basic housing costs. The lowest $20 \%$ of the wage distribution appears to gain little from the agglomeration effect on wages once housing costs are taken into consideration.

- This effect becomes more pronounced when analysing agglomeration effects at the place of residence. In this case, the lower half of the wage distribution retains little of the agglomeration wage benefit, after controlling for housing cost. Notably, agglomerations may also generate non-wage benefits that are not captured in this analysis.

- Overall, the results in this section highlight the role that housing markets and affordability plays in distributing gains from agglomeration. For environmentally and socially sustainable urban transitions, the implication is that housing policy and affordability are key to harnessing agglomeration benefits at the societal level. 


\subsection{Introduction}

In this section, we turn to the relationship between agglomeration effects and housing markets. The basic spatial equilibrium principle would suggest that higher wages are offset by higher housing costs or less attractive environments. However, the world is more complicated than this, as households also derive wellbeing from lots of non-employment-related elements of their lives and these too are spatially contingent. However, adjusting wages for housing costs and then re-testing for the presence of agglomeration effects provides a means of testing whether agglomeration effects also generate net wellbeing effects (higher wages). RQ 3 asks:

- To what extent do spatial wage differences reflect spatial variation in housing costs?

- And, do housing market effects vary between high- and low-wage workers?

From the discussion in Section 2, it follows that spatial sorting resulting from wage differentials is also reflected in higher living costs, including housing costs. In practice, both wages and house prices are therefore measures of potential agglomeration effects. According to the spatial equilibrium principle, once differences in housing costs and congestion costs are accounted for, there may be no additional spatial wage differential. Throughout this section, our variable of interest is hourly earnings after adjusting for basic housing costs.

Basic housing costs only include mortgage and rental payments. In practice, many households receive additional housing related 'income' support, such as CRA, or other social benefits or pensions that may adjust waged income. In many cases, CRA and other social benefits will improve the affordability of housing and result in individuals (households) spending a lesser proportion of their total income on housing. However, these are transfer payments. As such, their income-adjusting effect is unrelated to productivity or agglomeration effects. Similarly, these are important public policies in addressing inequalities that arise from market processes, but their inclusion as part of a productivity measure (wages) would potentially obscure the relationship between agglomeration and housing market effects.

\subsubsection{Employment density and basic housing cost-adjusted wages}

In this section, we summarise the result from estimating our wage model with basic housing cost-adjusted wages as the dependent variable. Section 3 established that there appears to be a wage benefit from agglomeration across the wage distribution (even though it is uneven). In this section, a key issue is whether this wage benefit is retained by the individual, or spent on additional housing costs. Note: commuting costs are dealt with separately.

Under the spatial equilibrium assumption, higher wages compensate for greater congestion costs near centres of employment. In this perspective, the individual's wellbeing should begin to equalise across space when focussing on net wages. In practice, variations in outcomes then reflect other determinants of wellbeing or location-such as urban amenities, lack of appropriate housing and, potentially, lack of employment opportunity. In line with the objective of this research, the focus is on wages and housing costs.

However, housing costs are not the only congestion costs that workers experience. Commuting costs and other costs of living may also play a role in household location. As in Section 3, we control for commuting costs separately, rather than attempting to adjust wages for commuting costs as well. In practice, commuting and housing costs are likely to be jointly determined. In other words, households consider both housing costs and commuting costs when making location decisions. However, combining the two measures would reduce the direct connection with the objective of the research: agglomeration and variation in housing costs. The results in Section 3 suggest that the locational decisions of lower-income individuals are more responsive to variations in commuting costs than higher-income households.

The construction of hourly wages net of housing costs is discussed in Appendix A, Section 7.2. As in Section 3, the housing cost-adjusted wage model is estimated using a range of estimation methods. The results in Table 9 summarise the RE and IV panel estimates. 
Table 9: Agglomeration effects and hourly wages net of basic housing costs

\begin{tabular}{|c|c|c|c|c|c|c|c|c|c|c|}
\hline & \multicolumn{5}{|c|}{ SA2 inputs } & \multicolumn{5}{|c|}{ SA4 inputs } \\
\hline & \multicolumn{2}{|c|}{ All employment } & \multirow{2}{*}{$\begin{array}{r}\text { Skills level A } \\
\text { RE panel }\end{array}$} & \multirow{2}{*}{$\begin{array}{r}\text { Skills level B } \\
\text { RE panel }\end{array}$} & \multirow{2}{*}{$\frac{\text { Skills level C }}{\text { RE panel }}$} & \multicolumn{2}{|c|}{ All employment } & \multirow{2}{*}{$\begin{array}{r}\text { Skills level A } \\
\text { RE panel }\end{array}$} & \multirow{2}{*}{$\begin{array}{r}\text { Skills level B } \\
\text { RE panel }\end{array}$} & \multirow{2}{*}{$\begin{array}{r}\text { Skills level C } \\
\text { RE panel }\end{array}$} \\
\hline & RE panel & IV panel & & & & RE panel & IV panel & & & \\
\hline Density & 0.009 & 0.079 & 0.010 & 0.008 & 0.007 & 0.016 & 0.025 & 0.016 & 0.015 & 0.015 \\
\hline$p$-value & $(0.002)$ & $(0.000)$ & $(0.001)$ & $(0.006)$ & (0.029) & $(0.000)$ & $(0.023)$ & $(0.000)$ & $(0.000)$ & $(0.002)$ \\
\hline Market potential & 0.003 & -0.123 & 0.001 & 0.005 & 0.009 & -0.028 & -0.064 & -0.032 & -0.025 & -0.018 \\
\hline$p$-value & $(0.697)$ & $(0.000)$ & $(0.941)$ & (0.519) & $(0.280)$ & $(0.113)$ & $(0.134)$ & (0.070) & $(0.167)$ & $(0.342)$ \\
\hline Relative div & -0.014 & 0.113 & -0.011 & -0.017 & -0.020 & 0.019 & 0.021 & 0.023 & 0.018 & 0.012 \\
\hline$p$-value & $(0.534)$ & $(0.001)$ & $(0.623)$ & (0.439) & $(0.375)$ & $(0.279)$ & $(0.256)$ & $(0.205)$ & (0.318) & (0.509) \\
\hline Relative spec & 0.050 & 0.137 & 0.051 & 0.050 & 0.047 & 0.062 & 0.066 & 0.062 & 0.063 & 0.059 \\
\hline$p$-value & $(0.000)$ & $(0.000)$ & $(0.000)$ & $(0.000)$ & $(0.000)$ & $(0.000)$ & $(0.000)$ & $(0.000)$ & $(0.000)$ & $(0.000)$ \\
\hline Commute & 0.016 & 0.011 & 0.016 & 0.016 & 0.016 & 0.018 & 0.017 & 0.018 & 0.018 & 0.018 \\
\hline$p$-value & (0.009) & $(0.074)$ & (0.009) & $(0.008)$ & $(0.008)$ & (0.004) & $(0.007)$ & $(0.004)$ & $(0.004)$ & $(0.003)$ \\
\hline \multicolumn{11}{|l|}{ Fixed effects for: } \\
\hline Demographics & Yes & Yes & Yes & Yes & Yes & Yes & Yes & Yes & Yes & Yes \\
\hline Skills/education & Yes & Yes & Yes & Yes & Yes & Yes & Yes & Yes & Yes & Yes \\
\hline COB/ethnicity & Yes & Yes & Yes & Yes & Yes & Yes & Yes & Yes & Yes & Yes \\
\hline Indu./occup. & Yes & Yes & Yes & Yes & Yes & Yes & Yes & Yes & Yes & Yes \\
\hline Union & Yes & Yes & Yes & Yes & Yes & Yes & Yes & Yes & Yes & Yes \\
\hline Employer chr. & Yes & Yes & Yes & Yes & Yes & Yes & Yes & Yes & Yes & Yes \\
\hline State or territory fixed effect & Yes & Yes & Yes & Yes & Yes & Yes & Yes & Yes & Yes & Yes \\
\hline Year dummy & Yes & Yes & Yes & Yes & Yes & Yes & Yes & Yes & Yes & Yes \\
\hline
\end{tabular}




\begin{tabular}{|c|c|c|c|c|c|c|c|c|c|c|}
\hline & \multicolumn{5}{|c|}{ SA2 inputs } & \multicolumn{5}{|c|}{ SA4 inputs } \\
\hline & \multicolumn{2}{|c|}{ All employment } & \multirow{2}{*}{$\frac{\text { Skills level A }}{\text { RE panel }}$} & \multirow{2}{*}{$\frac{\text { Skills level B }}{\text { RE panel }}$} & \multirow{2}{*}{$\frac{\text { Skills level C }}{\text { RE panel }}$} & \multicolumn{2}{|c|}{ All employment } & \multirow{2}{*}{$\frac{\text { Skills level A }}{\text { RE panel }}$} & \multirow{2}{*}{$\frac{\text { Skills level B }}{\text { RE panel }}$} & \multirow{2}{*}{$\frac{\text { Skills level C }}{\text { RE panel }}$} \\
\hline & RE panel & IV panel & & & & RE panel & IV panel & & & \\
\hline _cons & 1.728 & 2.558 & 1.760 & 1.719 & 1.700 & 2.071 & 2.468 & 2.127 & 2.041 & 1.985 \\
\hline$p$-value & $(0.000)$ & $(0.000)$ & $(0.000)$ & $(0.000)$ & $(0.000)$ & $(0.000)$ & $(0.000)$ & $(0.000)$ & $(0.000)$ & $(0.000)$ \\
\hline Number & 14,771 & 14,771 & 14,771 & 14,771 & 14,771 & 14,774 & 14,774 & 14,774 & 14,774 & 14,774 \\
\hline Overall $\mathrm{R}^{2}$ & 0.366 & 0.336 & 0.366 & 0.366 & 0.366 & 0.366 & 0.366 & 0.366 & 0.366 & 0.365 \\
\hline Number of groups & 8,974 & 8,974 & 8,974 & 8,974 & 8,974 & 8,975 & 8,975 & 8,975 & 8,975 & 8,975 \\
\hline
\end{tabular}

Note: figures in brackets are p-values, robust standard errors. Minor variation in sample size are due to confidentiality censoring (null cells) when disaggregating by skills level. All effects are elasticities. Estimates obtained using Stata's xtreg command. Full list of estimation variables are enclosed in Appendix A, Table 4. Bold type indicates significant at the conventional 5 per cent level.

Source: Authors' estimations, HILDA Survey Waves 17 and 18; ABS Census TableBuilder, 2016.

Overall, the results in Table 9 resonate broadly with the results in Section 3 (this is also the case when including a non-linear employment density term). In other words, after adjusting wages for housing costs, there is a significant wage benefit associated with greater concentration of employment.

- With SA2 level inputs, the point estimates (0.9 per cent, C195: 0.3-1.5 per cent) are some 20 per cent less than the point estimates in Table 2, but overall within the margin of error. The point estimates with SA4 level inputs are almost as before (1.6 per cent, C195: 0.8-2.4 per cent). Thus, based on these results there is little evidence that, on average, spatial differences in wages are fully equivalised by adjustments in housing costs. Notably, given that housing costs are not the only congestion cost, this is not expected either. As in Section 3, the IV panel results are somewhat higher than the RE panel results. This is particularly the case with SA2 level inputs but, as in Table 2, this higher effect is offset by a negative market potential effect, making the overall effect smaller than the point estimate. There is no equivalent negative market potential effect with SA4 level inputs.

- Specification diagnostic based on pooled OLS again show a marginally raised VIF statistic for market potential with SA4 level inputs. Dropping the market potential reduces the RE panel estimates to 1.1 per cent (CI95: 0.6-1.6 per cent) $(p<0.000)$ and increases the IV panel estimates to 4 per cent $(C / 95: 2.5-5.6$ per cent) $(p<0.000)$. (Results are reported in Appendix B, Table A5.). There are no inflated VIF statistics at SA2 level.

Overall, the results suggest that after adjusting for basic housing costs, there remains an overall benefit for individuals to earn their wages in employment clusters. The main difference between the results in Table 2 and Table 9, is the additional variability in the economic diversity (urbanisation economies) outcome. With SA2 level inputs, economic diversity is, as before, not statistically significant for the RE panel results, but is significant when adjusting for endogeneity in the IV panel estimates. With SA4 level inputs, diversity is not statistically significant until market potential is dropped, in which case it becomes positive and significant at conventional levels ( $p<0.05)$. Otherwise, the estimates for relative specialisation and commuting time are broadly as before. 
Since agglomeration effects are measured at the place of employment, rather than residence, an individual's preferences for urban living-or the constraints imposed by housing availability - are not fully taken into account. That is, individuals may live and work in different localities. The commuting variable, as before, shows that longer commutes typically have to be compensated by higher wages. However, many individuals may not be able to fully choose their locality due to lack of appropriate or affordable housing options. Instead of wages adjusting to variations in housing costs, some or all of the adjustment may take place in the form of individuals either:

- spending more of their income on housing costs

- living in poorer quality housing - thus extending the economic life of physically depreciated properties

- utilising dwellings more intensively-overcrowding or shared housing.

To test for variation in agglomeration effects across the wage distribution, the housing cost-adjusted wage model was estimated using quantile regression. Table 10 summarises key results and provides insight into whether all workers benefit similarly from agglomeration effects. In Table 10, we focus on all employment density and market potential (employment in proximate locations)

Table 10: Quantile regression, agglomeration effects and hourly wages net of basic housing cost

\begin{tabular}{|c|c|c|c|c|c|c|c|c|c|c|c|c|}
\hline & \multicolumn{6}{|c|}{ SA2 level inputs } & \multicolumn{6}{|c|}{ SA4 level inputs } \\
\hline & Density & $p$-value & Potential & $p$-value & Commute & $p$-value & Density & $p$-value & Potential & $p$-value & Commute & $p$-value \\
\hline q10 & 0.016 & $(0.011)$ & -0.022 & $(0.176)$ & 0.035 & $(0.002)$ & 0.007 & $(0.436)$ & -0.019 & $(0.624)$ & 0.033 & $(0.005)$ \\
\hline q20 & 0.009 & $(0.020)$ & -0.010 & $(0.362)$ & 0.024 & $(0.001)$ & 0.010 & $(0.056)$ & -0.016 & $(0.469)$ & 0.028 & $(0.000)$ \\
\hline q30 & 0.005 & $(0.094)$ & 0.003 & $(0.688)$ & 0.019 & $(0.004)$ & 0.012 & $(0.008)$ & -0.014 & $(0.494)$ & 0.020 & $(0.003)$ \\
\hline$q 40$ & 0.004 & $(0.166)$ & 0.008 & $(0.311)$ & 0.017 & $(0.006)$ & 0.012 & $(0.001)$ & -0.011 & $(0.463)$ & 0.022 & $(0.000)$ \\
\hline q50 & 0.003 & $(0.236)$ & 0.014 & (0.059) & 0.018 & $(0.002)$ & 0.013 & $(0.000)$ & -0.01 & $(0.518)$ & 0.020 & $(0.000)$ \\
\hline$q 60$ & 0.005 & $(0.059)$ & 0.010 & $(0.164)$ & 0.019 & $(0.001)$ & 0.013 & $(0.001)$ & -0.018 & $(0.297)$ & 0.021 & $(0.000)$ \\
\hline q70 & 0.007 & $(0.010)$ & 0.012 & $(0.138)$ & 0.014 & $(0.023)$ & 0.016 & $(0.000)$ & -0.025 & $(0.140)$ & 0.017 & $(0.007)$ \\
\hline q80 & 0.008 & $(0.004)$ & 0.012 & $(0.137)$ & 0.013 & $(0.073)$ & 0.016 & $(0.000)$ & -0.023 & $(0.188)$ & 0.015 & $(0.033)$ \\
\hline q90 & 0.005 & $(0.135)$ & 0.020 & $(0.058)$ & 0.008 & $(0.355)$ & 0.016 & $(0.003)$ & -0.013 & $(0.625)$ & 0.008 & $(0.378)$ \\
\hline
\end{tabular}

Note: Figures in brackets are p-values, robust standard errors. All effects are elasticities. Estimates obtained using Stata's qreg command. Full list of estimation variables are enclosed in Appendix A, Table A4. Bold type indicates significant at the conventional 5 per cent level. Italics indicate significant at 10 per cent level.

Source: Authors' estimations, HILDA Survey Waves 17 and 18; ABS Census TableBuilder, 2016. 
Again, the results in Table 10 are largely consistent with the results in Table 5. With SA2 level inputs, there is less structure to the employment-density coefficient. There is little evidence of significant productivity spillover effects from employment in proximate locations, with market potential only weakly significant at the $50 \%$ quantile and $90 \%$ quantile.

With SA4 level inputs, the magnitude of the agglomeration coefficients is increasing across the wage distribution. Notably, for the lowest income quintile (20 per cent) there is no longer a significant agglomeration effect. In the SA4 level input estimates, there is also, as per Table 5, no additional productivity benefit from employment in proximate locations. Dropping the market potential variable has little impact on the overall structure of the coefficients, but does affect the significance of the $20 \%$ quantile. (Results are reported in Appendix B, Table A7.)

Therefore, the results in Table 9 and Table 10 suggest that for higher-wage earners (and many lower-wage earners), the wage premium remains after adjusting for housing costs. In other words, while higher wages translate into higher housing costs in the Melbourne and Sydney CBDs, the benefit from earning wages in these areas compared to less dense areas-such as regional alternatives-does not, on average, disappear because of higher housing costs. In terms of population deconcentration, this suggests that, all things being equal-such as individual preference for large and small towns, commuting patterns and other housing adjustments-individuals are better off in terms of wages in more concentrated labour markets.

However, for the lowest income earners (10\% and $20 \%$ quantiles), the benefits from agglomeration in terms of higher wages appear to be largely consumed by higher housing costs. Moreover, the locations of lower-income earners are more responsive to changes in commuting costs, with the wage-commuting responsiveness of wage earners in the $10 \%$ and $20 \%$ quantiles nearly two twice that of the wage-commuting responsiveness of wage earners in $80 \%$ and $90 \%$ quantiles for longer commutes.

Of course, not all jobs are located in a central place. Hulse, Reynolds et al. (2019) show that different types of employment show considerable variation in the extent to which they are dispersed or concentrated across metropolitan regions. Similarly, working in a CBD does not necessitate living in a CBD. The results in Table 9, as in Table 2, suggest that longer commutes typically require compensation. Thus, a different way of looking at the impact of employment agglomeration and housing markets is to estimate the housing cost-adjusted wage model based on location of residence, as opposed to location of employment. This allows us to implicitly control for the locational preferences (or necessities) of individual earners.

One of the arguments in Section 2 is that preference for urban amenities may compel some workers to locate in areas of higher employment concentration without the additional wage compensation. In other words, they would be willing to spend a greater portion of their income on housing costs. Alternatively, lack of appropriate or affordable housing options may also necessitate locational decisions that result in additional housing costs or housing adjustments that are not captured by mortgage or rental costs alone. If this were the case, then we would expect wages adjusted for housing costs to no longer exhibit an agglomeration wage premium at the place of residence. This proposition is tested in Table 11 and Table 12. Note: the analysis in Table 11 no longer relates to productivity effects from employment agg/omeration, but to the extent to which the urban premium is absorbed by housing costs, at place of residence.

Table 11 turns to the average effect across all workers. 
Table 11: Agglomeration effects and wages net of basic housing costs, at place of residence

\begin{tabular}{|c|c|c|c|c|c|c|c|c|}
\hline & \multicolumn{4}{|c|}{ SA2 inputs } & \multicolumn{4}{|c|}{ SA4 inputs } \\
\hline & All employment & Skills level A & Skills level B & Skills level C & All employment & Skills level A & Skills level B & Skills level C \\
\hline & RE panel & RE panel & RE panel & RE panel & RE panel & RE panel & RE panel & RE panel \\
\hline Density & -0.012 & -0.010 & -0.012 & -0.015 & 0.008 & 0.009 & 0.007 & 0.006 \\
\hline$p$-value & $(0.005)$ & $(0.017)$ & $(0.003)$ & $(0.000)$ & $(0.075)$ & $(0.042)$ & (0.095) & (0.199) \\
\hline Market potential & 0.018 & 0.017 & 0.018 & 0.020 & -0.004 & -0.008 & -0.002 & 0.003 \\
\hline$p$-value & $(0.000)$ & $(0.001)$ & $(0.000)$ & $(0.000)$ & (0.819) & $(0.669)$ & $(0.907)$ & $(0.871)$ \\
\hline Relative diversity & 0.023 & 0.022 & 0.025 & 0.025 & 0.003 & 0.006 & 0.002 & -0.002 \\
\hline$p$-value & $(0.340)$ & $(0.370)$ & $(0.308)$ & $(0.301)$ & $(0.888)$ & $(0.784)$ & $(0.926)$ & $(0.927)$ \\
\hline Relative specialisation & 0.017 & 0.018 & 0.016 & 0.017 & 0.032 & 0.033 & 0.032 & 0.029 \\
\hline$p$-value & (0.133) & $(0.102)$ & $(0.168)$ & $(0.132)$ & $(0.012)$ & $(0.010)$ & $(0.012)$ & $(0.019)$ \\
\hline Commute & 0.020 & 0.020 & 0.020 & 0.020 & 0.022 & 0.022 & 0.022 & 0.022 \\
\hline$p$-value & $(0.001)$ & $(0.001)$ & $(0.001)$ & $(0.001)$ & $(0.000)$ & $(0.000)$ & $(0.000)$ & $(0.000)$ \\
\hline \multicolumn{9}{|c|}{ Fixed effects included as per Table 9} \\
\hline Constant & 1.769 & 1.755 & 1.762 & 1.747 & 1.848 & 1.878 & 1.841 & 1.820 \\
\hline$p$-value & $(0.000)$ & $(0.000)$ & $(0.000)$ & $(0.000)$ & $(0.000)$ & $(0.000)$ & $(0.000)$ & $(0.000)$ \\
\hline Number & 14,754 & 14,754 & 14,754 & 14,754 & 14,758 & 14,758 & 14,758 & 14,758 \\
\hline
\end{tabular}

Note: figures in brackets are p-values, robust standard errors. Minor variations in sample size are due to confidentiality censoring (null cells) when disaggregating by skills level. All effects are elasticities. Estimates obtained using Stata's xtreg command. Full list of estimation variables are enclosed in Appendix A, Table A4. Bold type indicates significant at the conventional 5 per cent level. Italics indicate significant at 10 per cent level. Source: Authors' estimations, HILDA Survey Waves 17 and 18; ABS Census TableBuilder, 2016. 
A high concentration of employment based on both SA2 or SA4 level inputs indicates that dwellings in these areas are closer to larger labour market opportunities, but also that there is increased competition between land use for residential purposes and land use for other forms of economic activity. There is no assumption in the estimates that individuals live and work in the same area, although this likelihood increases at larger spatial scales. A number of results stand out in Table 11:

- With SA2 level inputs, there is no longer a positive net wage effect. The overall net wage effect is negative and significant. This is the case also across skills levels. However, spillover effects from nearby employment concentration remain in place so that the combined effect is difficult to derive from the SA2 level input estimates.

- With SA4 level inputs, there remains an average positive effect that is weakly significant for all employment, but significant for Skills level A. However, when estimating net wages at the place of residence, the net agglomeration benefit declines by nearly 50 per cent relative to the estimates in Table 9.

The difference between the estimates in Table 2, Table 9 and Table 11 suggest that, for some workers, the productivity gains from agglomeration are substantively capitalised in housing costs. Differences in net wage effects also reflect individuals' preferences for commuting or the availability of housing options. In Australia, where the majority of residents live in a small number of capital cities, wage setting for cities as a whole is likely to vary less than variation in intra-urban housing costs. ${ }^{5}$ Thus while net wages based on place of employment suggest that an element of the urban wage premium is captured by higher housing costs or rents, the share of the urban wage premium captured by higher housing costs or rents increases closer to denser employment centres.

- Compared to the commuting compensation estimates in Table 9, the compensation required for longer commutes has now increased by just over nearly 20 per cent. Where before (as shown in Table 9) a 10 per cent increase in commuting time required an hourly wage compensation of approximately 0.16 per cent, once residential location is taken into consideration a 10 per cent increase in commuting time requires an hourly wage compensation of 0.20 per cent (SA2 level input estimates).

Other things being equal, workers' valuation of commuting time is greater when we control for employment density where individuals live than where they work. One interpretation of this is that areas with greater employment density also provide greater urban amenities. In this interpretation, the differential between the estimates in Table 9 and Table 11 implies a premium — or additional willingness to pay for housing service-for proximity to urban amenities. However, international evidence also suggests that higher construction costs associated with the more intensive patterns of land use - for example, multi-unit developments - that arise from competition for land for multiple uses (residential and economic) can be disproportionately reflected in rents rather than wages (Ahlfeldt and Pietrostefani 2019). Under conditions of inelastic supply, an agglomerationinduced wage-productivity effect would result in a disproportional increase in housing costs. This effect might be accentuated where households face a lack of spatial housing options across metropolitan areas.

Table 12 examines the housing-costs-adjusted wages across the wage distribution.

5 Ahlfeldt and Pietrostefani (2019) found in their meta-analysis of density effect that while wage agglomeration effects tend to be linear, housing cost effects are often non-linear. 
Table 12: Quantile regression, agglomeration effects and wages net of basic housing costs, at place of residence

\begin{tabular}{|c|c|c|c|c|c|c|c|c|c|c|c|c|}
\hline & \multicolumn{6}{|c|}{ SA2 level input } & \multicolumn{6}{|c|}{ SA4 level input } \\
\hline & Density & $p$-value & Potential & $p$-value & Commute & $p$-value & Density ${ }^{1}$ & $p$-value & Potential & $p$-value & Commute & $p$-value \\
\hline$q 10 \%$ & -0.006 & $(0.462)$ & 0.011 & $(0.177)$ & 0.036 & $(0.001)$ & 0.004 & $(0.663)$ & -0.016 & $(0.702)$ & 0.036 & $(0.004)$ \\
\hline q20\% & -0.006 & $(0.234)$ & 0.012 & $(0.056)$ & 0.029 & $(0.000)$ & 0.003 & $(0.588)$ & 0.003 & $(0.909)$ & 0.031 & $(0.000)$ \\
\hline q30\% & -0.009 & $(0.039)$ & 0.014 & $(0.006)$ & 0.023 & $(0.000)$ & 0.002 & $(0.693)$ & 0.009 & $(0.657)$ & 0.023 & $(0.001)$ \\
\hline$q 40 \%$ & -0.006 & $(0.092)$ & 0.012 & $(0.004)$ & 0.021 & $(0.000)$ & 0.005 & $(0.193)$ & 0.011 & $(0.486)$ & 0.024 & $(0.000)$ \\
\hline$q 50 \%$ & -0.008 & $(0.034)$ & 0.016 & $(0.000)$ & 0.023 & $(0.000)$ & 0.005 & $(0.250)$ & 0.018 & $(0.296)$ & 0.025 & $(0.000)$ \\
\hline$q 60 \%$ & -0.005 & $(0.215)$ & 0.013 & $(0.005)$ & 0.024 & $(0.000)$ & 0.007 & $(0.072)$ & 0.008 & $(0.644)$ & 0.026 & $(0.000)$ \\
\hline$q 70 \%$ & -0.003 & $(0.466)$ & 0.013 & $(0.005)$ & 0.024 & $(0.000)$ & 0.011 & $(0.007)$ & -0.005 & $(0.754)$ & 0.024 & $(0.000)$ \\
\hline q80\% & -0.007 & (0.099) & 0.018 & $(0.000)$ & 0.019 & $(0.006)$ & 0.011 & $(0.005)$ & -0.002 & $(0.935)$ & 0.022 & $(0.001)$ \\
\hline q90\% & -0.007 & $(0.179)$ & 0.022 & $(0.000)$ & 0.011 & $(0.187)$ & 0.009 & $(0.108)$ & 0.019 & $(0.405)$ & 0.011 & $(0.190)$ \\
\hline
\end{tabular}

Note: Figures in brackets are p-values, robust standard errors. All effects are elasticities. Estimates obtained using Stata's qreg command. Full list of estimation variables are enclosed in Appendix A, Table A4. Bold type indicates significant at the conventional 5 per cent level.

1 Dropping market potential from the specification does have some impact on the structure of employment density with SA4 level inputs. In the alternative estimation, it is only for the lowest 1/3 of earners that the net wage benefit disappears. Results are reported in Appendix B, Table A8.

Source: Authors' estimations, HILDA Survey Waves 17 and 18; ABS Census TableBuilder, 2016.

- With SA2 level inputs, the agglomeration effect is again difficult to interpret. The density variable is negative and insignificant, whereas the spillover effect is positive and (mostly) significant.

- With SA4 level inputs, there is a positive effect on wages, also after adjusting for basic housing costs. However, this is not the case for the lowest half of the wage distribution. For higher-wages earners there is a positive wage effect also when adjusting for basic housing costs. Dropping market potential for the SA4 level input estimates in Table 12 has a limited impact on the structure of the coefficients, but does affect significance levels. Without the market potential variable, the wage benefit for those close to employment concentrations disappears for the lower $1 / 3$ of the wage distribution — see note to Table 12.

Taken together with the results in Table 2, Table 9 and Table 11, the results in Table 12 suggest that a higher concentration of employment (based on SA4 level inputs) where workers live is associated with higher wages - this is the agglomeration-productivity effect-but that higher wages for lower-wage earners are frequently capitalised in higher housing costs (Table 10 and Table 12) 
- Finally, a 10 per cent increase in commuting distance at the $10 \%$ and $20 \%$ quantiles is associated with a 0.36 and 0.31 per cent increase in wages, whereas the same increase in commuting distance requires a 0.24 and 0.22 per cent increase for the $70 \%$ and $80 \%$ quantiles. The difference in these elasticities also reflect how commuting costs constitute a larger proportion of low-wage incomes compared to higher-wage incomes. The residential location of lower-wage earners is thus more sensitive (or responsive) to variation in income. Other things being equal, this greater sensitivity suggest a tendency to seek housing options closer to places of employment.

The results in tables 9, 10, 11 and 12 suggest that agglomeration benefits for lower-wage earners are frequently capitalised in housing costs. This is not the case for higher-wage earners. Taken together, the results in Section 4 suggest that while agglomeration effects have a positive effect on wages, the interaction of productivity gains with housing markets ensures that benefits accruing to lower-wage earners are transferred to owners of land and housing. We return to the potential productivity impacts of this effect in Section 5.

\subsubsection{Policy implications}

The results in this section suggest that agglomeration effects remain after adjusting for basic housing costs. In other words, with all things being equal-for example, individual preferences for residential environment, or perceptions of quality of life-individuals would be better off (receive and retain higher wages) working in locations with greater concentration of employment.

There are important variations across the wage distribution. These become particularly marked when evaluating housing cost-adjusted wages at the place of residence. The interaction between housing markets and employment concentration thus accentuates the distributional impacts of agglomeration effects.

When adjusting for basic housing costs, the wage benefit (based on SA4 level inputs) from agglomeration-where people live-disappears for the lowest half of the wage distribution. The productivity benefit that is paid out in higher wages across the wage distribution is largely capitalised in higher housing costs for many workers. Notably, this does not necessarily imply that these workers would be better off elsewhere and non-wage benefits (urban amenities) may still provide an incentive for lower-wage earners to locate near employment concentrations. Nevertheless, differences across the wage distribution, and variations in the responsiveness of lower-income earners to commuting costs (Table 10 and Table 12), does suggest an inequality mechanism arising from how agglomeration effects are distributed via housing markets.

- One implication of this is that public sector expenditure, such as CRA, will likely increase as a function of urban productivity gains. In other words, when property prices in capital cities increase as a result of productivity gains - and inelastic housing supply - the cost of policies to address housing affordability and expenditure at household level increases too. First, there is an increase in the rent levels (with implications for the level of CRA). Second, there is an increase in the number of households requiring CRA assistance. Over the last two decades CRA expenditure increased from \$1.7bn to \$4.7bn (PC 2002; 2020).

- A related consideration is that public policies that reduce housing costs for some income groups potentially crowd out higher productivity workers from the same locations. However, the net cost or benefit of such a process requires a more detailed analysis than wage and housing cost considerations alone. On the one hand, such a policy can generate double costs - cost of policy, plus loss of productivity. On the other hand, enabling lower housing costs-for example, social, affordable or CRA-assisted housing-for low-income households can result in significant additional social returns.

At finer spatial scales, locational decisions are a function of travel and housing costs, but also housing availability and type. The positive commuting coefficient suggest that the relative travel horizon may differ for lower-wage and higher-wage earners. In other words, travel costs are a greater proportion of wages for lower-wage earners than higher-wage earners. Therefore, lower-wage earners have an incentive to locate closer to employment locations - after considering housing costs and availability - but will have to spend a greater proportion of their wages to compete for these locations. If this is the case, then an average increase in wages due to agglomeration benefits may have significant distributional impacts when considered at the location of residence. 


\section{Policy development options}

There is evidence of agglomeration economies relating to density of employment, localisation economies (specialisation) and urban economies (diversity). This creates an economic rationale for concentration of economic activity. At the same time, there are significant distributional considerations relating to social justice (inequality), and adequately distributing gains and losses.

- Housing policy and housing affordability are necessary complements to harnessing societal agglomeration benefits. This is the case regardless of whether population growth is concentrated in capital cities or regional centres.

- Investment in skills and education are key to harnessing agglomeration benefits and can enable individual (employee) resilience in light of technological transformation.

- Digital connectivity and automation can potentially reshape some agglomeration logics by enabling proximity effects without physical proximity.

- Government-led development and regulation is critical to ensuring that agglomeration benefits generate socially equitable outcomes and deliver long-term productivity-enhancing incentives. 


\subsection{Introduction}

Australia is highly urbanised and has a large proportion of residents living in a small number of capital cities. Population growth over the coming decades is expected to remain concentrated in capital cities, but there is evidence to suggest that this is dispersing, especially in the wake of COVID-19. Further capital city growth may be a source of additional agglomeration benefits and productivity gains. However, it is also raising concerns about infrastructure and housing bottlenecks, and the economic and social benefits and costs of alternative population distribution strategies.

However, population growth is only one of the challenges facing Australian cities. In Future cities: planning for our growing population (Infrastructure Australia 2018: 4), the challenges outlined included:

- an ageing population

- the impact of climate change

- the continued transition to knowledge-intensive activities

- the changes to the nature and location of work.

The combined impact of these challenges raises important questions about the directions in which our cities should grow.

In this section, we reflect on the implications of the findings in this report for three policy issues raised by Future cities:

Should jobs be located centrally, or distributed across metropolitan and regional areas?

1. Should our cities expand at low density or consolidate inwards?

2. How may digital connectivity and automation affect agglomeration geographies?

3. We also reflect on the implications in relation to COVID-19 and the future of work.

\subsubsection{Should jobs be located centrally, or distributed across metropolitan and regional areas?}

Our estimates suggest that the productivity dividend to employment concentration is approximately 1 to 4 per cent. However, agglomeration effects vary by wage levels. There is also evidence for localisation economies, and some evidence for urbanisation economies. Viewed in isolation, the implication is that concentration of economic activity in higher-wage settings, rather than dispersion, will generate a greater productivity dividend.

- Larger cities, a priori, have greater potential for harnessing these productivity effects. For individual workers and firms, the urban premium associated with agglomeration economies makes it attractive to work and locate economic activity in employment clusters. For individual workers this effect may be additionally enhanced by other attractive features of agglomerations that make living in cities attractive-such as greater choice and variety in leisure, social and cultural amenities.

- However, concentration of employment without policies that also enable greater price elasticity of housing supply worsens housing affordability and exacerbate the role that housing markets play in redistributing agglomeration benefits. Alternative development strategies are within-capital city dispersion and regional dispersion, but both potentially come at a cost of forgoing agglomeration benefits in capital city CBDs. (The impact and role of housing markets is discussed further in Section 5.1.2.) Moreover, concentrated urbanisation within major capital cities has come at the expense and decline of regional economies that provide critical access to agricultural and tourism industries. Place-based policies, including area-based smart specialisation, can be effective in lifting the productivity, wellbeing and social opportunities within regional communities, and should be pursued as part of a strategic, well governed and innovative approach to economic recovery (Beer, McKenzie et al. 2020). 
Within-capital city dispersion

Polycentric urban growth models have the advantage of drawing on existing infrastructure and nearby employment markets within capital cities, consisting of multiple postcodes, SA2s and SA4s. However, under prevailing institutional planning powers there may be additional transaction costs and political economy considerations that inhibit the efficiency of developing-or in some cases, growing further-polycentric models. Our results suggest that the productivity spillovers (or interdependencies) between areas may be limited. This might suggest that polycentricity will not generate additional overall capital-city productivity gains, but we also cannot exclude this possibility without explicitly controlling for such an urban form. Also, under polycentric urban forms, the different sources of productivity will need to be considered (e.g. employment concentration, specialisation and diversity). Nevertheless, polycentricity does provide an option for:

- managing the employment-housing market interaction in a more spatially diffused manner

- allowing for additional economies of scale in the utilisation of some infrastructure

- allowing for within-city labour and housing market sorting.

Regional dispersion

If pursuing a strategy of regional dispersion of population, our results suggest that concentrating this in a smaller number of growth nodes may generate a greater productivity dividend than more general dispersion. This concentrated dispersion will:

- ensure an increase in employment density

- enable localisation and urbanisation economies that yield additional productivity gains

- maximise the returns to the additional infrastructure development that will be required.

Housing market impacts and inequality may provide a rationale for taking a longer-term view of population distributions (and the associated loss of agglomeration benefits as additional agglomerations emerge). However, such a policy will require:

- public policies that give businesses incentives to locate in additional agglomerations

- investment in infrastructure and housing to avoid transferring affordability issues from capital cities to regional centres.

A variation on regional dispersion of economic activity is dispersion of populations to towns and areas in proximity to a capital city or larger regional centre, while retaining their employment connection with the main city. For some workers, such a trend is already evident during COVID-19. Teleworking can enable professionals, managers and clerical/administrative occupations to retain their employment connection with city centres, but live in towns and areas within commutable distances or even further afield, depending on their need or expectations around working in the office as well.

As argued in Section 2.1.3, for many workers the productivity-enhancing elements that proximity generates in agglomerations becomes portable after a while. Under such a scenario, the wage benefits associated with employment in capital cities become spread more widely. Importantly, the dispersion of city wage benefits in agglomerations to nearby towns and areas can create additional employment opportunity in those locations as a result of an increase in local purchasing power. Dispersal of purchasing power may also generate flow-on effects to regional tourism and recreational industries. Notably, such a policy would also need to be accompanied by appropriate housing policies to avoid porting or exacerbating affordability issues more widely around capital cities.

The results in this report highlight the role of housing markets in distributing the gains from agglomeration and productivity. This means that housing policy and affordable housing policies are integral to harnessing the societal benefits from agglomeration effects. 


\subsubsection{Should our cities expand at low density or consolidate inwards?}

There is not a single answer to the question of low density or inwards consolidation-and key factors such as climate impact, wellbeing and political economy or planning, are not controlled for in our analysis. Nevertheless, our results provide a number of insights relevant to making decisions around consolidated employment density and consolidated residential density.

Consolidated employment density

Consolidated employment density is desirable, but hyper density may not be required to harness productivity gains. Across our estimations, the results using SA2 and SA4 level inputs are comparable. Additional research on the attenuation of agglomeration effects-in other words, whether (and at what rate, if any) agglomeration effects decline over distance-is required for more robust conclusions around employment concentrations, but the results here show little evidence of substantial average spillovers (or spatial interdependency) when using SA2 or SA4 level inputs for the analysis (the results vary somewhat by estimation approach when using SA2 level inputs). Moreover, there is some indication that the degree to which different industries/sectors derive productivity enhancing benefits from concentration (and so exert additional spatial concentration pressure) differs. This suggests that employment in general does not have to be hyper concentrated, although some industries/sectors may benefit more from concentration than others (in relation to both localisation and urbanisation economies) and there may also be variations across income groups. This can provide options for dispersing some economic activity, without forgoing significant productivity effects, but should be based on additional sectoral research.

Notably, the literature suggests that agglomeration effects do attenuate (Rosenthal and Strange 2008). Agglomeration effects arise from proximity and scale, so, in other words, consolidation is desirable. For Australian cities - whether capital or regional-an implication is that further growth of existing concentrations - such as CBDs or employment sub-centres-will also generate productivity dividends.

Decentralisation policies, which may be desirable for assorted reasons (see later discussion), will need to manage trade-offs between encouraging dispersal and restricting the growth of existing employment concentrations, and the productivity-enhancing agglomeration effects of specific industries and sectors.

Interaction between jobs density and housing markets

The interaction between jobs density and housing markets is critical to understanding the distributional impacts of agglomeration driven productivity. Viewed in isolation, capitalisation of productivity gains results in urban inequality that may provide a rationale for dispersing employment concentrations.

Our results suggest that there are clear benefits-or wage premiums-from agglomeration. However, for lowerwage earners this wage benefit is largely capitalised in higher housing costs. After adjusting wages for housing costs, there is no longer a discernible wage-related premium to working in agglomerations for the lowest 20 per cent of the wage distribution. In practice, housing markets effectively become a vehicle for redistributing agglomeration benefits from lower-wage earners to owners of housing assets.

The wage measure in this report does not net out commuting costs, but includes them as a separate control. Further research may also want to test whether the distributional impacts are exacerbated, after controlling for housing and commuting costs. Some indications that this might be the case can be gleaned from the commuting elasticity, which shows that lower-wage earners' locational decisions are more responsive to commuting costs than those of higher-wage earners. Similarly, when examining housing cost-adjusted wages where people live, the wage benefit from agglomerations appear capitalised in housing costs for a larger range of the wage distribution (between $1 / 3$ and $1 / 2$ ). 
This effect follows from the basic sorting dynamics described in Section 2. The value of proximity to employment concentrations is capitalised in nearby property prices. Individuals can either 'choose' to:

- live close to work - and pay higher housing costs

- commute longer distances-and pay higher commuting costs.

Notably, the responsiveness of lower-wage earners to commuting costs suggests that providing housing options in proximity to labour markets (and so some densification) may have additional distributional benefits if coupled with policies that ensure properties also remain affordable/ minimise the capitalisation effect at the lower end of the wage distribution.

Importantly, the sorting effect described in Section 2 also relates to other urban amenities, as property prices not only capitalise proximity to work, but also proximity to a range of other urban amenities. Further research is required to separate these two effects, both of which matter for planning or incentivising integrated housing and labour market policies.

Housing-market-generated inequality

Housing-market-generated inequality may reduce the productivity benefits of agglomerations. Viewed in isolation, the implication of this is that housing policy is also economic policy, irrespective of whether growth of economic activity is concentrated in capital cities or regionalised.

As discussed in the introduction to this report, Australia has experienced a decline in productivity over recent decades (McKinsey 2018), as have many other countries. Under conditions of low-price elasticities of housing supply, housing markets potentially become a vehicle for rent-seeking. For instance, growth in capital gainsdriven by population growth, technological change and capitalisation of agglomeration effects-increases the returns to investment in existing and new housing assets. Stiglitz (2016), McKinsey (2018), Brynjolfsson, Rock et al. (2019) and others argue that rent-seeking and concentrations of gains from investments all contribute to declining productivity rates in many advanced economies over the past three to four decades. According to this argument, these outcomes incentivise investment in non-productive capital-which is capital that facilitates rentseeking rather than production.

Investment in productive capital (or capital deepening) has been central to Australia's growth (Campbell and Withers 2017), but over the last decade the contribution of capital deepening has reversed (Productivity Commission 2019). Our results suggest that housing markets play a key distributional role. They distribute the urban wage premium from lower-wage earners to landlords and owners of property and real estate. While by no means conclusive, the increase in Australian households' housing-debt-to-disposable-income from 31 per cent to 142 per cent over the last three decades (Reserve Bank of Australia Table E2 n.d.) is an indication of allocation of investment funds to housing. Battellino (2007) similarly shows that the rapid increase in household lending was not accompanied by an increase in business lending.

Moreover, the increased diversification and targeting of rental housing finance and investment to niche markets - such as students, tourists, corporate multi-family build-to-rent-has had distinct spatial implications for the type of construction and location of affordable housing (Hulse Parkinson et al. 2018). Investors catering to these groups close to employment agglomerations have, up until the onset of COVID-19, gained higher rental yields at the expense of more even and affordable rental investment in outer and regional locations, which reinforces housing-market-generated inequality over time (Hulse, Reynolds et al. 2019). To this end, there is a need for carefully targeted place-based responses that align increased housing supply-especially via government-led and alternative financing models for investors - and enabling infrastructure, with economic development strategies within and around regional locations that can support diverse and concentrated employment growth. 
Concentration of jobs and higher incomes creates demand

Concentration of jobs and higher incomes also generate additional urban amenities-such as shopping centres, cafes and restaurants, museums and sports-which, separately from higher wages, creates demand for living close to employment agglomerations. Viewed in isolation, the implication for urban form is that if jobs are concentrated, then greater residential density (or inward consolidation) is also required.

Demand for urban amenities may cause people to want to live closer to employment, even in the absence of higher wages. Our results show that when controlling for density of employment at the place where the individual lives, the commuting elasticity is about 20 per cent higher than when controlling for density where the individual works. Workers thus require wage compensation for longer commutes. The difference between employment density at work and employment density at home may further indicate that there is additional demand for living close to areas with many jobs. This is consistent with the 'consumer city' thesis of Glaeser, Kolko et al. (2001), but also with a lack of available and affordable housing options for lower-income households. Additional research is required to test this proposition more robustly.

However, there are, three important caveats here.

First, residential densification is conditional on employment densification.

Second, other research shows that willingness to pay for housing is negatively associated with 'too much' density (Nygaard and Glackin 2019). Analysis of residential densification in Melbourne also shows that low-density and medium-density infill of two to 49 properties per lot does not have a negative impact on willingness to pay (Nygaard and Glackin 2019). Thus there is scope to consolidate cities inwards. However, inward consolidation may in the long run be detrimental to productivity gains from agglomeration unless the supply, design and affordability challenges noted earlier are addressed.

Third, teleworking may enable diffusion of wage benefits to towns and areas surrounding capital and regional cities (which is discussed in the next section).

\subsubsection{How may digital connectivity and automation affect the agglomeration-housing market dynamic?}

Productivity is critical to long-term prosperity. However, inadequate employment protection and barriers to employment participation can erode productivity gains, for some wage earners. In the context of digital transformations, automation and economic recovery, employment protection and participation are critical to reducing income and housing inequalities.

The future of work within many industries and job functions is likely to consolidate and accelerate the move towards a greater reliance on the digital economy, leading to the growth of virtual agglomerations. Digital connectivity and automation may benefit some workers and work processes-and in turn benefit multifactor productivity - and create digital geography-based returns to scale, leading to productivity and wage benefits. This can have multiple outcomes for agglomeration-housing market dynamics. If access to jobs is the key determinant for residential location, then digital connectivity and automation may reduce demand for centrally located residential areas. However, aspatial jobs may also increase the demand for locations with urban amenities, which in part are determined by agglomeration dynamics.

Importantly, digital connectivity and automation raise significant issues for urban governance and wage determination in balancing productivity gains with equity outcomes across workers and industries. Housing market pressures may decline in some geographies but then appear in others. The role of housing markets in distributing productivity gains will thus likely remain. 
Over time, increased practices of teleworking will have a significant impact on how cities can be governed, including ways of promoting access to more affordable housing and for policies that can mitigate climate change through reducing traffic congestion and the reorganisation of work-residence commutes. Teleworking enables the porting for human capital to more decentralised locations without necessarily losing productivity benefits (see Section 2.1.3). In tandem with decentralised housing policies, teleworking can relieve housing demand for more central city locations - at least for some types of workers and occupations.

The future of work, including digital transitions, generates new opportunities for connectivity and the fostering of virtual agglomerations. These can draw upon a more dispersed workforce of 'crowdworkers' and be mediated by platforms and locational applications to allocate individuals to specific geographical areas (Berg, Furrer et al. 2018). These range from mega companies to more niche models, many of which have accelerated throughout the COVID-19 period. Small-scale ventures have the potential to link regional and metropolitan markets though initiatives such as online food supply markets that connect producers, distribution storage and deliveries. However, scaling up such initiatives requires 'sharing technological dividends' (World Bank 2016) through adequate governance models if wage inequalities are to be minimised.

Job losses due to automation need to be managed with significant investment in skills training. Ongoing investment in skills and education (or human capital) may ensure that adequate wages can be maintained. It also enables worker transition across industries through the development of cross-professional skills (Balliester and Elsheikhi 2018; Borland and Coelli 2017; Deloitte 2014). The results in Section 3 demonstrate that compared to other determinants of wages - such as demographics, human capital, and firm/employer environmentagglomeration effects are relatively small. Access to education and training, along with pathways for current and new generations of workers, are critical to long-term productivity and equitability, and as part of a post-COVID-19 economic recovery process. A large proportion of spatial variation in wages reflects the types of employees required by different firms in different locations. This, in turn, may reflect the type of infrastructure and locational characteristics that attract firms to different locations. Workers also self-select into areas with different degrees and types of amenities. These additional sorting effects do not necessarily raise worker productivity, but may generate wellbeing and income effects that shape local housing market dynamics.

\subsubsection{Policy development options to harness the productivity potential of agglomerations}

In conclusion, harnessing the productivity potential of agglomerations requires industrial, urban and regional policy support. The following summary points focus on development options relating to the overall research question: the impact of jobs and skills concentration on labour productivity and housing costs.

1. Planning and regulatory reform to increase the price elasticity of housing supply is central to enabling employment agglomeration. This is the case regardless of whether a capital city or regionalised strategy is pursued. Precinct-style planning can enable co-location of housing and employment and manage some of the wage-housing costs effects arising through market-based sorting.

2. COVID-19 has highlighted the important role housing can play as a place of living and working. Design and building standards can ensure that new dwellings are attractive substitutes for older properties, including size and functionality, and access to green space and transport infrastructure. However, in the absence of affordability, the dual role of architectural and design interventions provides a further fault line of inequality.

3. Greater density is a means of providing more dwellings in locations closer to employment and other amenity agglomerations - but scale of supply alone is an insufficient response to addressing housing requirements. More general densification through inner and middle-ring suburbs, rather than concentrated densification in selective locations, provides a means of balancing out household demand for space with more intensive utilisation of land. 
4. To preserve the longer-term productivity benefits that agglomerations can generate, policies are required to counteract regressive redistribution of productivity gains from lower-wage workers to owners of land and housing. Specific policies may relate to the following:

- Supporting direct provision and supply of affordable dwellings, including within precinct. Rent assistance provides an income contribution that compensates for this re-distributional role for some households.

- Development and private-rental support packages in close proximity to major employment hubs, and within direct access to transport. This may counter effects that exacerbate inequality and, in the long-term, counter rent-seeking behaviour related to land use and development.

- An active strategy that provides incentives for businesses and employers to facilitate a more 'permanent' transition to teleworking can have significant 'social dividends'-also in regards to housing costs. There is a need to further investigate the future scenarios associated with new ways of working and living. 


\section{References}

Abelson, P., Joyeux, R., Milunovich, G. and Ching, D. (2005) ‘Explaining house prices in Australia', The Economic Record, vol. 81, no. 255: 96-103.

ABS see Australian Bureau of Statistics

Acemoglu, D. (2002) 'Technical change, inequality and the labour market', Journal of Economic Literature, vol. XL, March: 7-72.

Adamson, D., Clark, D. and Partridge, M. (2004) 'Do urban agglomeration effects and household amenities have a skills bias?', Journal of Regional Science, vol. 44, no. 2: 201-223.

Ahlfeldt, G. and Pietrostefani, E. (2019) 'The economic effects of density: a synthesis', Journal of Urban Economics, vol. 111, no. C: 93-107.

Australian Bureau of Statistics (2006) Australian and New Zealand Standard Industrial Classification (ANZSIC), 2006 (Revision 2.0), cat. no. 1292.0, ABS, Canberra.

Australian Bureau of Statistics (2013) ANZSCO -- Australian and New Zealand Standard Classification of Occupations, 2013, Version 1.2, cat. no. 1220.0, ABS, Canberra.

Australian Bureau of Statistics (2013) Population projections, 2012 to 2101, cat. no. 3222.0, ABS, Canberra.

Australian Bureau of Statistics (2018) Census of population and housing: commuting to work-more stories from the Census, 2016, cat. no. 2071.0, ABS, Canberra.

Australian Bureau of Statistics (2020) Australian national accounts: national income, expenditure and product, cat. no 5206.0, ABS, Canberra.

Australian Bureau of Statistics (2021) Australian Statistical Geography Standard (ASGS), www.abs.gov.au. Online text.

Australian Government (2019) Planning for Australia's future population, Department of Prime Minister and Cabinet, Canberra, accessed 10 August 2020, https://www.pmc.gov.au/resource-centre/domestic-policy/planningaustralias-future-population

Bailey, N. and Minton, J. (2018) 'The suburbanisation of poverty in British cities, 2004-16: extent, processes and nature', Urban Geography, vol. 39, no. 6: 892-915.

Ball, M., Meen, G. and Nygaard, C. (2010) 'Housing supply price elasticities revisited: evidence from international, national, local and company data', Journal of Housing Economics, vol. 19, no. 4: 255-268.

Balliester, T. and Elsheikhi, A. (2018) The future of work: a literature review, Research Department Working Paper no. 29, International Labour Organization, United Nations, accessed 10 August 2020, https://www.ilo.org/global/research/ publications/working-papers/WCMS_625866/lang--en/index.htm

Battellino, R. (2007) Some observations on financial trends, Reserve Bank of Australia, https://www.rba.gov.au/ speeches/2007/sp-dg-250907.html

Beer, A., McKenzie, F., Blažek, J. and Ayres, S. (2020) Every Place Matters: Towards Effective Place-based Policy, Taylor \& Francis, Abingdon.

Belzunegui-Eraso, A. and Erro-Garcés, A. (2020) 'Teleworking in the context of the Covid-19 crisis', Sustainability, vol. 12, no. 9: 3662. doi:10.3390/su12093662 
Berg, J., Furrer, M., Harmon, E., Rani, U. and Silberman, M. (2018) Digital labour platforms and the future of work: towards decent work in the online world, International Labour Office, Geneva.

Borjas, G. (1994) ‘The economics of immigration', Journal of Economic Literature, vol. 32, no. 4: 1667-1717.

Borland, J. and Coelli, M. (2017) 'Are robots taking our jobs?', The Australian Economic Review, vol. 50, no. 4: $377-397$.

Brueckner, J., Thisse, J.-F. and Zenou, Y. (1999) 'Why is central Paris rich and downtown Detroit poor? An amenity-based theory', European Economic Review, vol. 43, no. 1: 91-107.

Brülhart, M. and Mathys, N. (2008) 'Sectoral agglomeration economies in a panel of European regions', Regional Science and Urban Economics, vol. 38, no. 4: 348-362.

Brynjolfsson, E., Rock, D. and Syverson, C. (2019) 'Artificial Intelligence and the modern productivity paradox: a clash of expectations and statistics', in A. Agrawal, J. Gans, and A. Goldfarb (eds), The Economics of Artificial Intelligence: An Agenda, NBER, University of Chicago Press.

Campbell, S. and Withers, H. (2017) Australian productivity trends and the effect of structural change, Economic Roundup, Australian Government Treasury, Canberra, accessed 10 August 2020, https://treasury.gov.au/ publication/p2017-t213722c

Ciccone, A. and Hall, R. (1996) 'Productivity and the density of economic activity', American Economic Review, vol. 86, no. 1: 54-70.

Collier, P. and Venables, A. (2017) 'Who gets the urban surplus?', Journal of Economic Geography, vol. 18, no. 3: 523-538.

Combes, P. and Gobillon, L. (2015) 'The empirics of agglomeration economics', in G. Duranton, V. Henderson and W. Strange, Handbook of Urban and Regional Economics, vol. 15, Elsevier, Amsterdam.

Combes, P., Duranton, G. and Gobillon, L. (2008) 'Spatial wage disparities: sorting matters!' Journal of Urban Economics, vol. 63, no. 2: 723-742.

Combes, P., Duranton, G. and Gobillon, L. (2011) 'The identification of agglomeration economies', Journal of Economic Geography, vol. 11, no. 2: 253-266.

CoreLogic (2021) 'Housing markets build momentum through the end of 2020, pointing to a strong start to 2021', CoreLogic, 4 January 2021, www.corelogic.com.au

Coulson, N.E. and Fisher, L.M. (2009) 'Housing tenure and labor market impacts: the search goes on', Journal of Urban Economics, vol. 65, no. 3: 252-264.

Deloitte (2014) Agiletown: the relentless march of technology and London's response, London Futures series, Deloitte, London.

Delventhal, M., Kwon, E. and Parkhomenko, A. (2020) How do cities change when we work from home? version 30 June 2020: https://www.andrii-parkhomenko.net/files/DKP_Covid_Urban.pdf

Dodson, J. (2005) Is there a spatial mismatch between housing affordability and employment opportunity in Melbourne? AHURI Final Report No. 80, Australian Housing and Urban Research Institute Limited, Melbourne, https://www. ahuri.edu.au/research/final-reports/80,

Dodson, J., de Silva, A., Dalton, T. and Sinclair, S. (2017) Housing, multi-level governance and economic productivity, AHURI Final Report No. 284, Australian Housing and Urban Research Institute, Melbourne, https://www.ahuri.edu. au/research/final-reports/284, doi:10.18408/ahuri-5307501

Duranton, G. and Puga, D. (2000) 'Diversity and specialisation in cities: why, where and when does it matter?', Urban Studies, vol. 37, no. 3: 533-555.

Duranton, G. and Puga, D. (2015) 'Urban land use', in G. Duranton, V. Henderson and S. Strange, (eds), Handbook of Regional and Urban Economics (vol. 5), North-Holland/Elsevier, Amsterdam

Dustman, C. and Frattini, T. (2014) 'The fiscal effects of immigration to the UK', The Economic Journal, vol. 124, no. 580: 593-643.

Ferreira, F., Gyourko, J. and Tracy, J. (2010) 'Housing busts and household mobility', Journal of Urban Economics, vol. 68, no. 1: 34-45. 
Frank, M., Sun, L., Cebrian, M., Youn, H. and Rahwan, I. (2018) 'Small cities face greater impact from automation', Journal of the Royal Society Interface, vol. 15, doi.org/10.1098/rsif.2017.0946

Fujita, M., Krugman, P. and Venables, A. (2001) The Spatial Economy: Cities, Regions, and International Trade, MIT Press, Cambridge, MA.

Gitelman, E. and Otto, G. (2012). 'Supply elasticity estimates for the Sydney housing market', Australian Economic Review, vol. 45, no. 2: 176-190.

Glaeser, E. (1999) 'Learning in cities', Journal of Urban Economics, vol. 46, no. 2: 254-277.

Glaeser, E. (2010) Agglomeration Economics, National Bureau of Economic Research, University of Chicago Press.

Glaeser, E. and Gottlieb, J. (2009) 'The wealth of cities: agglomeration economies and spatial equilibrium in the United States', Journal of Economic Literature, vol. 47, no. 4: 983-1028.

Glaeser, E., Kolko, J. and Saiz, A. (2001) ‘Consumer city’, Journal of Economic Geography, vol. 1, no. 1: 27-50.

Gurran, N., Phibbs, P., Yates, J., Gilbert, C., Whitehead, C., Norris, M., McClure, K., Berry, M., Maginn, P. and Goodman, R. (2015) Housing markets, economic productivity, and risk: international evidence and policy implications for Australia-Vol. 1: Outcomes of an investigative panel, AHURI Final Report No. 254, Australian Housing and Urban Research Institute Limited, Melbourne, accessed 10 August 2020, https://www.ahuri.edu.au/research/finalreports/254

Henderson, J. (1974) 'The sizes and types of cities', American Economic Review, vol. 64, no. 4: 640-656.

Hulse, K., Parkinson, S. and Martin, C. (2018) Inquiry into the future of the private rental sector, AHURI Final Report No. 303, Australian Housing and Urban Research Institute Limited, Melbourne, http://www.ahuri.edu.au/research/finalreports/303, doi: 10.18408/ahuri5112001

Hulse, K., Reynolds, M., Nygaard, C., Parkinson, S. and Yates, J. (2019) The supply of affordable private rental housing in Australian cities: short-term and longer-term changes, AHURI Final Report No. 323, Australian Housing and Urban Research Institute Limited, Melbourne, https://www.ahuri.edu.au/research/final-reports/323, doi:10.18408/ ahuri-5120101

Infrastructure Australia (2018) Future cities: planning for our growing population, Infrastructure Australia, Sydney.

Jacobs, J. (1969) The Economy of Cities, Random House, New York.

Kahn, M. and Walsh, R. (2014) Cities and the environment, NBER Working Paper no. 20503, NBER, Cambridge, MA.

Maclennan, D., Ong, R. and Wood, G. (2015) Making connections: housing, productivity and economic development, AHURI Final Report No. 251, Australian Housing and Urban Research Institute Limited, Melbourne, https://www. ahuri.edu.au/research/final-reports/251,

McKinsey Global Institute (2018) Solving the productivity puzzle: the role of demand and the promise of technology, McKinsey and Company, accessed 10 August 2020, https://www.mckinsey.com/featured-insights/regions-in-focus/ solving-the-productivity-puzzle\#

Meen, G. (2008) 'Ten new propositions in UK housing macroeconomics: an overview of the first years of the century', Urban Studies, vol. 45, no. 13: 2759-2781.

Meen, G., Gibb, K., Leishman, C. and Nygaard, C. (2016) Housing Economics: A Historical Approach, Palgrave Macmillan, London.

Melo, P. and Graham, D. (2009) Agglomeration economies and labour productivity: evidence from longitudinal worker data for GB's travel-to-work areas, SERC Discussion Paper 31, Spatial Economics Research Centre, London.

Melo, P., Graham, D. and Noland, R. (2009) 'A meta-analysis of estimates of urban agglomeration economies', Regional Science and Urban Economics, vol. 39, no. 3: 332-342.

Mincer, J. (1958) 'Investment in human capital and personal income distribution', Journal of Political Economy, vol. 66, no. 4: 281-302.

Mion, G. and Naticchioni, P. (2009) 'The spatial sorting and matching of skills and firms', Canadian Journal of Economics, vol. 42, no. 1: 28-55. 
Nakrošienè, A., Bučiūnienè, I. and Goštautaitè, B. (2019) 'Working from home: characteristics and outcomes of telework', International Journal of Manpower, vol. 40, no. 1: 87-101.

Nygaard, C. and Glackin, S. (2019) 'Infill and urban consolidation in Melbourne: spillovers and adjustment effects', National Housing Conference, Darwin, 28-30 August.

Nygaard, C. and Meen, G. (2013) 'The distribution of London residential property prices and the role of spatial lock-in', Urban Studies, vol. 50, no. 12: 2535-2552.

OECD. (2021) Multifactor productivity (indicator). doi: 10.1787/a40c5025-en (Accessed on 10 June 2021).

OECD. (2001) OECD Productivity Manual: A Guide to the Measurement of Industry-Level and Aggregate Productivity Growth, OECD: Paris.

Oswald, A.J. (1996) A conjecture on the explanation for high unemployment in the industrialized nations: part 1, University of Warwick Economic Research Paper No. 475, Coventry.

PC see Productivity Commission

Pennington, A. and Standford, J. (2020) Working from home: opportunities and risks: briefing paper, Centre for Future Work, The Australia Institute. https://d3n8a8pro7vhmx.cloudfront.net/theausinstitute/pages/3288/attachments/ original/1586714739/Working_From_Home_Opportunitites_and_Risks_April2020.pdf?1586714739

Peri, G. (2016) 'Immigrants, productivity, and labour markets', Journal of Economic Perspectives, vol. 30, no. 4: 3-30.

Pill, M., Gurran, N., Gilbert, C. and Phibbs, P. (2020) Strategic planning, 'city deals' and affordable housing, AHURI Final Report No. 331, Australian Housing and Urban Research Institute Limited, Melbourne, http://www.ahuri.edu.au/ research/final-reports/331, doi: 10.18408/ahuri-7320301

Productivity Commission (2002) Report on government services in 2002, Productivity Commission, Canberra, https://www.pc.gov.au/research/ongoing/report-on-government-services

Productivity Commission (2015) Housing assistance and employment in Australia, Commission Research Paper, Productivity Commission, Canberra.

Productivity Commission (2019) PC Productivity Bulletin, May 2019, Productivity Commission, Canberra.

Productivity Commission (2021) Report on government services in 2021, Productivity Commission, Canberra, https://www.pc.gov.au/research/ongoing/report-on-government-services

Putri, D. and Shearmur, R. (2020) 'Workplace mobility in Canadian agglomerations, 1996-2006: have workers really flown the coop?', Canadian Geographer, 1-17, doi: 10.1111/cag.12622

Rawnsley, T. and Szafraniec, J. (2010) Agglomeration and labour productivity in Australian cities, SGS Planning and Economics, Melbourne.

Reserve Bank of Australia (n.d.) Statistical tables, E2 Household finances: selected ratios, https://www.rba.gov.au/ statistics/tables/

Rosenthal, S. and Strange, W. (2003) 'Geography, industrial organisation, and agglomeration', Review of Economics and Statistics, vol. 85, no. 2: 377-393.

Rosenthal, S. and Strange, W. (2004) 'Evidence on the nature and sources of agglomeration economies', in J.V. Henderson and J.F. Thisse (eds), Handbook of Urban and Regional Economics (vol. 4), Elsevier, Amsterdam.

Rosenthal, S. and Strange, W. (2008) 'The attenuation of human capital spillovers', Journal of Urban Economics, vol. 64: 373-389.

Saiz, A. (2010) 'The geographical determinants of housing supply', Quarterly Journal of Economics, vol. 125, no. 3: 1253-1296.

SGSPE see SGS Planning and Economics

SGS Planning and Economics (2012) Productivity and agglomeration benefits in Australian capital cities: final report for COAG Reform Council, SGS Planning and Economics, Brisbane.

SGS Planning and Economics (2019) Melbourne functional economics region report, prepared for Infrastructure Victoria, https://www.infrastructurevictoria.com.au/wp-content/uploads/2019/04/SGS-Melbourne-Functional-Economic-

Region-Report-March-2019.pdf 
Standing Committee on Infrastructure, Transport and Cities [SCITC] (2018) Building up \& moving out: inquiry into the Australian Government's role in the development of cities, Commonwealth of Australia, Canberra.

Stiglitz, J. (2016) 'Inequality and economic growth', The Political Quarterly, vol. 86, no. S1: 134-155.

Summerfield, M., Bevitt, A., Fok, Y., Hahn, M., La, N., Macalalad, N., O'Shea, M., Watson, N., Wilkins, R. and Wooden, M. (2019), HILDA User Manual-Release 17 (with 2019 update), Melbourne Institute: Applied Economic and Social Research, University of Melbourne.

Terrill, M., Batrouney, H., Ha, J. and Hourani, D. (2018) Remarkably adaptive: Australian cities in a time of growth, accessed 18 August 2019, Grattan Institute, Melbourne, https://grattan.edu.au/wp-content/uploads/2018/10/909Remarkably-adaptive-Australian-cities-in-a-time-of-growth.pdf

Treasury (2020) Economic response to the Coronavirus: fact sheet, Australian Government, Canberra, accessed 10 August 2020, https://treasury.gov.au/sites/default/files/2020-05/Overview-Economic_Response_to_the_ Coronavirus_3.pdf

Trubka, R. (2011) Agglomeration economies in Australian cities: productivity benefits of increasing urban density and accessibility [PhD thesis], Curtin University, Perth.

van den Nouwelant, R., Crommelin, L., Herath, S. and Randolph, B. (2016) Housing affordability, central city economic productivity and the lower income labour market, AHURI Final Report No. 261, Australian Housing and Urban Research Institute Limited, Melbourne, https://www.ahuri.edu.au/research/final-reports/261,

Whelan, S. and Parkinson, S. (2017) Housing tenure, mobility and labour market behaviour, AHURI Final Report No. 280, Australian Housing and Urban Research Institute Limited, Melbourne, https://www.ahuri.edu.au/research/finalreports/280, doi:10.18408/ahuri-7307101

Woodward, H.B. (1906) Soils and Subsoils: From a Sanitary Point of View with Especial Reference to London and its Neighbourhood (2nd edn), His Majesty's Stationery Office, London.

World Bank (2016) World development report 2016: digital dividends, World Bank, Washington, D.C., https://www. worldbank.org/en/publication/wdr2016

Wu, X., Nethery, R.C., Sabath, B.M., Braun, D., and Dominici, F. (2020). 'Exposure to air pollution and COVID-19 mortality in the United States: a nationwide cross-sectional study', medRxiv: the preprint server for health sciences, https:// doi.org/10.1101/2020.04.05.20054502 


\section{Appendix A: Variable construction and estimation strategy}

\section{Dependent variable: hourly wages}

The OECD defines productivity as the 'ratio between the output volume and the volume of inputs' (OECD 2001). There are different ways of operationalising this. However, central to any measure is that the volume of inputs is measured consistently and appropriately. For instance, output per worker does not take into account the fact that different workers may work different hours, which means that overall labour input is not consistent.

Therefore, in operationalising productivity, this report uses wages per hour worked, with hours providing a consistent and appropriate measure of labour input. The conceptual basis for the approach taken in this report follows that of Combes, Duranton et al. (2008), Melo and Graham (2009) and standard assumptions in economics whereby labour is paid (wages) the marginal value of their product. In this scenario, wages are a function of the relative efficiency of labour (quality/skills), the price of output produced by labour, the efficiency of the local economy (including agglomeration) and other input costs.

HILDA surveys do not collect information on hourly wages directly, but they do provide information on hours usually worked and usual weekly earnings. The HILDA Survey manual provides the following syntax for constructing hourly wages (hwr) (Summerfield, Bevitt et al. 2019: 51):

hwr = imputed current weekly gross wages \& salary in main job / combined hrs per week usually worked in main job IF Broad labour force status is 'employed' and hours worked and weekly wage are greater than zero. ${ }^{6}$

As noted in the HILDA Survey manual, calculation of hourly wages results in a number of outliers, so 'it is important that users are aware that there are some odd cases when deriving hourly wage rates. This is, unfortunately, unavoidable' (Summerfield, Bevitt et al. 2019: 52). This issue applies to both of our dependent variables. To reduce the influence of odd cases (or outliers), we winsorise the dependent variables at the 1st and 99th percentiles. ${ }^{7}$ In addition, a number of cases in the multivariate specification do not have valid entries across all variables. Table A1 provides summary statistics for dependent variable hourly wage.

Table A1: Descriptive statistics hourly wage

\begin{tabular}{lllllrr}
\hline & $N$ & Mean & SD & 25th per & 50 th per & 75th per \\
\hline Hourly wage, \$ & 14,817 & 33.70 & 15.77 & 23.21 & 30.00 & 40.91 \\
\hline
\end{tabular}

Note: Per=percentile. Winsorised at the 1st and 99th percentile of housing-adjusted hourly wage. Wages adjusted for CPI (\$=2017). $\mathrm{SD}=$ standard deviation.

Source: HILDA Waves 17 and 18 (authors' calculations)

6 STATA syntax: gen hwr $17 m=($ wscmei/jbmhruc) if (esbrd==1 \& jbmhruc $>0$ \& wscmei $>0$ )

7 To facilitate comparison of point estimates across Eq (3) and E4 (4), we harmonise the estimation sample. This is done by winsorising the housing-adjusted hourly wage rate at the 1st and 99th percentiles, and setting the estimation sample size accordingly. 
This operationalisation enables direct testing of the extent to which wages are enhanced by agglomeration economies, and allows us to answer RQ2:

- To what extent is labour productivity in Australia a function of agglomeration externalities arising from employment density and market potential?

\section{Dependent variable: hourly wages adjusted for housing costs}

RQ3 asks:

- To what extent do spatial wage differences reflect spatial variation in the costs of living?

This research question is of particular interest with respect to understanding any effect of agglomeration economies, productivity and housing market dynamics.

From the discussion in Section 2, firms in more productive locations-for instance, where there are agglomeration economies - are able to pay higher wages than elsewhere because labour becomes more productive. This attracts more productive and better skilled labour to compete for better access (or proximity) to this location, outbidding less productive labour because of higher wages. In turn, this increases the agglomeration-but also raises the cost of living near or access to agglomerations.

Such competition for access leads to number of conceivable outcomes:

- Competition for access drives up the cost of living (housing) to such an extent that wage gains are entirely offset by additional living cost. This generates a spatial equilibrium where the differences in wages largely reflect differences in the cost of living. Under this scenario, productivity gains are primarily capitalised in land and property values - and potentially in other non-mobile services.

- Competition for access drives up the cost of living, but productivity gains from agglomeration differ across skills or income distributions. Assuming that productivity gains from agglomeration are greater for higherincome jobs than lower-income jobs, then the rate of capitalisation will differ across the income distribution. As a result, productivity gains may lead to worsening affordability outcomes for lower-income individuals.

To answer RQ3 we adjust the hourly wage (Eq 1) for the individuals' basic hourly housing cost. We construct basic hourly housing costs as follows:

\section{hrhscost=([hscost*12] * [indwklwg/hswklwg] )/ [indwklhrs*52.14] IF employed and earnings} and hours greater than zero.

where hscost is the monthly rent or mortgage payment for the household, annualised. The housing cost per income unit is then multiplied by the ratio of the individual's weekly gross wages to the household's weekly gross wages (an assumption is made here that income units pool their wages, so that the individual's contribution is proportional to the households' earnings contribution). This is then divided over the annualised usual hours worked per week. ${ }^{8}$ For the small number of individuals who live rent free, housing costs are equal to zero. Finally, hourly housing costs are subtracted from hourly wages to give a measure of hourly wages adjusted for housing costs.

8 STATA syntax: gen hhsc $17 \mathrm{~m}=$.

replace $h$ hsc $17 m=\left(\left(\right.\right.$ hsmgi $\left.^{\star} 12\right) \star($ wscmei/hiwscmi $\left.)\right) /(j b h r u c * 52.14)$ if (hstenr==1 \& hsmgi $\left.>=0\right) \&($ esbrd $==1$ \& jbhruc $>0$ \& wscmei $>0$ \& hiwscmi>0) \&(hhiu>0)

replace hhsc17m=((hsrnti*12)*(wscmei/hiwscmi) $) /(j b h r u c \star 52.14)$ if $($ hstenr==2 \& hsrnti $>0) \&($ esbrd $==1 \&$ jbhruc $>0$ \& wscmei $>0$ \& hiwscmi>0) \& (hhiu>0)

replace $h$ hsc $17 m=0$ if (hstenr $==4) \&($ esbrd==1 \& jbhruc $>0$ \& wscmei $>0)$ 
As with hourly wages, there are a number of outliers for the housing-costs-adjusted hourly wages variable. We therefore winsorise the variable at the 1st and 99th percentiles. In addition, a number of cases in the multivariate specification do not have valid entries across all variables. Table A2 provides summary statistics for dependent variable hourly wages adjusted for housing costs.

Table A2: Descriptive statistics hourly wage adjusted for housing costs

\begin{tabular}{lrrrrrr}
\hline & $N$ & Mean & SD & 25th per & 50th per & 75th per \\
\hline Hourly wage, \$ & 14,817 & 28.51 & 14.96 & 18.67 & 25.26 & 35.42 \\
\hline
\end{tabular}

Note: Per=percentile. Wages and basic housing costs adjusted for CPI ( $\$=2017)$. SD=standard deviation.

Source: HILDA Waves 17 and 18 (authors' calculations).

\section{Measures of agglomeration}

Data to construct agglomeration variables was sourced from the ABS Census TableBuilder dataset 'Counting Employed Persons, Place of Work (2016)'. Information collected in the Census is available for the place where a person was enumerated (or where they usually lived) on Census night, and also for their 'place of work', relating to the location of the main job held during the week before Census night. Our primary interest is in agglomeration effects at the location of employment, as this more directly captures the theoretical concepts of agglomeration economies, including spillovers and labour market pooling. However, we also use agglomeration effects at the place of enumeration when analysing housing market impacts.

The key variable is 'Industry of Employment'. The variable was examined at the '1-digit' level, which is the most aggregated grouping of the variable classifications. At this level, industries are coded into 20 groups. ${ }^{10}$

These variables were obtained nationally at the SA2 scale (2,310 spatial units) and SA4 scale (107 spatial units). We test agglomeration effects using both Statistical Area levels as inputs. In HILDA Surveys, place of employment is recorded at POA level. Agglomeration measures are therefore produced as the spatially weighted average of SA2 and SA4 level measures intersecting with the POAs recorded in HILDA. ABS (2021) gives the following definitions for these two Census geographies:11

Statistical Areas Level 2 (SA2s) "are designed to reflect functional areas that represent a community that interacts together socially and economically. They consider Suburb and Locality boundaries to improve the geographic coding of data to these areas and in major urban areas SA2s often reflect one or more related suburbs. The SA2 is the smallest area for the release of many ABS statistics, including the Estimated Resident Population (ERP), Health \& Vitals and Building Approvals data. SA2s generally have a population range of 3,000 to 25,000 persons, and have an average population of about 10,000 persons. SA2s are aggregations of whole SA1s".

Statistical Areas Level 4 (SA4s) "are specifically designed for the output of Labour Force Survey data and reflect labour markets within each State and Territory within the population limits imposed by the Labour Force Survey sample. Most SA4s have a population above 100,000 persons to provide sufficient sample size for Labour Force estimates. In regional areas, SA4s tend to have lower populations (100,000 to 300,000). In metropolitan areas, the SA4s tend to have larger populations (300,000 to 500,000). SA4s are aggregations of whole SA3s".

9 Census TableBuilder is an online program that allows users to generate their own tables derived from Census data.

10 Industries are coded using the Australian and New Zealand Standard Industrial Classification (ANZSIC), 2006 (Revision 2.0) (ABS 1292.0). Occupations are coded using the Australian and New Zealand Classification of Occupations (ANZSCO), 2013, Version 1.2 (ABS 1220.0).

11 From: https://www.abs.gov.au/websitedbs/D3310114.nsf/home/Australian+Statistical+Geography+Standard+(ASGS) . Since we cannot determine where within a POA the place of employment is, the agglomeration measures are generated based on spatially weighted averages of intersecting SA2s and SA4s. When analysing spatial interdependence, the variable construction has an impact on SA4 level estimations, with some evidence of colinearity. Results with and without spatial interdependence (market potential) are discussed throughout. 
In the HILDA Survey, place of employment is recorded by postcode. This necessitates concording SA2 and SA4 level Census information to postcodes. Concordance tables are available from the ABS. ${ }^{12}$ Employment, size of geography and industrial structure were therefore collected at SA2 and SA4 level, before being apportioned to postcodes. Apportionment is based on the proportion overlap between postcode and SA2/SA4 geography. In many cases, postcodes are significantly larger than SA2s, and typically smaller than SA4s. SA2 level and SA4 level input variables are thus the weighted value (at each POA) of constituent SA2s and SA4s. In practice the POA weighted averages thus capture the employment characteristics of a smaller (SA2 level inputs) and broader (SA4 level inputs) areas that each POA/HILDA respondent relates to.

Before concording, each of the agglomeration measures is calculated at SA2 and SA4 levels, respectively.

A number of agglomeration measures are typically used in the literature. These aim to capture specific labour agglomerations, but also interactions with neighbouring labour markets (dubbed 'market potential') and the industrial structure of areas. We drew on Melo and Graham (2009) and Duranton and Puga (2000) and construct the following measures:

- Employment and skills density: divide the number of jobs (or number of jobs by skill level) by the total land area of the SA2 or SA4 $\left(\mathrm{km}^{2}\right)$ :

$$
\text { Empldens }_{S A x}=\text { Empl }_{S A x} / \text { Area }_{S A x}
$$

where $S A x$ is either SA2 or SA4 for location $i$ in 2016. This measure is the key variable of interests related to measuring productivity-related agglomeration externalities arising from employment density. The measure is calculated for all employment, as well as employment by the following three skills levels based on occupational groups:

- Skills level A combines the two Major Groups 'Managers' and 'Professionals' that have predominant Australian and New Zealand Standard Classification of Occupation (ANZSCO) skill levels of 1 and 2.

- Skills level B combines the four Major Groups of 'Technicians and Trades Workers', 'Community and Personal Service Workers', 'Clerical and Administrative Workers' and 'Sales Workers' that have predominant ANZSCO skill levels of 3, 4 and 5 (and some skill level 2).

- Skills level C combines the two Major Groups of 'Machinery Operators and Drivers' and 'Labourers' that have predominant ANZSCO skill levels of 4 and 5 only - no skill levels of 3.

\section{Market potential}

Market potential is used to capture employment in nearby location, including related product market interactions (or input-output linkages). This variable ranges from negative to positive in the literature. Our market potential is based on the distance-weighted sum of all labour markets, where markets at further distance are assumed to have little impact:

$$
M P_{P O A \_S A x, i}=\sum_{j \neq i} E m p l_{P O A \_S A x, j} / d_{P O A \_S A x, i j} a
$$

where $i$ and $j$ are indices of SA2 and SA 4 weighted POAs, respectively; and $d_{S A x i j}$ is the distance between centroids of POA $i$ and $j$, and $a$ is the distance decay gradient. In line with the literature, we use a linear distance decay parameter (Melo and Graham 2009). Give the size differences between SA2s and SA4s neighbouring POAs will exhibit greater variation when based on SA2 level inputs than when based on SA4 level inputs. As discussed in the report, there is some evidence of colinearity in the SA4 level input estimations for this agglomeration measure.

12 https://data.gov.au/dataset/ds-dga-23fe168c-09a7-42d2-a2f9-fd08fbd0a4ce/distribution/dist-dga-951e18c7-f187-4c86-a73ffcabcd19af16/details?d 


\section{Index of relative economic diversity}

The index of relative economic diversity measures the similarity of the industrial composition of an area (either SA2 or SA4) compared with the economy of the state within which it is located. This measure captures the extent to which labour markets are diversified. The index is defined as the inverse of the summed absolute differences between the industry shares at these geographic scales. The greater the value of the index, the more similar the composition of each area is to that of the state economy overall; a smaller index signals less diversification in the local economy compared with the state economy.

$$
D I V_{S A x}=\left[\sum_{S=1}^{S}\left|\left(E m p l_{S A x, S} / E m p l_{S A x}\right)-\left(E m p l_{S} / E m p l\right)\right|\right]^{-1}
$$

where $S A x$ is SA2 and SA4 level, respectively; $s$ is industry/occupation of employment, and Empl is employment. Empl without subscript total state employment.

\section{Relative specialisation index}

The relative specialisation index compares industrial specialisation within an SA2/SA4 state-level specialisation. This index divides the share of an industry in an SA2 or SA4 by the corresponding share at the state level. The index for an area takes the largest value of this ratio across twenty industrial groups.

$$
S P E C_{S A x}=\operatorname{Max}_{S}\left[\left(E m p l_{S A x, S} / E m p l_{S A x}\right) /\left(E m p l_{S} / E m p l\right)\right]
$$

\section{Instrumental variables}

A key identification challenge in estimating the productivity effect of agglomeration economies is the circular causality that we highlighted earlier: higher wages enable more productive workers to outcompete others for access to agglomerations, thereby increasing the size of the agglomeration and-if agglomeration economies exist-also their productivity. ${ }^{13}$ In order to deal with this endogeneity issue, the literature typically uses long lagged variables or geological (or geographical) variables to instrument for current agglomeration, e.g. the density measure (SA2/SSA4 level inputs) used in estimation.

The reasoning is that initial concentrations of employment were historically driven by different economic imperatives than occur today-for instance, in economies dominated by agriculture or manufacturing-as the role of natural characteristics in production differ from those same characteristics in a knowledge-based or service-dominated economy. Past concentrations of people (agglomerations) or geological conditions should therefore be correlated with current concentrations, but are no longer directly relevant for explaining current productivity. They remain indirectly correlated with productivity only through their correlation with a concentration of people (or agglomeration).

There is an established tradition for using long lagged variables as instruments in agglomeration analysis (Ciccone and Hall 1996; Combes and Gobillon 2015; Combes, Duranton et al. 2008). It is feasible to follow such a strategy for Australia, too. The ABS makes available historic Census data that contain population records at a spatial scale similar to a local government area. If historic reporting areas are digitalised, they can be concorded (or spatially matched) to current Census geographies, and then used as a basis for creating historic population density measures. While feasible for smaller areas, this strategy is impractical and very labour intensive when considering the whole of Australia. 
A second instrumenting tradition is based on the use of geological or geographical indicators. These can safely be assumed to be exogenous - unaffected by spatial wage rates-but their relevance is not always clear.

Nevertheless, a number of studies relate geological indicators to:

- past agricultural productivity (Combes and Gobillion 2015)

- construction costs (Rosenthal and Strange 2008)

- amenity value of residential land (Meen, Gibb et al. 2016).

Geological information for Australia is readily available from GeoScience Australia. A discussion remains around the use of geology for intra-city variation in density (Combes, Duranton et al. 2011). Nevertheless, geology is also used in the literature as an intra-city instrument (Meen, Gibb et al. 2016; Rosenthal and Strange 2008).

In constructing the instruments, current SA2 boundaries were overlaid on Geoscience Australia's 1:1 Million Surface Geology map. The proportion of each lithological classification per SA2 was then calculated. Lithological classifications were then rationalised by their main lithological category. This resulted in eight main geological groups:

- Alluvium

- Igneous

- Meta-sedimentary

- Meta-igneous

- Quartz-rich

- Regolith (less alluvium)

- Sedimentary rock formations..$^{14}$

In estimation alluvium, sedimentary and quartz-rich rock formations are used. When regressing these geological variables directly on hourly wages there is no significant correlation. The restriction assumptions - that is, entering geology only indirectly - are valid according to under-identification, weak identification and over-identification test diagnostics following instrumental variable regression.

Exclusion restrictions (validity of the instruments) is tested by examining F-test for first stage regressions (xtivreg). We also test for over, under and weak instrument diagnostic test following ivreg2 in Stata, although these are not directly transferrable. The results reported in Table 8 meet under-identification and weak identification tests; there is some evidence of over-identification, particularly in SA2 level input estimations (ivreg2).

In addition to the density measure, a second potentially endogenous variable is commuting time (or time taken from home to work). If workers only commute longer distances when compensated by higher wages, then demand for travel also depends on income levels (Melo and Graham 2009). In order to instrument for commuting time, we follow Melo and Graham (2009) and instrument individual commuting time with the medium commuting distance $\left(\mathrm{km}^{2}\right)$ for all workers in each SA2. Commuting distances at SA2 level are available from the Australian Census (ABS 2018). The reasoning behind this instrument is that the median commuting distance likely reflects the accessibility of an area and so affects commuting patterns. That is, workers in well-connected areas may have longer commutes because accessibility is better. At the same time, the median commuting distance of all workers is unlikely to determine the wage of the individual worker, after controlling for industry, occupation and skills.

Note: Exclusion restrictions for this instrument were also tested, but not found valid. This variable is therefore not instrumented in the final estimations.

14 The grouping by main lithological category follows Woodward (1906), and is also used in Meen, Gibb et al. 2016. The rationale is that productivity impacts are related to geotechnical properties of the different rock formations, rather than their age characteristics (which is the conventional way of ordering rock formations). 


\section{Estimation specification}

Eq (5) and Eq (6) set out the key empirical specifications that test RQ 2 and RQ3, respectively.

$$
\begin{gathered}
\ln W H R_{i}=\alpha+X_{i} \beta_{1}+A_{m} \beta_{2}+F_{i} \beta_{3}+M E_{i} \beta_{4}+\sigma_{o c}+\gamma_{i n}+\mu_{r}+\varepsilon_{i} \\
\ln W H R H C_{i}=\alpha+X_{i} \beta_{1}+A_{m} \beta_{2}+F_{i} \beta_{3}+M E_{i} \beta_{4}+\sigma_{o c}+\gamma_{i n}+\mu_{r}+\varepsilon_{i}
\end{gathered}
$$

Where $\ln W H R$ is the log of worker $i$ 's hourly earnings and $\ln W H R H C$ is the log of worker $i$ 's hourly earnings adjusted for basic housing costs. Further, $X$ is a vector of $i$ 's demographic, educational and job-related characteristics, $A$ is a vector of agglomeration measures in labour market configuration $m$ (described in Section 3.3), $F$ is a vector of firm characteristics, and $M E$ is a vector of migration-ethnicity-related characteristics. This mainly reflects country of birth, but also includes Aboriginal and Torres Strait Islanders as a separate category. In addition, $\sigma, \gamma$ and $\mu$ are fixed effects for occupation, industry and broader geographic areas (regions). A list of variables and definitions are provided in this Appendix, Table A4.

The choice of explanatory variables is based on a long-established practice in labour economics where wages are considered a function of demographics, schooling and experience (Melo and Graham 2009; Mincer 1958; Rosenthal and Strange 2008). Experience is captured by the age variable, as well as tenure with current employer. Migration-related variables may reflect:

- country-specific differences in quality of schooling-as immigration to Australia also means importing human capital developed under different educational systems

- assimilation-related dynamics—such as transferability of skills

- potential discrimination.

We do not distinguish between these factors. Therefore, our variables control for a range of factors that may affect the productivity of individual workers apart from any agglomeration effects. Wages may also be affected by firm-specific wage policies or unobserved firm characteristics (Mion and Natcchioni 2009). We therefore include controls for firm size, as well as industry of activity.

For this project, density of workers is the main variable of interest (e.g. measure of agglomeration related productivity effects). For the first time, HILDA 17 provided postcode level (POA) information on individual places of work. This enables measuring agglomeration effects at the place of work, rather than using residential areas as a proxy for labour market agglomeration. We follow Melo and Graham (2009) and include each of the four agglomeration measures jointly in estimation. Variance Inflation Statistics (VIF) show minimal colinearity issues with SA2 level inputs. With SA4 level inputs, market potential has a marginally raised VIF statistic. Sensitivity analysis is thus done (and reported in the text) with and without the inclusion of market potential with SA4 level inputs. Appendix B reports RE, IV and quantile regressions results when dropping market potential.

Eq (5) and Eq (6) are estimated using random effects panel estimator, instrumental variable estimator and multilevel estimator techniques. Since the relationship between wages and employment density is also characterised by reverse causality, estimates of agglomeration elasticities are potentially biased. In the literature, the direction of this bias is not clear, with evidence of endogeneity corrected agglomeration elasticities being smaller and larger than OLS estimates. However, the quantitative impact of the bias is often negligible (Melo and Graham 2009). Diagnostics test shows that there is some evidence of heteroscedasticity. All standard errors are therefore based on White-corrected standard errors; IV estimation is based on two-stage least square (TSLS) approach.

Eq (5) is additionally estimated for individual industries of employment. Finally, quantile regressions and instrumental quantile regressions are estimated to analyse variation in agglomeration effects across the earnings distribution.

Table A3 reports descriptive statistics for the SA4 level input estimation sample. 
Table A3: HILDA Survey Waves 17 and 18 descriptive statistics, SA4 level inputs

\begin{tabular}{|c|c|c|c|c|c|}
\hline Variable & Number & Mean & SD & Min & Max \\
\hline Male & 14,817 & 0.468 & 0.499 & 0.000 & 1.000 \\
\hline (In) Age & 14,817 & 3.599 & 0.380 & 2.708 & 4.394 \\
\hline Legally married & 14,817 & 0.463 & 0.499 & 0.000 & 1.000 \\
\hline De facto married & 14,817 & 0.204 & 0.403 & 0.000 & 1.000 \\
\hline Managers & 14,817 & 0.124 & 0.329 & 0.000 & 1.000 \\
\hline Professionals & 14,817 & 0.262 & 0.440 & 0.000 & 1.000 \\
\hline Technicians & 14,817 & 0.109 & 0.311 & 0.000 & 1.000 \\
\hline Health and welfare & 14,817 & 0.135 & 0.341 & 0.000 & 1.000 \\
\hline Clerical/administrative & 14,817 & 0.145 & 0.352 & 0.000 & 1.000 \\
\hline Sales worker & 14,817 & 0.091 & 0.287 & 0.000 & 1.000 \\
\hline Machine operator & 14,817 & 0.058 & 0.235 & 0.000 & 1.000 \\
\hline COB main English speaking & 14,817 & 0.078 & 0.269 & 0.000 & 1.000 \\
\hline COB other & 14,817 & 0.059 & 0.236 & 0.000 & 1.000 \\
\hline ASTI & 14,817 & 0.023 & 0.151 & 0.000 & 1.000 \\
\hline COB Germany, Netherlands and Italy & 14,817 & 0.006 & 0.080 & 0.000 & 1.000 \\
\hline COB Vietnam & 14,817 & 0.004 & 0.060 & 0.000 & 1.000 \\
\hline COB Philippines & 14,817 & 0.012 & 0.108 & 0.000 & 1.000 \\
\hline COB China & 14,817 & 0.009 & 0.093 & 0.000 & 1.000 \\
\hline COB India & 14,817 & 0.011 & 0.105 & 0.000 & 1.000 \\
\hline Bachelor degree or above & 14,817 & 0.347 & 0.476 & 0.000 & 1.000 \\
\hline Advanced diploma or diploma & 14,817 & 0.107 & 0.309 & 0.000 & 1.000 \\
\hline Tenure with current employer (years) & 14,817 & 6.868 & 8.045 & 0.000 & 54.000 \\
\hline Employed fulltime & 14,817 & 0.674 & 0.469 & 0.000 & 1.000 \\
\hline Agriculture, forestry and fishing & 14,817 & 0.015 & 0.120 & 0.000 & 1.000 \\
\hline Mining and quarrying & 14,817 & 0.016 & 0.126 & 0.000 & 1.000 \\
\hline Manufacturing & 14,817 & 0.083 & 0.276 & 0.000 & 1.000 \\
\hline Electricity, gas and water & 14,817 & 0.008 & 0.087 & 0.000 & 1.000 \\
\hline Construction & 14,817 & 0.047 & 0.212 & 0.000 & 1.000 \\
\hline Wholesale trade & 14,817 & 0.143 & 0.350 & 0.000 & 1.000 \\
\hline Hotels and restaurants & 14,817 & 0.067 & 0.251 & 0.000 & 1.000 \\
\hline Transport storage and communication & 14,817 & 0.056 & 0.230 & 0.000 & 1.000 \\
\hline Financial intermediation & 14,817 & 0.036 & 0.186 & 0.000 & 1.000 \\
\hline Real estate renting and business activities & 14,817 & 0.103 & 0.304 & 0.000 & 1.000 \\
\hline Public administration & 14,817 & 0.080 & 0.271 & 0.000 & 1.000 \\
\hline Education & 14,817 & 0.119 & 0.324 & 0.000 & 1.000 \\
\hline Other community services & 14,817 & 0.048 & 0.213 & 0.000 & 1.000 \\
\hline Unionised & 14,817 & 0.239 & 0.427 & 0.000 & 1.000 \\
\hline Firm size: micro & 14,817 & 0.079 & 0.270 & 0.000 & 1.000 \\
\hline
\end{tabular}




\begin{tabular}{llllll}
\hline Variable & Number & Mean & SD & Min & Max \\
\hline Firm size: small & 14,817 & 0.253 & 0.435 & 0.000 & 1.000 \\
\hline Firm size: medium & 14,817 & 0.432 & 0.495 & 0.000 & 1.000 \\
\hline Business has only 1 work site in Australia & 14,817 & 0.278 & 0.448 & 0.000 & 1.000 \\
\hline Self-reported health condition & 14,817 & 0.115 & 0.320 & 0.000 & 1.000 \\
\hline Casual employment & 14,817 & 0.221 & 0.415 & 0.000 & 1.000 \\
\hline Commuting time & 14,817 & 1.421 & 0.737 & 0.000 & 3.434 \\
\hline VIC & 14,817 & 0.261 & 0.439 & 0.000 & 1.000 \\
\hline QLD & 14,817 & 0.214 & 0.410 & 0.000 & 1.000 \\
\hline SA & 14,817 & 0.085 & 0.279 & 0.000 & 1.000 \\
\hline WA & 14,817 & 0.087 & 0.281 & 0.000 & 1.000 \\
\hline TAS & 14,817 & 0.035 & 0.184 & 0.000 & 1.000 \\
\hline NT & 14,817 & 0.010 & 0.102 & 0.000 & 1.000 \\
\hline ACT & 14,817 & 0.024 & 0.153 & 0.000 & 1.000 \\
\hline Remote/very remote area classification & 14,817 & 0.012 & 0.108 & 0.000 & 1.000 \\
\hline (In) Employment density, SA4 level input & 14,817 & 4.459 & 2.885 & -3.682 & 9.085 \\
\hline In) Employment density adjecent, SA4 level input & 14,066 & 7.045 & 0.792 & 4.874 & 8.361 \\
\hline In) Relative economic diversity, SA4 level input & 14,817 & 1.485 & 0.617 & 0.337 & 3.528 \\
\hline (Ln) Relative economic specialisation, SA4 level input & 14,817 & 0.853 & 0.507 & 0.025 & 2.451 \\
\hline Year: 2018 & 14,817 & 0.511 & 0.500 & 0.000 & 1.000 \\
\hline
\end{tabular}

Note: $S D=$ standard deviation

Source: Authors' calculations, HILDA Survey Waves 17 and 18; ABS Census TableBuilder, 2016. 
Table A4: Variable definitions

\begin{tabular}{|c|c|}
\hline hwr17 & Hourly wage main job \\
\hline hwrhhsc & $\begin{array}{l}\text { Hourly wage adjusted for hourly housing } \\
\text { costs }\end{array}$ \\
\hline gender & Male $=1$ \\
\hline qhgage & Age of respondent \\
\hline qhgage2 & Age of respondent, squared \\
\hline mstatus1 & Legally married \\
\hline mstatus2 & De facto \\
\hline occupat1 & Managers \\
\hline occupat2 & Professionals \\
\hline occupat3 & Technicians \\
\hline occupat4 & Health and Welfare \\
\hline occupat5 & Clerical/Admin \\
\hline occupat6 & Sales workers \\
\hline occupat7 & Machine operators \\
\hline occupat8 & Labourers \\
\hline contbirth1 & Australia \\
\hline contbirth2 & main English speaking \\
\hline contbirth3 & Australian and Torres Strait Islanders \\
\hline contbirth4 & Germany+Netherlands+Italy (W-EU) \\
\hline contbirth5 & China \\
\hline contbirth6 & India \\
\hline contbirth7 & Philippines \\
\hline contbirth8 & Vietnam \\
\hline contbirth9 & Other \\
\hline educate1 & Bachelor or above \\
\hline educate2 & Adv diploma \\
\hline qjbempt & Tenure with current employer (years) \\
\hline lab_ft_pt1 & Employed full-time \\
\hline multisite_emp2 & $\begin{array}{l}\text { Employer / business has only one } \\
\text { workplace in Australia }\end{array}$ \\
\hline employdensa2, sa4 & $\begin{array}{l}\text { Employment density per sq } \mathrm{km} \text { based on } \\
\text { SA2 and SA4 level inputs }\end{array}$ \\
\hline employadjsa2, sa4 & $\begin{array}{l}\text { Total employment adjacent POA based } \\
\text { on SA2 and SA4 level inputs }\end{array}$ \\
\hline skill_a_dens_sa2, sa4 & $\begin{array}{l}\text { Skill A density per sq km based on SA2 } \\
\text { and SA4 level inputs }\end{array}$ \\
\hline skill_b_dens_sa2, sa4 & $\begin{array}{l}\text { Skill B density per sq km based on SA2 } \\
\text { and SA4 level inputs }\end{array}$ \\
\hline skill_c_dens_sa2, sa4 & $\begin{array}{l}\text { Skill C density per sq km based on SA2 } \\
\text { and SA4 level inputs }\end{array}$ \\
\hline relecodivsa2, sa4 & $\begin{array}{l}\text { Relative industrial diversity based on SA2 } \\
\text { and SA4 level inputs }\end{array}$ \\
\hline
\end{tabular}

\begin{tabular}{|c|c|}
\hline relecospecsa2, sa4 & $\begin{array}{l}\text { Relative industrial specialisation based } \\
\text { on SA2 and SA4 level inputs }\end{array}$ \\
\hline commute2 & Commuting time, hours \\
\hline indust_type1 & Agriculture forestry fishing \\
\hline indust_type2 & Mining Quarrying \\
\hline indust_type3 & Manufacturing \\
\hline indust_type4 & Electricity gas water \\
\hline indust_type5 & Construction \\
\hline indust_type6 & Wholesale trade \\
\hline indust_type7 & Hotels and restaurant \\
\hline indust_type8 & Transport storage \\
\hline indust_type9 & Financial intermediary \\
\hline indust_type10 & Real estate renting \\
\hline indust_type11 & Public administration \\
\hline indust_type12 & Education \\
\hline indust_type13 & Health and social care \\
\hline indust_type14 & Other community services \\
\hline indust_type15 & Private households \\
\hline indust_type16 & Extra territorial organisations \\
\hline union4 & Union member, yes=1 \\
\hline state & $\begin{array}{l}1=\mathrm{NSW}, 2=\mathrm{VIC}, 3=\mathrm{QLD}, 4=\mathrm{SA}, 5=\mathrm{WA} \\
6=\mathrm{TAS}, 7=\mathrm{NT}, 8=\mathrm{ACT}\end{array}$ \\
\hline firmsize1 & Number of employees 1-4 \\
\hline firmsize2 & Number of employees 5-19 \\
\hline firmsize3 & Number of employees 20-199 \\
\hline firmsize4 & Number of employees $200-500$ or more \\
\hline multisite_emp2 & $\begin{array}{l}\text { Employer has more than one location, } \\
\text { yes }=1\end{array}$ \\
\hline hlthcon1 & Has health condition, yes=1 \\
\hline contract1 & Employed on a fixed-term contract \\
\hline casual1 & Casual employee ABS definition \\
\hline remote & Remote or very remote location, yes $=1$ \\
\hline
\end{tabular}

Source: HILDA Survey Waves 17 and 18; ABS Census TableBuilder, 2016. 


\section{Appendix B: Additional results}

Table A5: Agglomeration effects, SA4 level input, no market potential

\begin{tabular}{|c|c|c|c|c|c|}
\hline & $\begin{array}{l}\text { Wages, } \\
\text { SA4 inputs }\end{array}$ & $\begin{array}{l}\text { Housing-adjusted } \\
\text { wages, SA4 inputs }\end{array}$ & $\begin{array}{l}\text { Wages, } \\
\text { SA4 inputs }\end{array}$ & $\begin{array}{l}\text { Housing-adjusted } \\
\text { wages, SA4 inputs }\end{array}$ & $\begin{array}{r}\text { Housing-adjusted } \\
\text { wages (home), } \\
\text { SA4 inputs }\end{array}$ \\
\hline & RE panel & RE panel & IV panel & IV panel & RE panel \\
\hline Density & 0.013 & 0.011 & 0.041 & 0.040 & 0.007 \\
\hline$p$-value & $(0.000)$ & $(0.000)$ & $(0.000)$ & $(0.000)$ & $(0.005)$ \\
\hline Market potential & $\mathrm{Na}$. & $\mathrm{Na}$. & $\mathrm{Na}$. & $\mathrm{Na}$. & $\mathrm{Na}$. \\
\hline$p$-value & $\mathrm{Na}$. & $\mathrm{Na}$. & $\mathrm{Na}$. & $\mathrm{Na}$. & $\mathrm{Na}$. \\
\hline Relative diversity & 0.025 & 0.022 & 0.127 & 0.128 & 0.003 \\
\hline$p$-value & (0.049) & $(0.203)$ & $(0.000)$ & $(0.000)$ & $(0.871)$ \\
\hline Relative specialisation & 0.048 & 0.064 & 0.140 & 0.160 & 0.032 \\
\hline$p$-value & $(0.000)$ & $(0.000)$ & $(0.000)$ & $(0.000)$ & (0.011) \\
\hline Commute & 0.019 & 0.018 & 0.007 & 0.004 & 0.022 \\
\hline$p$-value & $(0.000)$ & $(0.000)$ & $(0.209)$ & $(0.563)$ & $(0.000)$ \\
\hline \multicolumn{6}{|l|}{ Fixed effects for: } \\
\hline Demographics & No & Yes & Yes & Yes & Yes \\
\hline Skills/education & No & Yes & Yes & Yes & Yes \\
\hline COB/ethnicity & No & Yes & Yes & Yes & Yes \\
\hline Industry/occupation & No & Yes & Yes & Yes & Yes \\
\hline Union & No & Yes & Yes & Yes & Yes \\
\hline Employer characteristics & No & Yes & Yes & Yes & Yes \\
\hline State or territory fixed effect & Yes & Yes & Yes & Yes & Yes \\
\hline Year dummy & Yes & Yes & Yes & Yes & Yes \\
\hline Constant & 2.057 & 1.743 & 1.755 & 1.442 & 1.819 \\
\hline$p$-value & $(0.000)$ & $(0.000)$ & $(0.000)$ & $(0.000)$ & $(0.000)$ \\
\hline Number & 14,814 & 14,774 & 14,814 & 14,774 & 14,758 \\
\hline Overall $\mathrm{R}^{2}$ & 0.433 & 0.366 & 0.420 & 0.355 & 0.365 \\
\hline Number of groups & 8,999 & 8,975 & 8,999 & 8,975 & 8,967 \\
\hline
\end{tabular}

Note: figures in brackets are p-values, robust standard errors. Minor variation in sample size are due to confidentiality censoring (null cells) when disaggregating by skills level. All effects are elasticities. Estimates obtained using Stata's xtreg command. Full list of estimation variables are enclosed in Appendix A, Table A4. Bold type indicates significant at the conventional 5 per cent level. Italics indicate significant at 10 per cent level.

Source: Authors' estimations, HILDA Survey Waves 17 and 18; ABS Census TableBuilder, 2016. 
Table A6: Quantile regression, SA4 level inputs, wages, no market potential

\begin{tabular}{|c|c|c|c|c|c|c|c|c|}
\hline & Density & $p$-value & Diversity & $p$-value & Specialisation & $p$-value & Commute & $p$-value \\
\hline$q 10 \%$ & 0.010 & $(0.001)$ & 0.026 & $(0.186)$ & 0.026 & $(0.110)$ & 0.034 & $(0.000)$ \\
\hline$q 20 \%$ & 0.010 & $(0.000)$ & 0.028 & $(0.048)$ & 0.040 & $(0.000)$ & 0.024 & $(0.000)$ \\
\hline$q 30 \%$ & 0.009 & $(0.000)$ & 0.016 & $(0.331)$ & 0.037 & $(0.001)$ & 0.024 & $(0.000)$ \\
\hline$q 40 \%$ & 0.010 & $(0.000)$ & 0.011 & $(0.411)$ & 0.035 & $(0.001)$ & 0.019 & $(0.000)$ \\
\hline$q 50 \%$ & 0.011 & $(0.000)$ & 0.006 & $(0.624)$ & 0.034 & $(0.001)$ & 0.020 & $(0.000)$ \\
\hline$q 60 \%$ & 0.013 & $(0.000)$ & 0.014 & $(0.270)$ & 0.042 & $(0.000)$ & 0.026 & $(0.000)$ \\
\hline q70\% & 0.013 & $(0.000)$ & -0.001 & $(0.941)$ & 0.039 & $(0.000)$ & 0.022 & $(0.000)$ \\
\hline q80\% & 0.014 & $(0.000)$ & -0.009 & $(0.582)$ & 0.035 & $(0.007)$ & 0.016 & $(0.007)$ \\
\hline q90\% & 0.016 & $(0.000)$ & 0.008 & $(0.735)$ & 0.038 & $(0.017)$ & 0.010 & $(0.253)$ \\
\hline
\end{tabular}

Note: figures in brackets are p-values, robust standard errors. All effects are elasticities. Estimates obtained using Stata's qreg command. Full list of estimation variables are enclosed in Appendix A, Table A4. Bold type indicates significant at the conventional 5 per cent level. Italics indicate significant at 10 per cent revel. See Note to Table 1 for additional specification details.

Source: Authors' estimations; HILDA Survey Waves 17 and 18; ABS Census TableBuilder, 2016.

Table A7: Quantile regression, SA4 level inputs, net wages no market potential

\begin{tabular}{lcccccccc}
\hline & Density & $p$-value & Diversity & $p$-value & Specialisation & $p$-value & Commute & $p$-value \\
\hline $\mathrm{q} 10 \%$ & 0.003 & $(0.470)$ & -0.017 & $(0.642)$ & 0.025 & $(0.312)$ & 0.034 & $(0.005)$ \\
\hline $\mathrm{q} 20 \%$ & 0.006 & $(0.014)$ & 0.016 & $(0.406)$ & 0.049 & $(0.002)$ & 0.029 & $(0.000)$ \\
\hline $\mathrm{q} 30 \%$ & 0.009 & $(0.001)$ & 0.026 & $(0.196)$ & 0.058 & $(0.000)$ & 0.020 & $(0.002)$ \\
\hline $\mathrm{q} 40 \%$ & 0.009 & $(0.000)$ & 0.015 & $(0.305)$ & 0.059 & $(0.000)$ & 0.021 & $(0.000)$ \\
\hline $\mathrm{q} 50 \%$ & 0.011 & $(0.000)$ & 0.009 & $(0.532)$ & 0.056 & $(0.000)$ & 0.021 & $(0.000)$ \\
\hline $\mathrm{q} 60 \%$ & 0.010 & $(0.000)$ & 0.011 & $(0.528)$ & 0.050 & $(0.000)$ & 0.021 & $(0.000)$ \\
\hline $\mathrm{q} 70 \%$ & 0.012 & $(0.000)$ & 0.009 & $(0.536)$ & 0.044 & $(0.000)$ & 0.016 & $(0.015)$ \\
\hline $\mathrm{q} 80 \%$ & 0.012 & $(0.000)$ & -0.006 & $(0.665)$ & 0.039 & $(0.001)$ & 0.016 & $(0.023)$ \\
\hline $\mathrm{q} 90 \%$ & 0.014 & $(0.000)$ & 0.022 & $(0.406)$ & 0.044 & $(0.013)$ & 0.008 & $(0.371)$ \\
\hline
\end{tabular}

Note: figures in brackets are p-values, robust standard errors. All effects are elasticities. Estimates obtained using Stata's qreg command. Full list of estimation variables are enclosed in Appendix A, Table A4. Bold type indicates significant at the conventional 5 per cent level. Italics indicate significant at 10 per cent revel. See Note to Table 1 for additional specification details.

Source: Authors' estimations; HILDA Survey Waves 17 and 18; ABS Census TableBuilder, 2016. 
Table A8: Quantile regression, SA4 level inputs, net wages no market potential, place of residence

\begin{tabular}{lcccccccc}
\hline & Density & $p$-value & Diversity & $p$-value & Specialisation & $p$-value & Commute & $p$-value \\
\hline $\mathrm{q} 10 \%$ & 0.001 & $(0.856)$ & -0.030 & $(0.444)$ & 0.013 & $(0.606)$ & $\mathbf{0 . 0 3 7}$ & $(\mathbf{0 . 0 0 1 )}$ \\
\hline $\mathrm{q} 20 \%$ & 0.003 & $(0.242)$ & -0.002 & $(0.914)$ & 0.029 & $(0.057)$ & $\mathbf{0 . 0 3 1}$ & $(\mathbf{0 . 0 0 0 )}$ \\
\hline $\mathrm{q} 30 \%$ & 0.004 & $(0.203)$ & -0.010 & $(0.652)$ & 0.022 & $(0.123)$ & $\mathbf{0 . 0 2 3}$ & $(\mathbf{0 . 0 0 0 )}$ \\
\hline $\mathrm{q} 40 \%$ & $\mathbf{0 . 0 0 7}$ & $\mathbf{( 0 . 0 0 3 )}$ & -0.019 & $(0.297)$ & $\mathbf{0 . 0 3 0}$ & $\mathbf{( 0 . 0 1 3 )}$ & $\mathbf{0 . 0 2 6}$ & $\mathbf{( 0 . 0 0 0 )}$ \\
\hline $\mathrm{q} 50 \%$ & $\mathbf{0 . 0 0 8}$ & $\mathbf{( 0 . 0 0 0 )}$ & -0.015 & $(0.373)$ & $\mathbf{0 . 0 2 8}$ & $\mathbf{( 0 . 0 1 5 )}$ & $\mathbf{0 . 0 2 6}$ & $\mathbf{( 0 . 0 0 0 )}$ \\
\hline $\mathrm{q} 60 \%$ & $\mathbf{0 . 0 0 9}$ & $\mathbf{( 0 . 0 0 0 )}$ & -0.001 & $(0.932)$ & $\mathbf{0 . 0 2 8}$ & $\mathbf{( 0 . 0 1 4 )}$ & $\mathbf{0 . 0 2 6}$ & $\mathbf{( 0 . 0 0 0 )}$ \\
\hline $\mathrm{q} 70 \%$ & $\mathbf{0 . 0 1 0}$ & $\mathbf{( 0 . 0 0 0 )}$ & -0.009 & $(0.649)$ & 0.022 & $(0.079)$ & $\mathbf{0 . 0 2 3}$ & $\mathbf{( 0 . 0 0 0 )}$ \\
\hline $\mathrm{q} 80 \%$ & $\mathbf{0 . 0 1 1}$ & $\mathbf{( 0 . 0 0 0 )}$ & -0.022 & $(0.240)$ & 0.019 & $(0.125)$ & $\mathbf{0 . 0 2 3}$ & $\mathbf{( 0 . 0 0 1 )}$ \\
\hline $\mathrm{q} 90 \%$ & $\mathbf{0 . 0 1 2}$ & $\mathbf{( 0 . 0 0 0 )}$ & -0.028 & $(0.214)$ & -0.006 & $(0.717)$ & 0.010 & $(0.229)$ \\
\hline
\end{tabular}

Note: figures in brackets are p-values, robust standard errors. All effects are elasticities. Estimates obtained using Stata's qreg command. Full list of estimation variables are enclosed in Appendix A, Table A4. Bold type indicates significant at the conventional 5 per cent level. Italics indicate significant at 10 per cent revel. See Note to Table 1 for additional specification details.

Source: Authors' estimations; HILDA Survey Waves 17 and 18; ABS Census TableBuilder, 2016. 


\section{AHURi}

Australian Housing and Urban Research Institute Level 12, 460 Bourke Street

Melbourne VIC 3000

\section{Australia}

+61396602300

information@ahuri.edu.au

ahuri.edu.au

(2) twitter.com/AHURI_Research

f facebook.com/AHURI.AUS

in Australian Housing and Urban Research Institute 